\title{
Fundamental and methodological investigations for the improvement of elemental analysis by inductively coupled plasma mass spectrometry
}

\author{
by \\ Christopher Hysjulien Ebert \\ A dissertation submitted to the graduate faculty \\ in partial fulfillment of the requirements for the degree of \\ DOCTOR OF PHILOSOPHY
}

Major: Analytical Chemistry

Program of Study Committee:

Robert S. Houk, Major Professor

Andreja Bakac

Joseph Burnett

Emily Smith

Patricia Thiel

Iowa State University

Ames, Iowa

2012

Copyright (C Christopher Hysjulien Ebert, 2012. All rights reserved. 


\section{Table of contents}

Abstract $\quad$ vii

Chapter 1. General introduction 1

Inductively coupled plasma-mass spectrometry 1

Merits and general information 1

Inductively coupled plasma 1

Mass spectrometry $\quad 2$

Extraction stage $\quad 3$

$\begin{array}{ll}\text { Polyatomic ions } & 4\end{array}$

Concern 4

Methods of reducing polyatomic ion abundance 5

$\begin{array}{ll}\text { Origins and behavior of polyatomic ions } & 7\end{array}$

$\begin{array}{lr}\text { Laser ablation ICP-MS } & 8\end{array}$

Merits and general information $\quad 8$

Fractionation $\quad 9$

Laser ablation under helium atmosphere $\quad 11$

$\begin{array}{lr}\text { Femtosecond laser ablation } & 12\end{array}$

$\begin{array}{ll}\text { Dissertation organization } & 12\end{array}$

$\begin{array}{ll}\text { References } & 14\end{array}$

$\begin{array}{ll}\text { Figures } & 18\end{array}$

Chapter 2. Digital photographic studies of vaporization and atomization in the inductively coupled plasma with fast shutter speed and high framing rate. Part I: Emission clouds surrounding wet droplets from a pneumatic nebulizer and solid particles from laser ablation

$\begin{array}{ll}\text { Abstract } & 21\end{array}$

$\begin{array}{ll}\text { Introduction } & 22\end{array}$

$\begin{array}{ll}\text { Methods } & 26\end{array}$

Results and discussion $\quad 28$

Droplets from nebulized yttrium solutions 28

Entrainment of yttrium oxide powder into sample gas flow 30 
Laser ablation of yttrium oxide powder $\quad 31$

Solution emission profiles of $\mathrm{Si}, \mathrm{Na}$, and $\mathrm{Ca} \quad 32$

Ablation of NIST $610 \quad 34$

$\begin{array}{ll}\text { Conclusions } & 37\end{array}$

$\begin{array}{ll}\text { Acknowledgements } & 38\end{array}$

References $\quad 39$

$\begin{array}{ll}\text { Tables } & 42\end{array}$

$\begin{array}{ll}\text { Figures } & 43\end{array}$

Chapter 3. Digital photographic studies of vaporization and atomization in the 53 inductively coupled plasma with fast shutter speed and high framing rate. Part II: Effects of solid particles from laser ablation at $266 \mathrm{~nm}$ with $10 \mathrm{~ns}$ and 150 fs pulses using helium and argon carrier gas.

Abstract $\quad 53$

Introduction $\quad 54$

Methods $\quad 56$

Results and discussion $\quad 58$

Solution emission profiles of $\mathrm{Si}, \mathrm{Na}$, and $\mathrm{Ca} \quad 58$

Nanosecond laser ablation in argon $\quad 59$

$\begin{array}{ll}\text { Nanosecond laser ablation in helium } & 60\end{array}$

$\begin{array}{ll}\text { Femtosecond laser ablation in argon } & 61\end{array}$

Femtosecond laser ablation in helium $\quad 64$

$\begin{array}{ll}\text { Conclusions } & 64\end{array}$

$\begin{array}{ll}\text { Acknowledgements } & 65\end{array}$

$\begin{array}{ll}\text { References } & 66\end{array}$

$\begin{array}{ll}\text { Tables } & 68\end{array}$

$\begin{array}{lr}\text { Figures } & 69\end{array}$

Chapter 4. Investigation into the behavior of metal-argon polyatomic ions $\left(\mathrm{MAr}^{+}\right)$ in the extraction region of inductively coupled plasma-mass spectrometry

Abstract 
$\begin{array}{ll}\text { Introduction } & 75\end{array}$

Method - Calculations $\quad 79$

$\begin{array}{ll}\text { Expected } \mathrm{M}^{+} / \mathrm{MAr}^{+} \text {signal ratio } & 79\end{array}$

$\begin{array}{ll}\text { Mass bias corrections } & 81\end{array}$

$\begin{array}{ll}\text { Correction for background monatomic ions } & 81\end{array}$

Determination of plasma potential $\quad 83$

$\begin{array}{ll}\text { Methods - Instrumentation } & 83\end{array}$

$\begin{array}{ll}\text { ICP-MS device } & 83\end{array}$

$\begin{array}{lr}\text { Shielded load coil } & 84\end{array}$

$\begin{array}{ll}\text { Skimmer geometry } & 85\end{array}$

Samples $\quad 86$

Results and discussion $\quad 86$

Measured $\mathrm{MAr}^{+} / \mathrm{M}^{+}$signal ratios under standard operating conditions $\quad 86$

$\begin{array}{ll}\text { Effect of skimmer cone on } \mathrm{MAr}^{+} / \mathrm{M}^{+} & 87\end{array}$

Effect of plasma potential and ion kinetic energy on $\mathrm{MAr}^{+} / \mathrm{M}^{+}$ratios $\quad 88$

Effect of extraction lens voltage on $\mathrm{MAr}^{+} / \mathrm{M}^{+}$ratios 90

$\begin{array}{ll}\text { Conclusions } & 91\end{array}$

$\begin{array}{ll}\text { Acknowledgements } & 92\end{array}$

$\begin{array}{ll}\text { References } & 93\end{array}$

$\begin{array}{ll}\text { Tables } & 95\end{array}$

$\begin{array}{ll}\text { Figures } & 100\end{array}$

Chapter 5. Elemental and isotopic analysis of uranium oxide and NIST glass 104 standards by femtosecond-LA-ICP-MIC-MS

$\begin{array}{ll}\text { Introduction } & 104\end{array}$

$\begin{array}{ll}\text { Experimental } & 105\end{array}$

$\begin{array}{ll}\text { Results and discussion } & 107\end{array}$

$\begin{array}{ll}\text { Uranium isotope ratios } & 107\end{array}$

$\begin{array}{lr}\text { Thorium/uranium concentration ratios } & 109\end{array}$

$\begin{array}{ll}\text { Conclusions } & 111\end{array}$

$\begin{array}{ll}\text { References } & 113\end{array}$

$\begin{array}{ll}\text { Tables } & 114\end{array}$

$\begin{array}{ll}\text { Figures } & 117\end{array}$ 
Chapter 6. Laser ablation method developments for environmental contamination 120 detection purposes

Abstract

Introduction

Methods

Inductively coupled plasma mass spectrometry

122

Laser ablation

123

Samples

Results and discussion

Ablation of soil particles in collodion matrix

Ablation of soil particles in grease matrices

125

Ablation of dust particles in spider silk matrix

Conclusions

References

Tables

Figures

Chapter 7. Improvements to the torch injector and skimmer cone for LA-ICP-MS 134

Abstract

Introduction

Methods

Instrumentation

Skimmer cone

138

Injector

138

Samples

139

Total gas flow

Results and discussion

Large orifice skimmer cone - figures of merit

Conclusion

References 
Figures

Chapter 8. General Conclusions

Acknowledgements 


\begin{abstract}
This dissertation describes a variety of studies meant to improve the analytical performance of inductively coupled plasma mass spectrometry (ICP-MS) and laser ablation (LA) ICP-MS. The emission behavior of individual droplets and LA generated particles in an ICP is studied using a high-speed, high frame rate digital camera. Phenomena are observed during the ablation of silicate glass that would cause elemental fractionation during analysis by ICP-MS. Preliminary work for ICP torch developments specifically tailored for the improvement of LA sample introduction are presented. An abnormal scarcity of metal-argon polyatomic ions $\left(\mathrm{MAr}^{+}\right)$is observed during ICP-MS analysis. Evidence shows that MAr ${ }^{+}$ ions are dissociated by collisions with background gas in a shockwave near the tip of the skimmer cone. Method development towards the improvement of LA-ICP-MS for environmental monitoring is described. A method is developed to trap small particles in a collodion matrix and analyze each particle individually by LA-ICP-MS.
\end{abstract}




\section{Chapter 1. General Introduction}

\section{Inductively coupled plasma-mass spectrometry}

\section{Merits and general information}

Inductively coupled plasma-mass spectrometry (ICP-MS) is a common analytical tool for the determination of trace elements ${ }^{1-3}$. Many fields employ the technique, including geology ${ }^{4,5}$, environmental chemistry ${ }^{6,7}$, biochemistry $^{8}$, semiconductors $^{9}$, nanomaterials ${ }^{10-12}$, and nuclear chemistry ${ }^{13}$. One of the principal advantages of ICP-MS is its extremely low limit of detection. For a typical solution analysis, the limit of detection varies from the parts-per-billion (ng/g) range to the parts-per-quadrillion (fg/g) range depending on the element of interest. While many methods of sample introduction are employed, the most common method is the nebulization of solution, after which the resulting aerosol is passed through a spray chamber and injected into the ICP. The plasma then heats the sample to $\sim 7000 \mathrm{~K}$ and ionizes the analyte. A mass analyzer separates the ions by their mass and then detects them.

\section{Inductively coupled plasma}

Figure 1 contains a depiction of the introduction system in ICP-MS. On all commercial instruments, the plasma is generated from argon gas. The plasma is shaped by a quartz torch made of three concentric tubes. Three different gas flows contribute to the plasma. Auxiliary $(\sim 1 \mathrm{~L} / \mathrm{min})$ and outer $(\sim 15 \mathrm{~L} / \mathrm{min})$ gases create a stable plasma and regulate the temperature. The sample gas $(\sim 1 \mathrm{~L} / \mathrm{min})$ carries the aerosol into the plasma; the sample gas flow rate also impacts the plasma temperature. The plasma is propagated by the load coil, a metal coil wound 2 to 4 times around the downstream end of the quartz torch. 
The load coil carries an RF wave, typically 27 or $40 \mathrm{MHz}$. The forward power is generally around $1200 \mathrm{~W}$, depending on the desired plasma conditions. The electromagnetic field caused by the RF wave excites free electrons in the plasma, which collide with gas and cause the heating and ionization of argon.

When the sample aerosol is introduced to the plasma through the centermost quartz tube, it begins heating and undergoes several physical processes. The sample is dried to small residues, then vaporized and atomized, and finally ionized. Figure 2 contains a photograph of the plasma during the introduction of yttrium solution, which well-exemplifies these processes. The highest sensitivity is achieved when ions are withdrawn from the plasma at the point of the onset of ionization, at the tip of the initial radiation zone (IRZ) ${ }^{14}$.

\section{Mass spectrometry}

After the sample is ionized by the plasma, the ions are extracted and separated according to their mass-to-charge ratio $(\mathrm{m} / \mathrm{z})$ by means of a mass spectrometer. Two types of mass spectrometers are used in this work, and they operate under different principles.

A magnetic sector instrument (such as the Element, Thermo Finnigan, Bremen, Germany) separates ions using a high magnetic field. This magnetic field separates ions based on their momentum - ions with greater momentum curve less than ions with lower momentum. An electrostatic analyzer (ESA) then refocuses the ions based on their kinetic energy. At the end of the ESA, ions of the same $\mathrm{m} / \mathrm{z}$ value are in the same vertical plane. An exit slit then removes ions to the left and right (i.e., heavier and lighter than the ion of interest) so only the analyte ions pass. During analysis, the slit width can be changed to increase the mass resolution while sacrificing sensitivity. After passing through the exit slit, the ions strike an electron multiplier and are detected and recorded. Some sector field 
instruments are equipped with a multichannel detector (such as the Neptune, Thermo Finnigan, Bremen, Germany). A multichannel detector can simultaneously measure multiple isotopes rather than quickly switching between them. This improves the precision of isotopic and elemental ratios.

A quadrupole mass analyzer (such as the XSeries 2, Thermo Fisher Inc, Bremen Germany) operates by passing ions through an electric field. Ions that are not of a desired mass undergo unstable trajectories and are $\operatorname{lost}^{15}$. A quadrupole has four parallel metal rods oriented in a square, with the ion beam entering one end. The sum of a DC voltage and an AC voltage are applied to each of the four rods - opposite rods have the same voltage, adjacent rods have opposite voltages. The magnitude of the AC and DC voltages are selected such that only ions of the desired $\mathrm{m} / \mathrm{z}$ are stable as they pass longitudinally between the rods. Ions of the wrong $\mathrm{m} / \mathrm{z}$ are ejected from the quadrupole and do not reach the detector.

The magnetic sector and quadrupole mass spectrometers differ in performance in several ways. At its lowest mass resolution, a magnetic sector instrument has a 10-fold or better increase in sensitivity over a quadrupole instrument. The best mass resolution achievable with the quadrupole instrument is $\sim 300(\mathrm{~m} / \Delta \mathrm{m})$. At its highest resolution, the magnetic sector instrument can achieve resolution of $\sim 12,000$. A quadrupole analyzer can switch between distant masses more quickly than a magnetic sector instrument, which is desirable during the analysis of transient signals. A magnetic sector instrument is significantly larger and more expensive than a quadrupole instrument.

\section{Extraction stage}

A mass spectrometer must operate at low pressure (generally $10^{-6}$ to $10^{-8}$ mbar). An important stage of ICP-MS is the transitional period between the atmospheric pressure 
plasma and the vacuum of the mass spectrometer. Current ICP-MS instruments employ multiple stages of differential pumping to maintain the low pressure needed in the mass spectrometer and still admit analyte ions from the $\mathrm{ICP}^{16}$. A metal sampler cone with a small aperture (1.2 $\mathrm{mm}$ diameter on the Thermo Finnigan Element, a typical instrument) is inserted into the plasma; gas flows and plasma parameters are controlled such that the sampler cone is at the tip of the initial radiation zone (IRZ). Behind the sampler cone is a skimmer cone with a smaller aperture (1.0 $\mathrm{mm}$ on the Thermo Finnigan Element). Between these cones is a region with intermediate pressure, $\sim 1$ torr. On some instruments, ions are drawn into the mass spectrometer by an extraction lens with a negative voltage on it.

Ions, electrons and gas comprise a supersonic jet as they travel through and beyond the sampler cone ${ }^{17}$. The skimmer cone disturbs this expansion, and evidence suggests that a shock wave occurs at the tip of the skimmer cone ${ }^{18-22}$. Hence at the tip of the skimmer cone is a region of background gas at low temperature ${ }^{16}$ and higher pressure than desired in the intermediate vacuum stage. This shock wave has numerous consequences, including the scattering of analyte ions and the possible creation or removal of polyatomic ions ${ }^{23,24}$.

\section{Polyatomic ions}

\section{Concern}

Polyatomic ions are a significant complication to ICP-MS analyses. Ideally, the ICP would produce only singly charged monatomic ions. While the high temperature of the plasma is very efficient at atomizing the sample, a small fraction of molecular ions remain. Argon, oxygen, and hydrogen make up the vast majority of the plasma during analysis of solutions, so most polyatomic ions have one or more atoms of these elements ${ }^{25}$. The 
abundance of a polyatomic ion depends mainly on its bond dissociation energy, the number densities of the neutral atom and metal ion, and the plasma temperature. The abundances vary greatly from one element to another, but generally metal oxide $\left(\mathrm{MO}^{+}\right)$signal is between $0.1 \%$ and $2 \%$ of the $\mathrm{M}^{+}$, metal argide $\left(\mathrm{MAr}^{+}\right)$is $0.01 \%$ to $0.1 \%$ of the $\mathrm{M}^{+}$signal, and metal hydride $\left(\mathrm{MH}^{+}\right)$is less than $0.01 \%$ of the $\mathrm{M}^{+}$signal.

Polyatomic ions are problematic because they have nearly the same mass as some analyte ions. For example, ${ }^{40} \mathrm{Ar}^{16} \mathrm{O}^{+}(\mathrm{m} / \mathrm{z}=55.95729)$ impairs analysis during the determination of ${ }^{56} \mathrm{Fe}^{+}(\mathrm{m} / \mathrm{z}=55.93494)$. Even though these species have the same number of protons, neutrons, and electrons, their mass is slightly different because the fraction of their mass that is converted to nuclear binding energy and bond energy differs with the nuclidic mass. A mass resolution of 2500 is required to separate ${ }^{56} \mathrm{Fe}^{+}$from ${ }^{40} \mathrm{Ar}^{16} \mathrm{O}^{+}$. As such, a quadrupole mass analyzer is unable to separate the two ions and determination of ${ }^{56} \mathrm{Fe}^{+}$will be inaccurate. The resolution necessary to separate polyatomic ions from monatomic ions can range into the hundreds of thousands; e.g., separating ${ }^{102} \mathrm{Rb}^{+}$from ${ }^{86} \mathrm{SrO}^{+}$requires resolution of $\sim 600,000$. No commercially available ICP-MS instrument can separate these ions.

\section{Methods of reducing polyatomic ion abundance}

There are numerous strategies to reduce polyatomic ion abundances in ICP-MS. Some of these methods are used routinely in commercial instruments and in industrial applications. However, there is no method currently available that completely eliminates polyatomic ions without some negative impact on analysis.

A sample is usually introduced as a nebulized solution. Efficient desolvation can effectively reduce the abundance of $\mathrm{MO}^{+}$and $\mathrm{MH}^{+}$ions ${ }^{26}$. By removing most of the solvent before injecting an aqueous sample into the ICP, the number densities of atomic oxygen and 
hydrogen in the plasma are greatly reduced. By this method, the abundances of $\mathrm{MO}^{+}$and $\mathrm{MH}^{+}$ions can be lowered by at least an order of magnitude ${ }^{27}$. However, the need to heat the aerosol during desolvation causes memory effects for some elements, particularly elements with very low boiling points like mercury or arsenic. Solvent removal does not significantly change the abundance of metal-argon $\left(\mathrm{MAr}^{+}\right)$ions. Desolvation also lengthens the washout: the amount of time needed after completion of an analysis before the signal returns to background level ${ }^{27}$.

Implementing a collision cell can also reduce polyatomic ion abundance ${ }^{28-31}$. A collision cell may contain a reactive gas, such as hydrogen or ammonia, to chemically convert an interfering ion into a different polyatomic ion with a different nominal mass. A reaction cell generally greatly complicates the mass spectrum by creating numerous new polyatomic species. If used with careful consideration, it can aid the determination of many elements. Sometimes a reactive gas is employed by analysts to solve one specific problem; for instance, introducing oxygen to a collision cell can improve the accuracy and limit of detection during vanadium measurement ${ }^{32}$, but would result in poor performance for most other analytes.

Alternatively, a collision cell can be filled with an inert gas (usually helium) to remove polyatomic ions by kinetic energy discrimination (KED) ${ }^{28}$. Figure 3 contains a depiction of the Thermo XSeries 2 during KED mode. In this approach, a positive attenuating voltage is added to the quadrupole - just beyond the collision cell - so only ions with sufficient kinetic energy can pass to the mass analyzer. Initially, ions of the same mass have roughly equal kinetic energy ${ }^{33}$. While the ions pass through the collision cell, collisions with helium atoms reduce their kinetic energy. Polyatomic ions are larger than monatomic ions 
and undergo more collisions, so they approach the attenuating voltage with lower average kinetic energy. The attenuating voltage is selected such that polyatomics have insufficient kinetic energy to pass, but a fraction of the desired monatomic ions are above the threshold. Subsequently, only monatomic ions reach the mass spectrometer. This method can successfully remove any polyatomic ion from the ion beam; however, it also impacts the sensitivity of the analysis. In particular, a collision cell does not transmit light analyte ions (e.g., ${ }^{7} \mathrm{Li}^{+}$or ${ }^{9} \mathrm{Be}^{+}$) well because they are susceptible to scattering. Fortunately, no polyatomic ions exist at very low mass.

\section{Origins and behavior of polyatomic ions}

Investigating the origins of polyatomic ions can aid the development of strategies to reduce their abundance. One approach to doing this is to calculate the gas kinetic temperature ( $\mathrm{T}_{\text {gas) }}$ of the ions, a method developed by Houk and Praphairaksit ${ }^{25}$. If $\mathrm{T}_{\text {gas }}$ is approximately plasma temperature, 4000 to $6000 \mathrm{~K}$, then polyatomic ions are present in abundances expected in the plasma ${ }^{34}$. If $\mathrm{T}_{\text {gas }}$ is higher than plasma temperatures, polyatomic ions are removed at some point after they leave the ICP. If $\mathrm{T}_{\text {gas }}$ is below plasma temperatures, then additional polyatomic ions are created downstream of the ICP.

$\mathrm{T}_{\text {gas }}$ is calculated from the signal ratio between a polyatomic ion and the monatomic ion that results from its dissociation ${ }^{25}$. An individual $\mathrm{T}_{\text {gas }}$ value can be measured for every polyatomic ion. If most polyatomic ions give the same $T_{\mathrm{gas}}$, then those polyatomic ions likely originate from a region that is at that temperature. Such a result could help determine the stage at which polyatomic ions are created.

Several publications report inconsistencies between $\mathrm{T}_{\text {gas }}$ measurements ${ }^{24,35,36}$. Recently, Witte and Houk ${ }^{24}$ reported $\mathrm{T}_{\text {gas }}$ values for $\mathrm{MAr}^{+}$ions ranging from 8,000 to 
$227,000 \mathrm{~K}$. The wide variation of these temperatures is as intriguing as their very high magnitude. The extensive variability between the values cannot be explained by thermodynamic principles; some non-equilibrium process influences the abundance of polyatomic ions. The high magnitude of the temperatures implies that $\mathrm{MAr}^{+}$ions are present at abundances much lower than expected. The fifth chapter of this dissertation is an investigation to determine if $\mathrm{MAr}^{+}$ions are eliminated by collision induced dissociation (CID) during the ion extraction process.

\section{Laser ablation-ICP-MS}

\section{Merits and general information}

In 1985, Gray $^{37}$ established laser ablation (LA) as a method of sample introduction in ICP-MS. Laser ablation allows the direct analysis of solid samples - a high energy laser vaporizes a small volume of the sample, resulting in an aerosol which is entrained into an argon flow and carried to the ICP. The limit of detection for LA-ICP-MS varies from the ppm $(\mu \mathrm{g} / \mathrm{g})$ range to the ppt $(\mathrm{pg} / \mathrm{g})$ range, depending on the element of interest ${ }^{38}$. The signal stability is generally worse during LA analysis than solution analysis. When possible, it is desirable to analyze a solid sample by digesting it in acid, diluting the acid, nebulizing the solution, and then injecting it into the ICP.

Dissolving the sample, however, loses spatial information. Laser ablation is capable of performing spatial imaging and determining the homo- or heterogeneity of trace elements $^{39-41}$. LA also holds an advantage over solution ICP-MS when the sample is exceedingly difficult to digest and to keep in solution ${ }^{42}$. For some investigations, laser ablation is preferred because it is minimally destructive - for instance, when analyzing 
gemstones $^{43}$, $\operatorname{artwork}^{44}$, or historical artifacts ${ }^{45}$. For these reasons, LA-ICP-MS is used in many fields including geology $\mathrm{y}^{46,47}$, biology ${ }^{40,41}$, and forensics ${ }^{48,49}$.

\section{Fractionation}

A literature review reveals that different authors use the term 'fractionation' to describe related but subtly different phenomena ${ }^{50-54}$. In this dissertation, fractionation is a broad term for the processes by which elemental ratios of a solid sample are determined inaccurately by LA-ICP-MS. The degree of fractionation depends on the matrix of the ablated material, so an external standard must be matrix-matched to the sample or analysis will be inaccurate ${ }^{55}$. Fractionation is a severe limitation on the capability of LA-ICP-MS as a tool for quantification, and the mitigation of fractionation would make LA-ICP-MS a more attractive analytical technique ${ }^{50}$.

Fractionation occurs due to many different processes. The presence of large particles $(>200 \mathrm{~nm})$ in the aerosol introduced into the ICP contributes to fractionation ${ }^{56-58}$. This occurs due to the mechanism by which particles vaporize in the $\mathrm{ICP}^{55}$. Elements with low boiling points vaporize earlier than elements with high boiling points. If a particle does not vaporize completely before it reaches the sampler cone, then the portion of volatile elements that vaporize from the particle will be greater than the portion of refractory elements that vaporize $^{50}$. Thus, a non-stoichiometric fraction of the analyte enters the mass spectrometervolatile elements are overrepresented. The incomplete vaporization of sample by the ICP is sometimes called plasma-induced fractionation.

Therefore, one way to reduce fractionation and improve LA-ICP-MS is to produce an aerosol with more uniform and generally smaller particles, and particularly to remove the largest particles. Optimizing the laser spot size, fluence $\left(\mathrm{J} / \mathrm{cm}^{2}\right)$, and power density $\left(\mathrm{W} / \mathrm{cm}^{2}\right)$ 
can reduce the average particle size ${ }^{57}$. Physical removal of the largest particles from the aerosol can be achieved by cascade impaction ${ }^{59}$, differential mobility ${ }^{54}$, and other methods of filtration $^{56,60}$.

The ablation process itself is also a source of fractionation; that is, the aerosol generated by laser ablation can have different composition than the actual solid sample ${ }^{53,61}$. One crucial source of laser-induced fractionation is preferential vaporization of volatile elements during laser ablation. This is particularly observed when the laser energy is not absorbed with complete efficiency - if some energy is transferred to heating the sample material, volatile elements tend to vaporize more than refractory elements ${ }^{51}$. Consequently, transparent samples suffer worse fractionation effects than opaque samples ${ }^{62}$. Ablating with a laser in the UV region, rather than IR or visible light, generally improves ablation efficiency $^{57,63}$. Sample matrices that transfer heat quickly (i.e., metals) suffer worse fractionation effects than matrices that transfer heat slowly (i.e., silicates), because sample melting and preferential vaporization are more extensive in the former case.

Laser ablation can produce aerosol in which large particles have different elemental composition than small particles, usually attributed to the mechanism of particle recondensation $^{61,64}$. This effect poses a problem because particles of different sizes are not transported to the ICP with the same efficiency ${ }^{65}$. Likewise, large particles are not processed as thoroughly as small particles by the ICP. This results in a discrepancy between the ion ratios measured by ICP-MS and the actual composition of the sample.

Yet another manifestation of laser-induced fractionation occurs because of redeposition of material at the rim of the ablation $\operatorname{spot}^{51,66,67}$. This redeposition is not a stoichiometric process. If the laser beam is moved laterally across a surface it ablates the 
redeposited material as well as the intended sample. The resulting aerosol will not properly represent the sample. Due to this effect, in fact, the measured signal ratios between elements can change over the course of an analysis even if the sample is homogeneous ${ }^{51}$.

\section{Laser ablation under helium atmosphere}

Carrying out laser ablation in a helium atmosphere improves sensitivity and precision and reduces the effects of fractionation during LA-ICP-MS ${ }^{51,68,69}$. Introduction of $100 \%$ helium to the axial channel will extinguish most ICPs, so typically ablation is carried out with a low helium flow (perhaps $0.6 \mathrm{~L} / \mathrm{min}$ ) and argon makeup gas (perhaps $0.5 \mathrm{~L} / \mathrm{min}$ ) is added between the ablation cell and the plasma. A number of processes change when ablation is carried out in helium, most of which are beneficial to analysis.

When ablation is performed in argon, the laser induces a plasma just above the sample surface. This plasma rapidly expands just as the sample is vaporized by absorbed laser energy. This expansion results in heating of the remaining sample and redeposition of sample material ${ }^{70}$. Helium requires more energy to ionize than argon, so the laser-induced plasma and sample redeposition are less extensive when ablation is performed in helium rather than $\operatorname{argon}^{70}$. This improves the sensitivity of LA-ICP-MS. Furthermore, this reduces laser-induced fractionation, because redeposition is a non-stoichiometric process $^{51,69}$.

Helium has a higher thermal conductivity than argon. Helium cools the sample more quickly than argon during ablation, which reduces sample melting and preferential vaporization of volatile elements. The high thermal conductivity of helium also induces the formation of smaller particles ${ }^{68}$ than argon, which reduces the effects of ICP-induced fractionation. Evidence also shows that helium reduces the average particle size introduced to 
the ICP because helium is lighter than argon and cannot transport the largest particles generated by laser ablation $^{71}$.

\section{Femtosecond laser ablation}

The laser pulse length is a critical parameter in the efficiency of laser ablation ${ }^{72}$. Heat transfer across a solid medium generally occurs in the picosecond regime ${ }^{52}$. Therefore, femtosecond laser pulses only minimally heat a matrix; absorbed laser energy goes more fully towards the vaporization of sample. Sample melting is reduced during femtosecond $\mathrm{LA}^{73}$, thereby reducing preferential vaporization of volatile elements. The aerosols produced by femtosecond laser ablation have a lower average particle size than those produced by nanosecond $\mathrm{LA}^{74}$. Femtosecond ablation also produces a more uniform particle size distribution, with fewer abnormally large particles ${ }^{75}$. As a result, femtosecond ablation produces stable ion signals and more accurate and precise elemental ratios than ablation with ns lasers ${ }^{75}$.

\section{Dissertation organization}

The first chapter of this dissertation is an introduction to ICP-MS and LA, including basic figures of merit for the techniques, characteristics of and technical information about the techniques pertinent to the research described in the dissertation, and current issues limiting the techniques. Chapters 2 and 3 are manuscripts prepared for submission to The Journal of Analytical Atomic Spectroscopy. These manuscripts describe an examination into the behavior of droplets and laser-generated particles in the ICP with a high speed, high frame rate digital camera. Chapter 4 is a manuscript accepted for publication by Spectrochimica Acta Part B: Atomic Spectroscopy. This manuscript describes a set of experiments which provide evidence that metal-argon polyatomic ions are lost due to 
collision induced dissociations in ICP-MS. Chapter 5 is a technical report submitted to the US Department of Energy describing the experiments performed during a visit to Oak Ridge National Laboratory in February, 2009 and related experiments performed at Ames Laboratory preceding and following that visit. These experiments compare femtosecond LA to nanosecond LA and scanning sector field ICP-MS to multiple ion collection sector field ICP-MS for the isotopic analysis of uranium oxide particulates. Chapters 6 and 7 are compilations of reported to the US Department of Energy in quarterly reports and other various reports. Chapter 6 describes experiments which introduce two novel matrices to the field of environmental contamination detection by LA-ICP-MS. Chapter 7 describes torch injector and skimmer cone developments designed for the improvement of LA and solution ICP-MS. Finally, chapter 8 presents general conclusions of the dissertation. 


\section{References}

1. R. S. Houk, V. A. Fassel, G. D. Flesch, H. J. Svec, A. L. Gray and C. E. Taylor, Anal. Chem., 1980, 52, 2283-2289.

2. K. E. Jarvis, A. L. Gray and R. S. Houk, Handbook of Inductively Coupled Plasma Mass Spectrometry, Chapman and Hall, New York. 1992.

3. A. Montaser, Inductively Coupled Plasma Mass Spectrometry, Wiley-VCH, New York. 1998.

4. $\quad$ K. L. Linge and K. E. Jarvis, Geostand. Geoanal. Res., 2009, 33, 445-467.

5. I. Horn, R. L. Rudnick and W. F. McDonough, Chem. Geol., 2000, 164, 281-301.

6. C.-D. Garbe-Schonberg, C. Reimann and V. A. Pavlov, Environ. Geol., 1997, 32, 916.

7. D. Beauchemin, Mass Spectrom. Rev., 2010, 29, 560-592.

8. F. Li, D. W. Armstrong and R. S. Houk, Anal. Chem., 2005, 77, 1407-1413.

9. M. Horn, Fresenius J. Anal. Chem., 1999, 364, 385-390.

10. C. Degueldre, P.-Y. Favarger and C. Bitea, Anal. Chem. Acta, 2004, 518, 137-142.

11. C. C. Garcia, A. Murtazin, S. Groh, V. Horvatic and K. Niemax, J. Anal. At. Spectrom., 2010, 25, 645-653.

12. A. R. Montoro Bustos, J. R. Encinar, M. T. Fernandez-Arguelles, J. M. CostaFernandez and A. Sanz-Medel, Chem. Commun., 2009, 3107-3109.

13. J. S. Becker, C. Pickhardt and H.-J. Dietze, Int. J. Mass Spectrometry, 2000, 202, 283-297.

14. D. B. Aeschliman, S. J. Bajic, D. P. Baldwin and R. S. Houk, J. Anal. At. Spectrom., 2003, 18, 1008-1014.

15. R. E. Finnigan, Anal. Chem., 1994, 66, 969-975A.

16. D. J. Douglas and J. B. French, J. Anal. At. Spectrom., 1988, 3, 743-747.

17. R. Campargue, J. Phys. Chem., 1984, 88, 4466-4474.

18. A. L. Gray, J. Anal. At. Spectrom., 1989, 4, 371-373.

19. H. Niu and R. S. Houk, Spectrochim. Acta Part B, 1994, 49, 1283-1303.

20. T. N. Olney, W. Chen and D. J. Douglas, J. Anal. At. Spectrom., 1999, 14, 9-17. 
21. J. E. Patterson, B. S. Duersch and P. B. Farnsworth, Spectrochim. Acta Part B, 1999, 54, 537-544.

22. N. Taylor and P. B. Farnsworth, Spectrochim. Acta Part B, 2012, 69, 2-8.

23. J. W. Ferguson and R. S. Houk, Spectrochim. Acta Part B, 2006, 61, 905-915.

24. T. M. Witte and R. S. Houk, Spectrochim. Acta Part B, 2012, 69, 25-31.

25. R. S. Houk and N. Praphairaksit, Spectrochim. Acta Part B, 2001, 56, 1069-1096.

26. M. G. Minnich and R. S. Houk, J. Anal. At. Spectrom., 1998, 13, 167-174.

27. L. C. Alves, D. R. Wiederin and R. S. Houk, Anal. Chem., 1992, 64, 1164-1169.

28. Z. Du and R. S. Houk, J. Anal. At. Spectrom., 2000, 15, 383-388.

29. B. Hattendorf and D. Guenther, J. Anal. At. Spectrom., 2000, 15, 1125-1131.

30. T. Arnold, J. N. Harvey and D. J. Weiss, Spectrochim. Acta Part B, 2008, 63, 666672.

31. S. D. Tanner, V. I. Baranov and D. R. Bandura, Spectrochim. Acta Part B, 2002, 57, 1361-1452.

32. A. J. Bednar, Talanta, 2009, 78, 453-457.

33. J. A. Olivares and R. S. Houk, Appl. Spectrosc., 1985, 39, 1070-1077.

34. S. M. McIntyre, J. W. Ferguson, T. M. Witte and R. S. Houk, Spectrochim. Acta Part $B, 2011,66,248-254$.

35. S. M. McIntyre, J. W. Ferguson and R. S. Houk, Spectrochim. Acta Part B, 2011, 66, 581-587.

36. J. W. Ferguson, T. J. Dudley, K. C. Sears, S. M. McIntyre, M. S. Gordon and R. S. Houk, Spectrochim. Acta Part B, 2009, 64, 690-696.

37. Gray, Analyst, 1985, 110, 551-556.

38. J. Koch and D. Guenther, Appl. Spectrosc., 2011, 65, 155A-162A.

39. P. G. Spry, A. Heimann, J. D. Messerly, R. S. Houk and G. S. Teale, Economic Geology, 2007, 102, 285-293.

40. J. S. Becker, M. Zoriy, V. L. Dressler, B. Wu and J. S. Becker, Pure Appl. Chem., 2008, 80, 2643-2655.

41. J. Feldmann, A. Kindness and P. Ek, J. Anal. At. Spectrom., 2002, 17, 813-818. 
42. T. E. Jefferies, S. E. Jackson and H. P. Longerich, J. Anal. At. Spectrom., 1998, 13, 935-940.

43. B. Hattendorf, C. Latkoczy and D. Guenther, Anal. Chem., 2003, 341A-347A.

44. K. Smith, K. Horton, R. J. Watling and N. Scoullar, Talanta, 2005, 67, 402-413.

45. J. A. Evans and V. Pashley, Archaeometry, 2003, 45, 591-597.

46. C. H. Stirling, D.-C. Lee, J. N. Christensen and A. N. Halliday, Geochim.

Cosmochim. Acta, 2000, 64, 3737-3750.

47. J. M. Cottle, M. S. A. Horstwood and R. R. Parrish, J. Anal. At. Spectrom., 2009, 24, $1355-1363$

48. S. J. Bajic, D. B. Aeschliman, N. J. Saetveit, D. P. Baldwin and R. S. Houk, J. Forensic Sci., 2005, 50, 1123-1127.

49. J. Messerly, N. Saetveit, S. J. Bajic, D. P. Baldwin and R. S. Houk, Ames Laboratory Report IS-5174, 2005.

50. I. Rodushkin, M. D. Axelsson, D. Malinovsky and D. C. Baxter, J. Anal. At. Spectrom., 2002, 17, 1231-1239.

51. S. M. Eggins, L. P. J. Kinsley and J. M. G. Shelley, Appl. Surf. Sci., 1998, 127-129, 278-286.

52. R. E. Russo, X. Mao, J. J. Gonzalez and S. S. Mao, J. Anal. At. Spectrom., 2002, 17, 1072-1075.

53. R. Jaworski, E. Hoffman and H. Stephanowitz, Int. J. Mass Spectrometry, 2002, 219, 373-379.

54. N. J. Saetveit, S. J. Bajic, D. P. Baldwin and R. S. Houk, J. Anal. At. Spectrom., 2008, 23, 54-61.

55. I. Rodushkin, M. D. Axelsson, D. Malinovsky and D. C. Baxter, J. Anal. At. Spectrom., 2002, 17, 1223-1230.

56. M. Guillong, J. Anal. At. Spectrom., 2002, 17, 831-837.

57. S. H. Jeong, O. V. Borisov, J. H. Yoo, X. L. Mao and R. E. Russo, Anal. Chem., 1999, 71, 5123-5130.

58. H.-R. Kuhn, M. Guillong and D. Guenther, Anal. Bioanal. Chem., 2004, 378, 10691074. 
59. C. Y. Liu, X. L. Mao, J. Gonzalez and R. E. Russo, J. Anal. At. Spectrom., 2005, 20, 200-203.

60. M. Guillong, H.-R. Kuhn and D. Guenther, Spectrochim. Acta Part B, 2003, 58, $211-$ 220.

61. H.-R. Kuhn and D. Guenther, Anal. Chem., 2003, 75, 747-753.

62. R. E. Russo, X. L. Mao, O. V. Borisov and H. Liu, J. Anal. At. Spectrom., 2000, 15, 1115-1120.

63. C. Geertsen, A. Briand, F. Chartier, J.-L. Lacour, P. Mauchien, S. Sjostrom and J.-M. Mermet, J. Anal. At. Spectrom., 1994, 9, 17-22.

64. H.-R. Kuhn and D. Guenther, J. Anal. At. Spectrom., 2004, 19, 1158-1164.

65. J. Koch, M. Walle, R. Dietiker and D. Guenther, Anal. Chem., 2008, 80, 915-921.

66. S. M. Eggins, R. Gurun, M. T. McCulloch, A. W. G. Pike, J. Chappell, L. Kinsley, G. Mortimer, M. Shelley, C. V. Murray-Wallace, C. Spotl and L. Taylor, Quaternary Science Reviews, 2005, 24, 2523-2538.

67. J. Mikova, J. Kosler, H. P. Longerich, M. Wiedenbeck and J. M. Hanchar, J. Anal. At. Spectrom., 2009, 24, 1244-1252.

68. R. Hergenroeder, J. Anal. At. Spectrom., 2006, 21.

69. D. Guenther and C. A. Heinrich, J. Anal. At. Spectrom., 1999, 14, 1363-1368.

70. J. Koch, S. Schlamp, T. Rosgen, D. Fliegel and D. Guenther, Spectrochim. Acta Part $B, 2007,62,20-29$.

71. I. Horn and D. Guenther, Appl. Surf. Sci., 2003, 207, 144-157.

72. F. Poitrasson, X. Mao, S. S. Mao, R. Freydier and R. E. Russo, Anal. Chem., 2003, 75, 6184-6190.

73. B. N. Chichkov, C. Momma, S. Nolte, F. von Alvensleben and A. Tuennermann, Appl. Phys. A, 1996, 63, 109-115.

74. J. Koch, A. von Bohlen, R. Hergenroeder and K. Niemax, J. Anal. At. Spectrom., 2004, 19, 267-272.

75. V. Mozna, J. Pisonero, M. Hola, V. Kanicky and D. Guenther, J. Anal. At. Spectrom., 2006, 21, 1194-1201. 


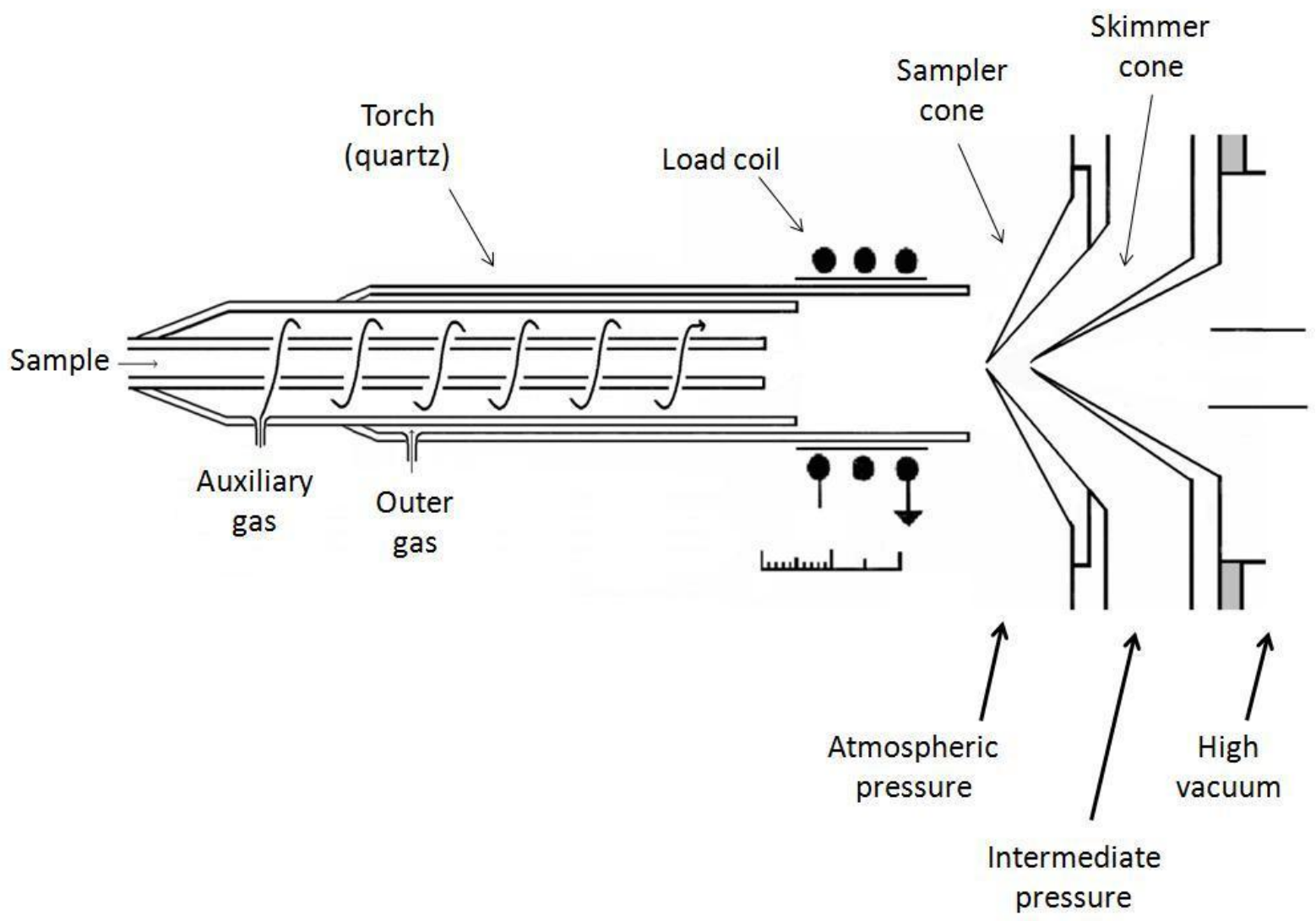

Figure 1. Depiction of the ICP torch and differential pumping stage of ICP-MS. 


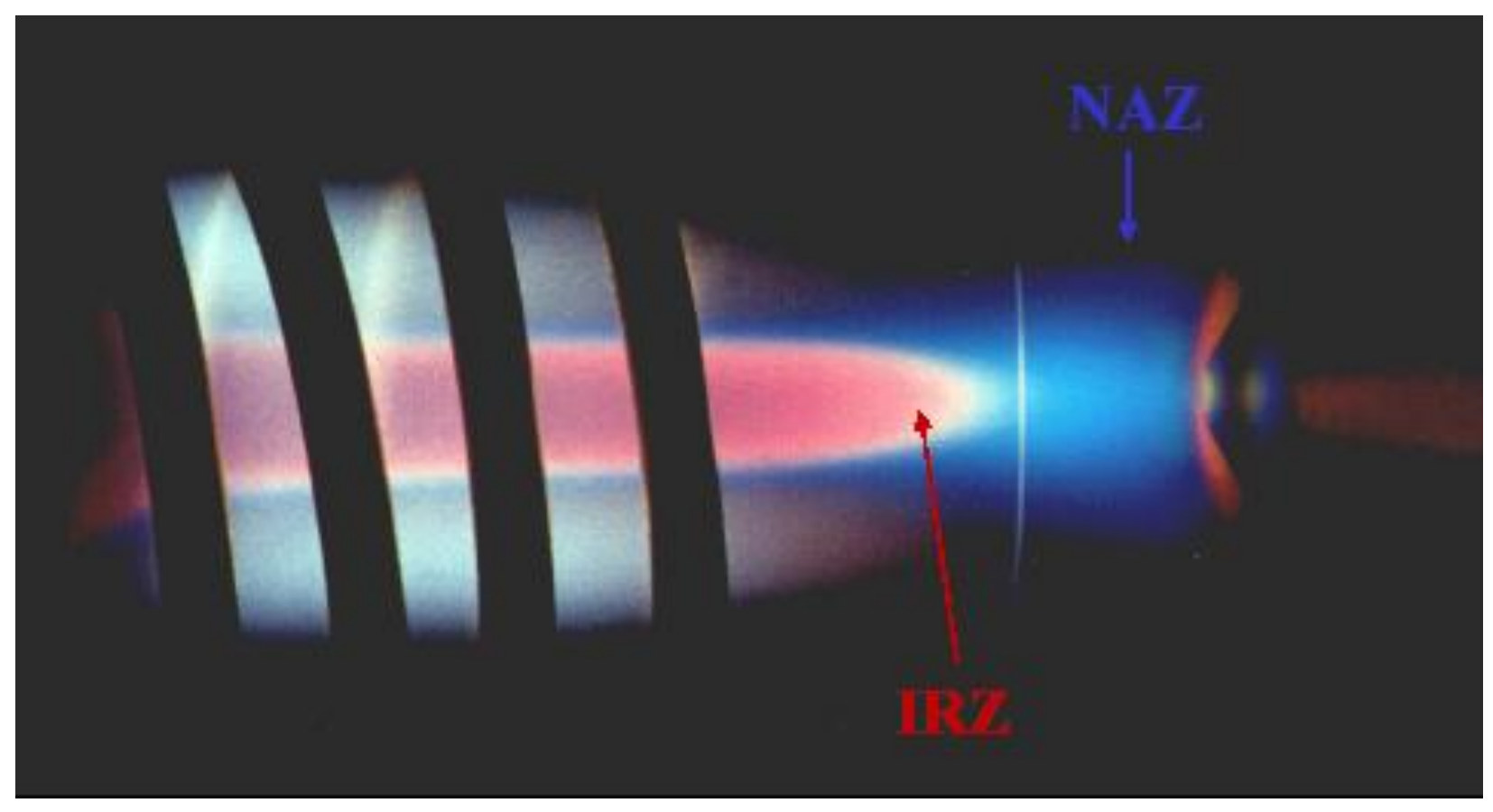

Figure 2. Photograph of the ICP during the introduction of a high concentration yttrium solution. Emission is observed from YO (red), neutral yttrium (white) and yttrium ions (blue). The sampler cone is visible on the right end of the photograph. Sensitivity is optimized when the sampler cone is at the tip of the IRZ (unlike in this photograph).

Another phenomenon of note is the halo of red emission at the skimmer cone. This occurs due to the reformation of YO near the skimmer cone, because the gas kinetic temperature of the plasma is lower near the skimmer cone. This region is called the boundary layer.

This photograph is courtesy of Varian, Inc (now Bruker). 

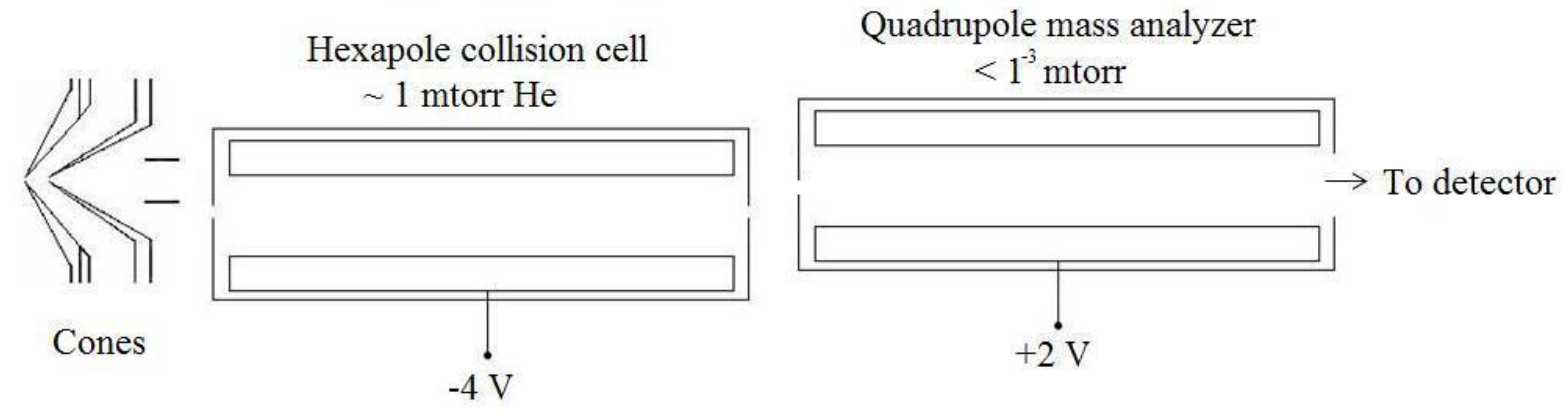

Figure 3. Depiction of the cones, hexapole, and quadrupole on the Thermo Xseries 2 ICPMS. The collision cell is intentionally offset relative to the quadrupole and the sampler and skimmer cones to deter the transmission of neutral species.

When running in KED mode, a small amount of helium is introduced to the hexapole. Polyatomic ions undergo more collisions than monatomic ions, and they approach the quadrupole with less kinetic energy than monatomic ions. A portion of polyatomic ions do not have sufficient kinetic energy to pass into the quadrupole, and are lost. A greater fraction of monatomic ions pass this threshold than polyatomic ions. 


\title{
Chapter 2. Digital photographic studies of vaporization and atomization in the inductively coupled plasma with fast shutter speed and high framing rate. Part I: Emission clouds surrounding wet droplets from a pneumatic nebulizer and solid particles from laser ablation
}

A manuscript submitted for publication in The Journal of Analytical Atomic Spectroscopy

Chris H. Ebert, Nathan J. Saetveit, Daniel S. Zamzow, David P. Baldwin, Stanley J. Bajic, and R. S. Houk

\begin{abstract}
The emission behavior of individual droplets and particles in an inductively coupled plasma (ICP) is characterized by high-speed images and videos. With a camera frame rate of 5,000 or $10,000 \mathrm{fps}$, the emission cloud surrounding an individual droplet or particle is captured in 8 to 12 successive images, allowing examination of its entire lifetime in the plasma. Individual yttrium oxide particles (original particle size $\sim 10 \mu \mathrm{m}$ ) are introduced by entraining $\mathrm{Y}_{2} \mathrm{O}_{3}$ powder into the sample gas flow. Particles are also generated by laser ablation (LA) of a) a hand-pressed $\mathrm{Y}_{2} \mathrm{O}_{3}$ pellet or b) NIST 610 silicate glass using a frequency doubled Nd:YAG laser $(532 \mathrm{~nm})$. Large droplets from concentrated yttrium solution exhibit $\mathrm{YO}$ and neutral yttrium emission as far as $2 \mathrm{~cm}$ beyond the initial radiation zone (IRZ), downstream from the typical sampling point for ICP mass spectrometry (MS). The droplet clouds consist of a core of red yttrium oxide emission surrounded by a thin shell of neutral yttrium emission, then a thick cloud of blue $\mathrm{Y}^{+}$emission. This spatial pattern is characteristic of a kinetic controlled process as yttrium oxide is vaporized, atomized, and
\end{abstract}


ionized. Large solid $\mathrm{Y}_{2} \mathrm{O}_{3}$ particles undergo neutral yttrium emission for the entire length of the plasma, indicating that some particles are not fully atomized and ionized. Particles created by laser ablation of NIST 610 exhibit distinct emission regions from sodium and calcium, often separated by more than $1 \mathrm{~cm}$ and more than $300 \mu \mathrm{s}$. This is attributed to sequential vaporization of the two elements, a detrimental phenomenon during LA-ICP-MS analysis.

\section{Introduction}

The inductively coupled plasma (ICP) is an established, highly sensitive source for either optical emission spectroscopy (OES) or $\mathrm{MS}^{1}$. Visual studies of droplet and particle behavior in the ICP can lead to improved methodology and better analytical capabilities of the technique ${ }^{2-6}$. The behavior of small particles and individual droplets in the plasma is of particular interest considering the emergence of ICP as a tool for the analysis of single species such as biological cells, colloids, and nanoparticles that yield fast transient signals ${ }^{7-14}$.

Solid-sample laser ablation is a growing subset of ICP-MS applications, as LA greatly reduces sample preparation, is minimally destructive, and can provide spatial information $^{15-17}$. Fractionation, defined in this work as the measurement of signal ratios for different elements that are not easily related to the concentration ratios in the sample, limits the analytical performance of the technique ${ }^{18-22}$. Fractionation is a consequence of multiple processes in LA-ICP-MS. It can occur during aerosol generation at the sample surface: by preferential vaporization of volatile elements and by redeposition of material caused by the expansion of laser-induced plasma above the sample surface ${ }^{18,23,24}$. The creation of aerosol that is not representative of the sample is often called laser-induced fractionation. 
Fractionation can also occur during atomization and ionization in the ICP due to incomplete vaporization of the sample, which is exacerbated by large, micron-sized particles $^{19,23,25-27}$. This is referred to as plasma-induced fractionation. Sufficiently large particles (generally >200 $\mathrm{nm}$ ) are only partially vaporized before they reach the MS sampler cone $^{28}$. These overly large particles contribute to fractionation more than small particles, because refractory elements in them are not efficiently vaporized and ionized so they are under-represented during analysis.

The degree of fractionation changes depending on the matrix of the ablated solid, so inaccuracy occurs when attempting quantification without matrix-matched external standards $^{29,30}$. Attempts to quantify aerosols produced by laser ablation with solution standards have demonstrated reasonable success ${ }^{31-33}$. However, the difference in behavior of droplets in wet plasma and laser-created dry particles make the comparison non-ideal. Moreover, this method is still vulnerable to laser-induced fractionation.

Over the last decade, ongoing research in many laboratories aimed at reducing the extent of fractionation has greatly improved the analytical capabilities of LA-ICP-MS. Efforts to mitigate fractionation generally do so by two approaches: improving ablation efficiency and reducing the particle size distribution. Use of UV lasers, optimizing the laser fluence, and homogenizing the laser energy profile each improve the absorption efficiency of laser energy ${ }^{19,29,34}$. Ablating in a helium atmosphere reduces laser-induced plasma and sample redeposition, improves ablation efficiency, aids the generation of smaller particles, and reduces the transmission of large particles ${ }^{35-37}$. Using a femtosecond pulse length laser reduces sample heating ${ }^{38-40}$; a thorough review of the benefits of fs LA is included in the accompanying paper ${ }^{41}$. Other contributions to alleviate fractionation include the physical 
removal of large particles from the laser generated aerosol by means of differential mobility $^{42}$, cascade impaction ${ }^{43}$ or a tightly coiled tube ${ }^{25}$.

Previous photographic studies contribute to an understanding of droplet and particle behavior in the ICP. For instance, Winge $e t a l{ }^{3}$ used a high-speed camera to study yttrium emission from droplets of various sizes in the ICP. They observed steady emission in the initial radiation zone (IRZ) and normal analytical zone (NAZ) attributed to yttrium from fine droplets that quickly dry as they enter the plasma. Discrete clouds of more intense emission from larger droplets were found in the axial channel and off-center. These droplets actively dried as they travel through the plasma and sometimes end in a rapid expansion or explosion of the droplet cloud. Yttrium oxide slurries $(3.2 \mu \mathrm{m}$ or $8.5 \mu \mathrm{m}$ diam.) were also introduced into the ICP; these particles produced white streaks that survived the entire length of the plasma.

These early photographic studies used expensive film, the development of which was slow and costly. Aeschliman et al. ${ }^{6}$ presented digital photographs and movies of the ICP during the introduction of particles generated by either solution nebulization or laser ablation. They found that many of the ablated particles traveled the full length of the plasma without being completely vaporized. They suggested these surviving particles can clog the cones and even damage the entrance slits of the mass spectrometer. They observed that atomization occurred at various axial positions and inferred that the laser aerosol contained particles of widely different sizes. They concluded that the wide particle size distribution was likely responsible for a number of previously observed problems ${ }^{21,27}$, such as preferential vaporization and different optimum plasma conditions for different elements and/or sample matrices. 
Olesik et al. introduced monodisperse droplets to the ICP to investigate their behavior $^{4,5,44}$. Consecutive measurements by OES captured images of emission from a single droplet for its entire lifetime in the plasma. They also employed laser-induced fluorescence to estimate the mass of analyte contained in each droplet. They discussed the rates of droplet drying and diffusion, dried particle vaporization and analyte ionization. Among many other important observations, Olesik and co-workers showed that while a droplet dries in the plasma, the sample vaporizes and diffuses faster than it can be ionized.

The behavior of droplets and particles in the ICP may be of interest to those analyzing single particles in droplets. The analysis of suspended particles by ICP spectroscopy has been a subject of research for decades, from older research on slurries ${ }^{45-47}$ to newer work on nanoparticles ${ }^{10,11}$. In a recent study, Niemax et al. ${ }^{11}$ dried monodisperse droplets to introduce individual dry particles to the plasma. They compared emission intensity from droplets that dry into residues of predicted mass to the emission intensity from gold and silicate nanoparticles. They found they could distinguish nanoparticles of $20 \%$ difference in mass, and suggested that variability in particle trajectory limits the accuracy of the measurement.

Günther et al. measured gas and particle velocities in the ICP from laser ablation using particle image velocimetry ${ }^{48}$. They found particle velocities could be varied significantly by changing the fraction of helium in the sample gas, the gas flows, the injector diameter, and the forward power. They compared the velocity of laser-generated particles to measured sensitivity in ICP-MS analysis; decreasing the particle dwell time decreased the sensitivity for $\mathrm{M}^{+}$ions from refractory elements, while the sensitivity for volatile elements was relatively unchanged. 
Our previous digital photographic studies ${ }^{6}$ of particle and droplet behavior in the ICP implemented either a still camera or a video camera with a fast shutter speed but a slow frame rate. The present study shows improved images and movie clips of an open ICP taken with a 5,000-10,000 fps shutter speed camera. A single droplet or particle produces a spherical emission cloud, as described by Olesik and co-workers ${ }^{5}$, which can be observed in many successive frames during its lifetime in the plasma. The emission behavior of individual particles in laser-induced aerosols is compared to the emission zones observed during solution nebulization. We discuss the possible repercussions the observed phenomena have on the analytical capabilities of ICP-MS, such as how they impact sensitivity, signal stability, calibration and fractionation using LA.

\section{Methods}

The experiments performed used an ICP (RF Plasma Products ICP-16L, 40 MHz) that was similar to, but not the same device as, the plasma used by our group in previous photographic studies $(27 \mathrm{MHz})^{6}$. The plasma flows vertically; images are sometimes rotated 90 degrees to conserve space. While the present work largely discusses how observed phenomena impact ICP-MS, this is an open plasma with no sampler cone or vacuum system.

The ICP conditions are listed in Table 1. The outer diameter of the torch is $20 \mathrm{~mm}$, which is often used to estimate sizes and distances since it is visible in all images. The torch has a tubular quartz injector (1.4 mm ID x $15 \mathrm{~mm}$ long).

An Olympus i-Speed 2 video camera captured videos and images of droplets and particles. A Navitron $25 \mathrm{~mm}$ focal length lens focused light from the plasma onto the camera. Images were recorded at 5,000 fps (320x240 pixels) or 10,000 fps (224x168 pixels), 
depending on whether image quality or frame rate was more important for the experiment. A shutter was used to shorten the exposure time to $20 \mu$ s unless otherwise noted.

Samples were ablated with a Big Sky CFR-200 laser, frequency doubled to $532 \mathrm{~nm}$. The laser operating parameters are listed in Table 1. The laser beam was focused at the sample surface. The ablation cell was a homemade, double-walled quartz cell. The ablated aerosol passed through tygon tubing (4.76 $\mathrm{mm}$ ID x $6 \mathrm{~m}$ long) from the ablation cell to the plasma torch. Ablation experiments were always single-spot analyses with approximately one second of ablation.

For solution samples, three different sample introduction systems were used. To produce an ICP typical of that used in most ICP-MS experiments, a concentric nebulizer (PFA400, Elemental Scientific) with a peristaltic pump sprayed 10,000 ppm solutions at an uptake rate of $400 \mu \mathrm{L} / \mathrm{min}$. The images included in this work were taken during rinse-out as the analyte solutions were being washed out by the blank. The particular images shown below were chosen because they are just intense enough to show all the emission zones without saturating the camera. The emission zone locations do not noticeably drift during the rinse-out, only the emission intensity changes.

To deliberately introduce very large droplets to the plasma, a 10,000 ppm yttrium solution was aspirated at $1.9 \mathrm{~mL} / \mathrm{min}$ with a Meinhard nebulizer at 35 psi argon pressure (approximately $0.65 \mathrm{~L} / \mathrm{min}$ ). This sample uptake rate was faster than typical for ICP-MS experiments, but it was helpful to generate many overly large droplets to study the desired phenomena. Finally, to mimic the emission zones from LA, dried aerosols from solutions of yttrium, sodium, calcium and silicon were introduced to the plasma using an ultrasonic nebulizer (CETAC, U-5000 $\mathrm{AT}^{+}$) with a single-pass spray chamber and desolvator. 
Solid $\mathrm{Y}_{2} \mathrm{O}_{3}$ (original particle size $\sim 10 \mu \mathrm{m}$ ) was introduced to the plasma by two different methods. The first was entraining $\mathrm{Y}_{2} \mathrm{O}_{3}$ particles into the axial channel by shaking a vial of the powder (with the largest particle size $\sim 10$ microns) with the sample Ar gas passing through it. This direct introduction was compared to laser ablation of a loose hand-pressed pellet of $\mathrm{Y}_{2} \mathrm{O}_{3}$ mixed in a 1-to-1 ratio with a binding agent (Spectroblend powder, Chemplex Industries Inc., Palm City, FL). NIST 610 glass was introduced to the ICP by laser ablation; this material is nominally $33.7 \%$ silicon, $10.4 \%$ sodium, and $8.6 \%$ calcium by mass ${ }^{49}$.

\section{Results and discussion}

During the course of experimentation, several hundred videos were recorded during the introduction of solutions or ablated aerosols. Every video and image cannot be included due to space limitations; the figures and videos reported in this work are those that best illustrate the interesting phenomena that occurred repeatedly during the experiments. In this study, particles and droplets are periodically described as 'large'. This term 'large' does not define a specific size; rather, a particle or droplet is considered 'large' if it creates a distinguishable cloud that perturbs the normal, steady-state emission background.

\section{Droplets from nebulized yttrium solutions}

Plasma photos during introduction of yttrium and blank water solutions are shown in Figure 1. The photograph taken during nebulization of pure water blank (Fig. 1a) shows slightly blue plasma emission - a property of the camera which tends to bias the colors. The familiar axial channel is darker because it is cooler than the rest of the plasma.

Yttrium has distinct visible emission spectra for excited YO (deep red), neutral yttrium (pale red, appears white) and $\mathrm{Y}^{+}$(blue). The emission profile of yttrium shows 
predominantly $\mathrm{YO}$ emission in the initial radiation zone (IRZ) and $\mathrm{Y}^{+}$in the normal radiation zone (NAZ) with a distinct region of neutral yttrium emission at the outer boundary of the IRZ. During ICP-MS experiments the signal is maximized when the ICP is located so the tip of the IRZ is just upstream from the sampler cone orifice.

Previous studies ${ }^{2,3}$ showed a "streaky" zone on center just downstream from the IRZ, which was attributed to the juxtaposition of clouds from dried particles. This zone is noted by the gray arrow in Fig. 1.

Video 1 (5,000 fps) shows a set of clouds from many large droplets from 10,000 ppm yttrium solutions for the duration of their time in the plasma. The sequence in Fig. 2 shows the first eight consecutive frames from Video 1. The sequence displays the fate of an unusually prominent cloud from a single individual droplet as it traverses the ICP. The droplet itself is too small (50 $\mu \mathrm{m}$ diam. or less) to be detected; the camera can only observe the cloud of yttrium cooled by passage of the droplet ${ }^{4,5}$. An expanded image of the frame at $\mathrm{t}=0.6 \mathrm{~ms}$ is also pictured (Figure $2 \mathrm{~b}$ ). This sequence is presented because this droplet cloud clearly exemplifies the different emission regions observed. There is a core of red radiation ascribed to YO emission, with a shell of "white" emission attributed to neutral Y lines.

As the droplet travels downstream, the cloud appears to get smaller due to several processes. The cloud diffuses, the outer shell of neutral yttrium is ionized so it is no longer distinguishable from $\mathrm{Y}^{+}$emission in the NAZ, and the core of the droplet heats so the YO dissociates to neutral yttrium. This progression is previously described by Olesik et $a l^{4}$.This same progression presumably occurs in small droplets as they enter the ICP, but the events are less prominent to the camera. The cloud of neutral yttrium does not appear to expand much until $\mathrm{t}=1.0 \mathrm{~ms}$; in fact the cloud gets smaller until $\mathrm{t}=0.8 \mathrm{~ms}$. This indicates that 
yttrium is ionized as quickly as it diffuses from the center of the droplet. The droplet core is apparently still present even when the droplet is some $10 \mathrm{~mm}$ downstream from the end of the torch $(\mathrm{t}=0.8 \mathrm{~ms})$. This is well beyond the sampling point in ICP-MS, so the extraction of $\mathrm{Y}^{+}$from this droplet would have poor efficiency compared to a smaller droplet. This would also result in the deposition of residue onto the extraction system of a mass spectrometer.

Video 1 also displays a wispy red plume at the downstream end of the plasma due to YO emission. Yttrium oxide is recreated at the end of the plasma by reaction between $\mathrm{Y}^{+}$ ions and $\mathrm{O}_{2}$ from entrained air, which cools the plasma and increases the gas density of oxygen. This YO cloud exhibits the swirls and eddies seen previously. This entrainment of air causes the familiar audible "whine" of the ICP".

\section{Entrainment of yttrium oxide powder into sample gas flow}

Figure 3 contains a series of frames recorded during the manual introduction of yttrium oxide powder. This method of sample introduction has an advantage over laser ablation for the purposes of this study because the IRZ and NRZ contain no background emission of any yttrium species. Instead, emission is confined to distinct analyte clouds vaporized from the individual particles as they are heated during their travel through the plasma. Furthermore, by this method the particle frequency is lower than during ablation of an $\mathrm{Y}_{2} \mathrm{O}_{3}$ pellet, so tracking the fate of one individual particle during its course through the plasma is easier.

The particle cloud observed in Figure 3 exhibits a faint core of neutral yttrium emission and a surrounding sphere of blue $\mathrm{Y}^{+}$emission. The plasma is dry and yttrium oxide emission is faint in the particle cloud until the particle reaches the end of the plasma, where it meets entrained oxygen from room air and starts cooling. While the cloud moves 
downstream and expands, Y(I) emission intensifies. There are two competing processes occurring: the neutral yttrium atoms heat, diffuse away from the center of the cloud, and are converted to $\mathrm{Y}^{+}$ions. At the same time, the particle at the center of the cloud evaporates, depositing additional cool yttrium in the cloud core. Neutral yttrium emission persists in the cloud until at least $20 \mathrm{~mm}$ downstream from the end of the torch at $\mathrm{t}=0.9 \mathrm{~ms}$, so the particle contents are not fully vaporized and ionized until well beyond the sampling position in ICP-MS. As a result, particles of various sizes vaporize and ionize to different degrees before they reach the sampler cone during analysis, contributing to signal instability and fractionation.

The particles recorded during these experiments travel at approximately $20 \mathrm{~m} / \mathrm{s}$. Particle velocity was calculated using the frame rate and the number of pixels particle clouds moved between frames. This finding is slower than a previously published measurement of 27 to $30 \mathrm{~m} / \mathrm{s}_{\text {from our group }}{ }^{6}$, but the sample gas flow in the present work is $\sim 1.0 \mathrm{~L} / \mathrm{min}$, lower than the $1.5 \mathrm{~L} / \mathrm{min}$ used in the previous study. These previous studies estimated particle velocity by measuring the elongation of a particle track and dividing by the exposure time, so this difference in method could also explain the inconsistency. The examined particles do not appear to change velocity as they traverse the ICP; however, the spatial resolution is poor when recording at 10,000 fps so a small change in velocity is not easily measured.

\section{Laser ablation of yttrium oxide powder}

Aeschliman et $a l .{ }^{6}$ noted that LA of this type of yttrium oxide pellet mainly removes material by chipping large "flakes" from the sample, rather than true ablation of material directly under the laser beam. Figure 4 shows the ablation cell while the laser impacts the 
sample and the assembly of particles created. The aerosol includes visible large particles and agglomerates. The large, asymmetric flakes of material were probably ejected by laserinduced vibration of the sample. Videos of the ablation cell during ablation show particles swirling slowly during the rinse-out phase (data not shown). This process is thoroughly described by Günther et al. ${ }^{50}$

Figure 5 contains successive frames of a typical cluster of particles generated by laser ablation of a loosely packed $\mathrm{Y}_{2} \mathrm{O}_{3}$ pellet and binder mixture. Video 2 (10,000 fps) shows many such particles and clusters. Like when the sample was introduced as a powder, far more emission originates from discrete clouds of yttrium surrounding large particles than from continuous emission in the IRZ or NAZ. Furthermore, an individual $\mathrm{Y}_{2} \mathrm{O}_{3}$ particle produced by laser ablation behaves much like a particle introduced by powder entrainment. The particle cloud has an emission intensity gradient across its diameter and significant time is necessary to vaporize the particle and heat the core. White emission from neutral Y or YO persists in the center of the cloud until the particle travels at least $20 \mathrm{~mm}$ past the end of the torch. Consequently, ICP-MS measurements of such transient analyte would be susceptible to plasma-induced fractionation, i.e., there is no single sampling position that is good for particles of such a large range of sizes.

\section{Solution emission profiles of $\mathrm{Si}, \mathrm{Na}$, and $\mathrm{Ca}$}

The glass samples contain large amounts of $\mathrm{SiO}_{2}, \mathrm{CaO}$ and $\mathrm{Na}_{2} \mathrm{O}$. Dried solution aerosols from these elements were used to characterize the visual appearance of the plasma when fine particulates of the elements were introduced. Typical individual images of the ICP during introduction of highly concentrated $\mathrm{Si}, \mathrm{Na}$, and $\mathrm{Ca}$ solutions and a mixed solution of $\mathrm{Si}, \mathrm{Na}$ and $\mathrm{Ca}$ are shown in Figure 6. Si (I), Si (II), and $\mathrm{SiO}$ have little emission in the visible 
spectrum $^{51-53}$. The observed emission in the outer edge of the IRZ is attributed to a weak neutral silicon emission line at $390 \mathrm{~nm}$ or a stronger emission line at $288 \mathrm{~nm}$. This second wavelength is not visible to the naked eye, but may be detected by the camera and displayed in the visible region.

The spatial emission profile for sodium (Fig. 6b) has emission localized to the IRZ, and only a small amount of emission in the normal analytical zone. Neutral sodium emits at $589 \mathrm{~nm}$ (yellow-orange), but ionized sodium does not emit in the visible region. As expected, sodium is almost entirely ionized beyond the tip of the IRZ.

Neutral calcium (Fig. 6c) emits at $422 \mathrm{~nm}$, in the purple-blue region. Singly-charged calcium emits at 393 and $397 \mathrm{~nm}$, in the purple region. The profile of calcium contains appreciable $\mathrm{Ca}$ (II) emission in the NAZ. It has less visible emission in the IRZ, only a faint halo of neutral calcium emission at the outer boundary of the zone. A possible cause of the lack of emission in the IRZ by calcium could be that most calcium in this zone is bound to oxygen or hydroxide. $\mathrm{CaO}$ has weak emission lines in the blue region ${ }^{51}$, but they may not be visible because the camera imparts a slight blue tinge to the entire plasma.

The appearance of the plasma is different when all three elements are atomized and ionized together (Fig 6d). The observed color from overlapping emission of sodium and calcium in the IRZ is magenta. Emission in the NAZ is dominated by purple $\mathrm{Ca}(\mathrm{II})$; the sodium atoms are ionized here. Silicon emission is not discernible in this mixture because visible emission from sodium and calcium are more intense, which simplifies the interpretation of results during the ablation of NIST 610. 


\section{Ablation of NIST 610}

Figure 7 and Video 3 present images of clouds from discrete particles generated during the ablation of NIST 610 glass. A faint trace of continuous calcium emission is visible in the NAZ. This is evidence that many small, indistinguishable particles are generated during the ablation of glass. These small particles vaporize and the resulting atoms diffuse quickly when introduced to the plasma. This contrasts with the ablation of the yttrium oxide pellet, when the perceived emission is localized in large distinct particle clouds. For glass, the steady-state background contains little or no sodium emission; presumably, sodium in these small particle clouds is already ionized before the clouds come into the $=$ field of vision of the camera.

Along with the background emission from many small particles are intermittent larger particles that generate distinct emission clouds. These particles exhibit separate regions of calcium and sodium emission in different zones than the overlapping emission profiles observable during introduction of the multielement solution. During LA, the IRZ is a thin, scraggly line along the central axis, in contrast to the wide, brightly colored zone during solution nebulization.

The particle cloud observed in Figure 7 is typical of that from the many large particles generated in this experiment. Orange sodium emission is observed from the particle cloud during the first 200 to $300 \mu$ s that it is in view of the camera. For about 5 subsequent frames there is no discernible emission from the cloud surrounding the large particle. From this particular particle, calcium emission is not observed until t $=0.8 \mathrm{~ms}$, nearly $20 \mathrm{~mm}$ downstream of the end of the torch and well beyond the sodium emission zone and the sampling position used in ICP-MS. It is possible that the particle cloud is, in fact, emitting 
calcium during the intermediate $300-500 \mu \mathrm{s}$, but the emission is not distinguishable from the background calcium emission in the NAZ. However for this particle and many like it, calcium emission is most intense when the particle is beyond the faint, continuous emission of the NAZ. For instance, the calcium emission from the particle cloud at $\mathrm{t}=1.0 \mathrm{~ms}$ is much more intense than the NAZ background.

This phenomenon is attributed to the sequential vaporization of sodium and calcium (or their compounds) from a large particle. As the particle heats toward plasma temperature, it first reaches the temperature where sodium is vaporized. For a period of time, the particle heats more slowly while the sodium removes energy to convert to vapor. Little calcium is vaporized during this time. After most of the sodium evaporates the particle heats further, but it takes several hundred microseconds before it becomes hot enough to vaporize calcium. During this interval sodium is already ionized, but calcium remains in the particle so calcium emission is not detected by the camera. The detrimental consequences of this event have been discussed at length ${ }^{19,28,42,43}$. If a laser-generated particle is too large, the relative signals for different elements at a single sampling position during ICP-MS do not represent the actual composition of the ablated sample.

This effect can be further observed in Figure $8 \mathrm{a}$. At $\mathrm{t}=0.0 \mathrm{~ms}$, a large particle emits sodium just above the load coil (yellow-orange arrow). A second particle cloud is visible just upstream from the first, beginning at $\mathrm{t}=0.2 \mathrm{~ms}$. This second particle, however, emits only calcium (purple arrow). For the entire length of the plasma, each particle only exhibits emission from one element.

It is tempting to claim the elemental composition of these particles are different, an instance observed by Kuhn et al. during the ns-laser ablation of silicate glass and attributed to 
laser-induced fractionation ${ }^{23}$. However, this incident could also occur because the two particles have similar initial composition but vastly different size. The particle at the center of the orange cloud is very large and sodium is still being vaporized as it exits the field of vision of the camera. Meanwhile, the particle at the center of the purple cloud is smaller and all the sodium it contained was already vaporized and ionized before it came into the frame. This second explanation is a manifestation of plasma-induced fractionation. Examination of many such sequences containing these particle clouds suggests that the primary cause of this phenomenon is the sequential vaporization of sodium and calcium from an individual particle that initially contains both elements. In any event, the apparent composition of these particles would differ dramatically when analyzed by ICP-MS, even though they came from the same sample.

Careful inspection of the orange cloud in Figure 8 reveals another interesting phenomenon. The sodium-emitting cloud is not in the middle of the axial channel as it first comes into view. The solid particle itself stays slightly left of center as it traverses the plasma, but once the sodium is vaporized the atom cloud drifts toward the center of the plasma. Particularly at $\mathrm{t}=0.2 \mathrm{~ms}$ (Figure $8 \mathrm{~b}$ ), bright emission from the core of the particle is not in the center of the particle cloud. By $\mathrm{t}=0.4 \mathrm{~ms}$, the cloud looks centered. This is attributed to the boundary between the axial channel and the outer gas. After being vaporized from the particle, the analyte cannot move into the hotter outer gas as easily as it diffuses into the cooler, laminar flow axial channel, so the orange cloud appears to correct its course. The particle itself is too small to be seen, but it likely stays off-center for its entire transit through the plasma. 
This observation also helps explain the observation of short-lived signal spikes during LA-ICP-MS analysis ${ }^{13,54}$. The sampler-skimmer combination transmits ions from a small zone just in front of the sampler. The diameter of this region is approximately equal to the skimmer diameter ${ }^{55}$. When particles are slightly off-center, the only metal ions extracted and analyzed are those that diffuse to the center of the plasma. If a particle is directly on center, its vapor cloud is extracted more efficiently, and a much larger fraction of its ions passes through both the sampler and skimmer cones. This yields a very sharp signal spike lasting 1

ms or less 54 , Fig. 3 . This occurrence will also impact single-particle analysis if the ions from occasional particles (i.e., those that are exactly on the axis through the sampler and skimmer) undergo extraction with much higher efficiency than most others. The variability in particle trajectory also complicates the analysis of colloids and nanoparticles, as described by Niemax et al. ${ }^{11}$

\section{Conclusions}

This study demonstrates that nanosecond laser ablation generates particles that the ICP are not completely atomized and ionized before they reach the tip of the IRZ, which is the usual sampling position for ICP-MS experiments. The camera used in this study offers an advantage over previous photographic studies because its high frame rate allows the capture of a given droplet or particle cloud in many successive images. Some particles and droplets observed in this study do not undergo complete vaporization and ionization until they are deep into the ICP, well beyond the normal ICP-MS sampling point. This corroborates previous assertions that wide particle size distributions lead to poor analytical measurements. During the ablation of NIST 610 glass, fractionation is exemplified by the greatly different 
zones of emission from calcium and sodium. This is ascribed to the sequential vaporization of calcium and sodium. Due to this concern, there is no optimum sampling point for extracting sample ions during LA-ICP-MS if the particles are too large. Finally, the abundance of off-center particles must be considered by those studying transient nanoparticles or biological cells because species of different axial position may have different extraction efficiency.

\section{Acknowledgements}

Research at the Ames Laboratory was supported by the U.S. Department of Energy- National Nuclear Security Agency under contract number DE-AC02-07CH11358. Funding was provided by the U.S. Department of Energy, Office of Nuclear Nonproliferation (NA-22). 


\section{References}

1. R. S. Houk, V. A. Fassel, G. D. Flesch, H. J. Svec, A. L. Gray and C. E. Taylor, Anal. Chem., 1980, 52, 2283-2289.

2. R. K. Winge, J. S. Crain and R. S. Houk, J. Anal. At. Spectrom., 1991, 6, 601-604.

3. R. S. Houk, R. K. Winge and X. Chen, J. Anal. At. Spectrom., 1997, 12, 1139-1148.

4. J. W. Olesik, Appl. Spectrosc., 1997, 51, 158A-175A.

5. J. W. Olesik, J. A. Kinzer and G. J. McGowan, Appl. Spectrosc., 1997, 51, 607-616.

6. D. B. Aeschliman, S. J. Bajic, D. P. Baldwin and R. S. Houk, J. Anal. At. Spectrom., 2003, 18, 1008-1014.

7. C. Degueldre, P.-Y. Favarger and C. Bitea, Anal. Chem. Acta, 2004, 518, 137-142.

8. C. Degueldre, P.-Y. Favarger and S. Wold, Anal. Chem. Acta, 2006, 555, 263-268.

9. I. Moreels, K. Lambert, D. De Muynck, F. Vanhaecke, D. Poelman, J. C. Martins, G. Allan and Z. Hens, Chem. Mater., 2007, 19, 6101-6106.

10. A. R. Montoro Bustos, J. R. Encinar, M. T. Fernandez-Arguelles, J. M. CostaFernandez and A. Sanz-Medel, Chem. Commun., 2009, 3107-3109.

11. C. C. Garcia, A. Murtazin, S. Groh, V. Horvatic and K. Niemax, J. Anal. At. Spectrom., 2010, 25, 645-653.

12. B. Franze, I. Strenge and C. Engelhard, J. Anal. At. Spectrom., 2012.

13. F. Li, D. W. Armstrong and R. S. Houk, Anal. Chem., 2005, 77, 1407-1413.

14. D. R. Bandura, V. I. Baranov, O. I. Ornatsky, A. Antonov, R. Kinach, X. Lou, S.

Pavlov, S. Vorobiev, J. E. Dick and S. D. Tanner, Anal. Chem., 2009, 81, 6813-6822.

15. J. Koch and D. Guenther, Appl. Spectrosc., 2011, 65, 155A-162A.

16. Gray, Analyst, 1985, 110, 551-556.

17. B. Hattendorf, C. Latkoczy and D. Guenther, Anal. Chem., 2003, 341A-347A.

18. S. M. Eggins, L. P. J. Kinsley and J. M. G. Shelley, Appl. Surf. Sci., 1998, 127-129, 278-286.

19. S. H. Jeong, O. V. Borisov, J. H. Yoo, X. L. Mao and R. E. Russo, Anal. Chem., 1999, 71, 5123-5130.

20. S. E. Jackson and D. Guenther, J Am Soc Mass Spectrom, 2003, 18, 205-212. 
21. I. Rodushkin, M. D. Axelsson, D. Malinovsky and D. C. Baxter, J. Anal. At. Spectrom., 2002, 17, 1231-1239.

22. D. C. Perdian, S. J. Bajic, D. P. Baldwin and R. S. Houk, J. Anal. At. Spectrom., 2008, 23, 336-341.

23. H.-R. Kuhn and D. Guenther, J. Anal. At. Spectrom., 2004, 19, 1158-1164.

24. J. Koch, S. Schlamp, T. Rosgen, D. Fliegel and D. Guenther, Spectrochim. Acta Part $B, 2007,62,20-29$.

25. M. Guillong, H.-R. Kuhn and D. Guenther, Spectrochim. Acta Part B, 2003, 58, 211220.

26. H.-R. Kuhn, M. Guillong and D. Guenther, Anal. Bioanal. Chem., 2004, 378, 10691074.

27. I. Rodushkin, M. D. Axelsson, D. Malinovsky and D. C. Baxter, J. Anal. At. Spectrom., 2002, 17, 1223-1230.

28. M. Guillong, J. Anal. At. Spectrom., 2002, 17, 831-837.

29. H.-R. Kuhn and D. Guenther, Anal. Chem., 2003, 75, 747-753.

30. I. Kroslakova and D. Guenther, J. Anal. At. Spectrom., 2007, 22, 51-62.

31. D. B. Aeschliman, S. J. Bajic, D. P. Baldwin and R. S. Houk, J. Anal. At. Spectrom., 2003, 18, 872-877.

32. J. S. Becker, C. Pickhardt and H.-J. Dietze, J. Anal. At. Spectrom., 2001, 16, 603-606.

33. M. Walle, J. Koch and D. Guenther, J. Anal. At. Spectrom., 2008, 23, 1285-1289.

34. C. Geertsen, A. Briand, F. Chartier, J.-L. Lacour, P. Mauchien, S. Sjostrom and J.-M. Mermet, J. Anal. At. Spectrom., 1994, 9, 17-22.

35. D. Guenther and C. A. Heinrich, J. Anal. At. Spectrom., 1999, 14, 1363-1368.

36. R. Hergenroeder, J. Anal. At. Spectrom., 2006, 21.

37. I. Horn and D. Guenther, Appl. Surf. Sci., 2003, 207, 144-157.

38. B. N. Chichkov, C. Momma, S. Nolte, F. von Alvensleben and A. Tuennermann, Appl. Phys. A, 1996, 63, 109-115.

39. R. E. Russo, X. Mao, J. J. Gonzalez and S. S. Mao, J. Anal. At. Spectrom., 2002, 17, 1072-1075. 
40. F. Poitrasson, X. Mao, S. S. Mao, R. Freydier and R. E. Russo, Anal. Chem., 2003, 75, 6184-6190.

41. C. H. Ebert, N. J. Saetveit, D. S. Zamzow, S. J. Bajic and R. S. Houk, J. Anal. At. Spectrom., 2012, Submitted.

42. N. J. Saetveit, S. J. Bajic, D. P. Baldwin and R. S. Houk, J. Anal. At. Spectrom., 2008, 23, 54-61.

43. C. Y. Liu, X. L. Mao, J. Gonzalez and R. E. Russo, J. Anal. At. Spectrom., 2005, 20, 200-203.

44. J. B. French, B. Etkin and R. Jong, Anal. Chem., 1994, 66, 685-691.

45. J. G. Williams, A. L. Gray, P. Norman and L. Ebdon, J. Anal. At. Spectrom., 1987, 2, 469-472.

46. P. Goodall, M. E. Foulkes and L. Ebdon, Spectrochim. Acta Part B, 1993, 48, 15631577.

47. J. A. Horner and G. M. Hieftje, Spectrochim. Acta Part B, 1998, 53, 1235-1259.

48. L. Flamigni, J. Koch, H. Wiltsche, R. Brogioli, S. Gschwind and D. Guenther, J. Anal. At. Spectrom., 2012, 27, 619-625.

49. K. P. Jochum, U. Weis, B. Stoll, D. Kuzmin, Q. Yang, I. Raczek, D. E. Jacob, A. Stracke, K. Birbaum, D. A. Frick, D. Guenther and J. Enzweiler, Geostand. Geoanal. Res., 2011, 35, 397-429.

50. J. Koch, M. Walle, R. Dietiker and D. Guenther, Anal. Chem., 2008, 80, 915-921.

51. R. Mavrodineanu and H. Boiteux, Flame Spectroscopy, John Wiley \& Sons, Inc., New York. 1965.

52. P. W. J. M. Boumans, Line Coincidence Tables for Inductively Coupled Plasma Atomic Emission Spectrometry, Pergamon Press Inc., New York. 1980.

53. R. K. Winge, V. A. Fassel, V. J. Peterson and M. A. Floyd, Inductively Coupled Plasma-Atomic Emission Spectroscopy, An Atlas of Spectral Information, Elsevier Science Publishers B. V., Amsterdam, The Netherlands. 1985.

54. D. C. Perdian, S. J. Bajic, D. P. Baldwin and R. S. Houk, J. Anal. At. Spectrom., 2008, 23, 325-335.

55. D. J. Douglas and J. B. French, J. Anal. At. Spectrom., 1988, 3, 743-747. 
Table 1. Operating parameters for ICP and laser

\begin{tabular}{|c|c|c|c|}
\hline ICP & $\begin{array}{c}\text { RF Plasma Products } \\
\text { ICP-16L }\end{array}$ & Laser & Big Sky CFR-200 \\
\hline \hline RF Power & $1100 \mathrm{~W}$ & Pulse Length & $11 \mathrm{~ns}$ \\
\hline RF Frequency & $40 \mathrm{MHz}$ & Spot Size & $\sim 100 \mu \mathrm{m}$ \\
\hline Sample Gas & $1.0 \mathrm{~L} / \mathrm{min}$ & Pulse Energy & $10 \mathrm{~mJ}$ \\
\hline Outer Gas & $15.0 \mathrm{~L} / \mathrm{min}$ & Repetition Rate & $30 \mathrm{~Hz}$ \\
\hline Auxiliary Gas & $0.5 \mathrm{~L} / \mathrm{min}$ & Fluence & $32 \mathrm{~J} / \mathrm{cm}^{2}$ \\
\hline
\end{tabular}




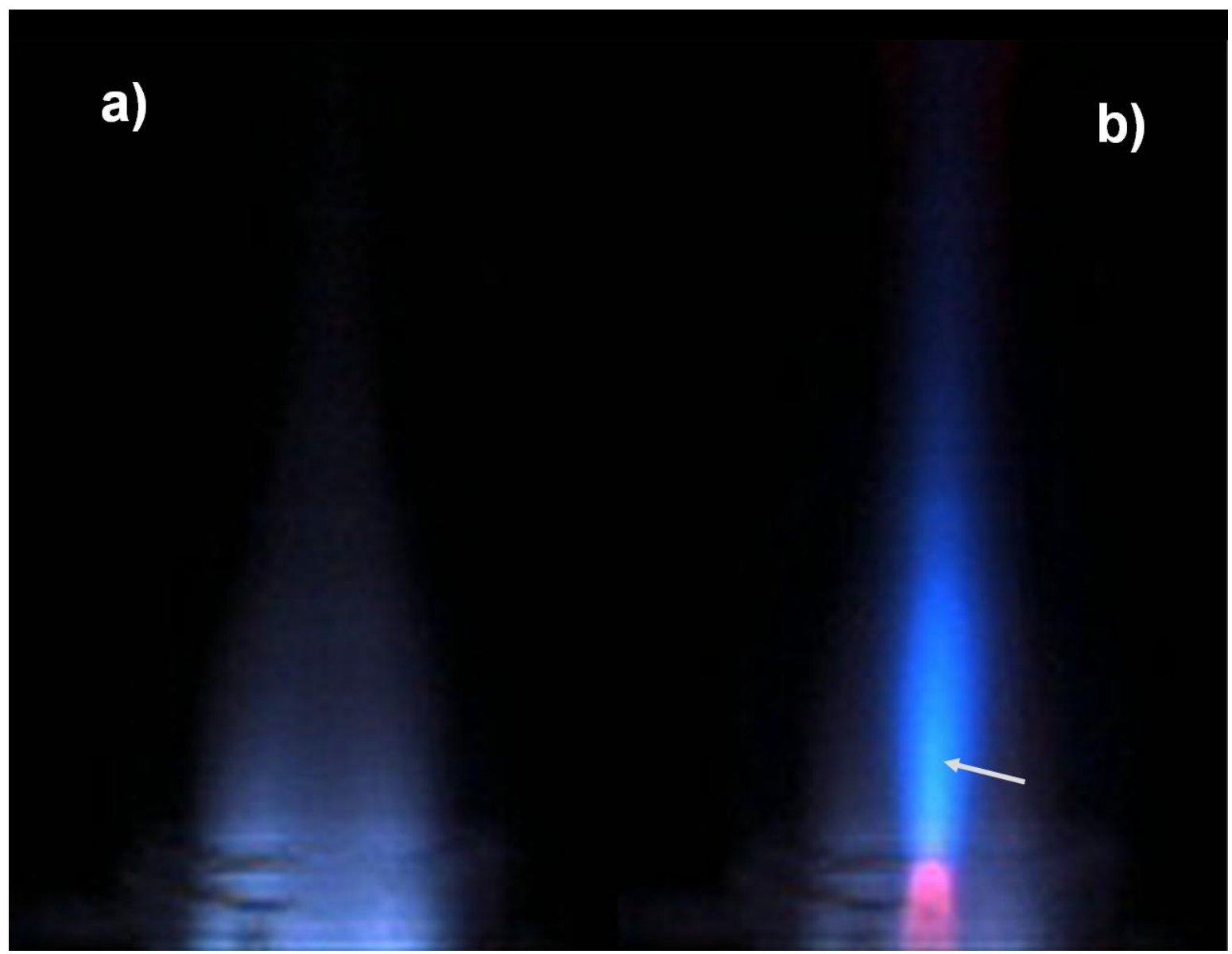

Figure 1. A high-speed photograph of the ICP during introduction of a) water and b) yttrium solutions by PFA nebulizer at $400 \mu \mathrm{L} / \mathrm{min}$. Frame rate is 5,000 fps. The region of pink-red emission from yttrium oxide and neutral yttrium is referred to as the Initial Radiation Zone (IRZ), and the region of blue $\mathrm{Y}^{+}$emission is the Normal Analytical Zone (NAZ). Frame b was selected so that droplet clouds are not evident. Gray arrow denotes "streaky" region attributed to passage of solid particles ${ }^{2,3}$. 


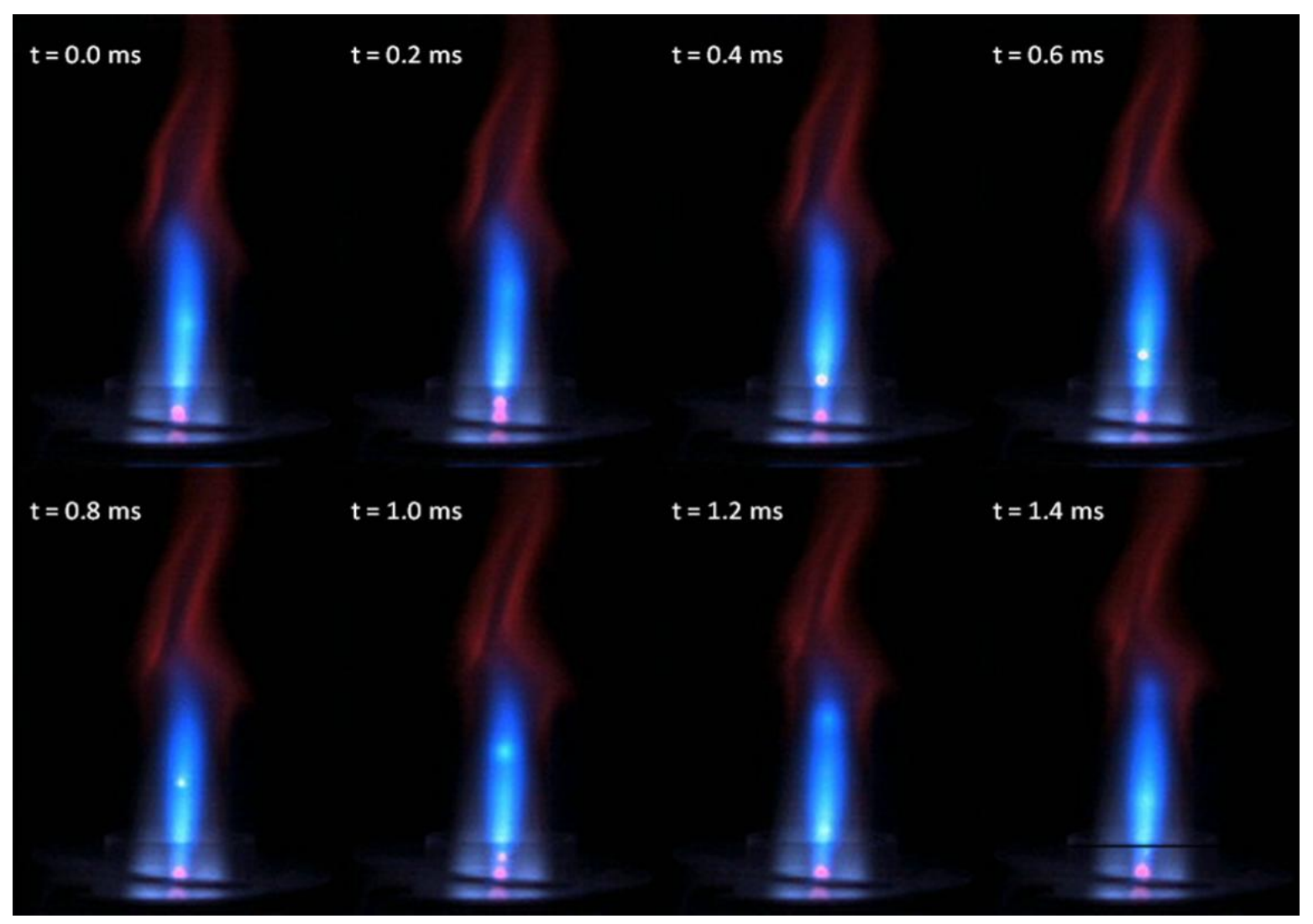

Figure 2a. Consecutive images of a large droplet cloud produced from a 10,000 ppm Y solution by a Meinhard nebulizer at $1.9 \mathrm{~mL} / \mathrm{min}$. Frame rate is $5000 \mathrm{fps}$, frames are ordered from left to right and top to bottom. Exposure time during this recording is reduced to $10 \mu \mathrm{s}$, to avoid camera saturation. 


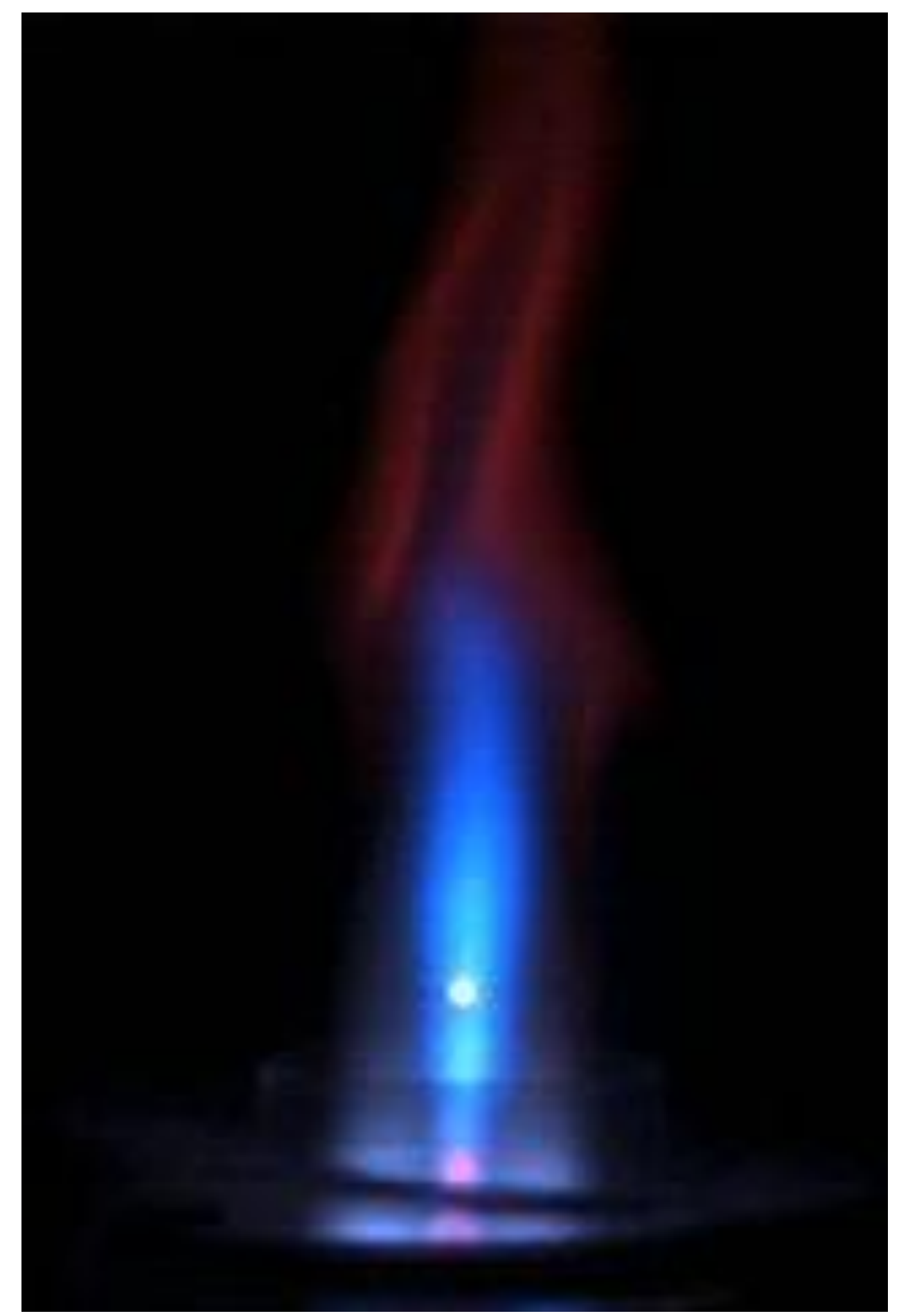

Figure 2b. Single high-speed image of the cloud surrounding a droplet produced from a Meinhard nebulizer at $1.9 \mathrm{~mL} / \mathrm{min}$. Notice the red YO emission in the core of the droplet and the neutral emission in the outer shell. 


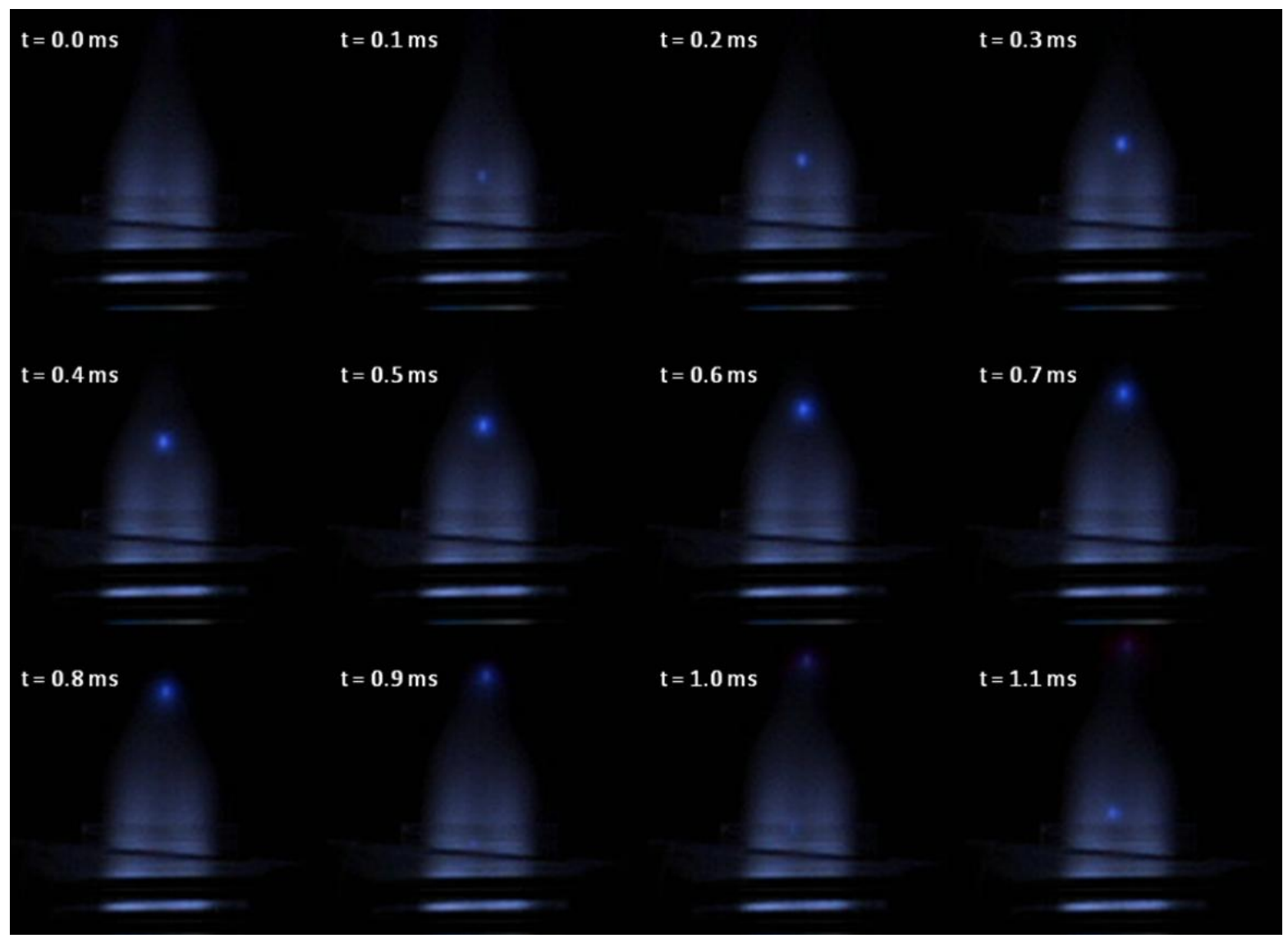

Figure 3. Consecutive images of the ICP during introduction of yttrium powder by entrainment into transport gas. Frame rate is $10,000 \mathrm{fps}$. Note bright blue $\mathrm{Y}^{+}$emission cloud, and that there is no continuous yttrium background emission from the ICP. 


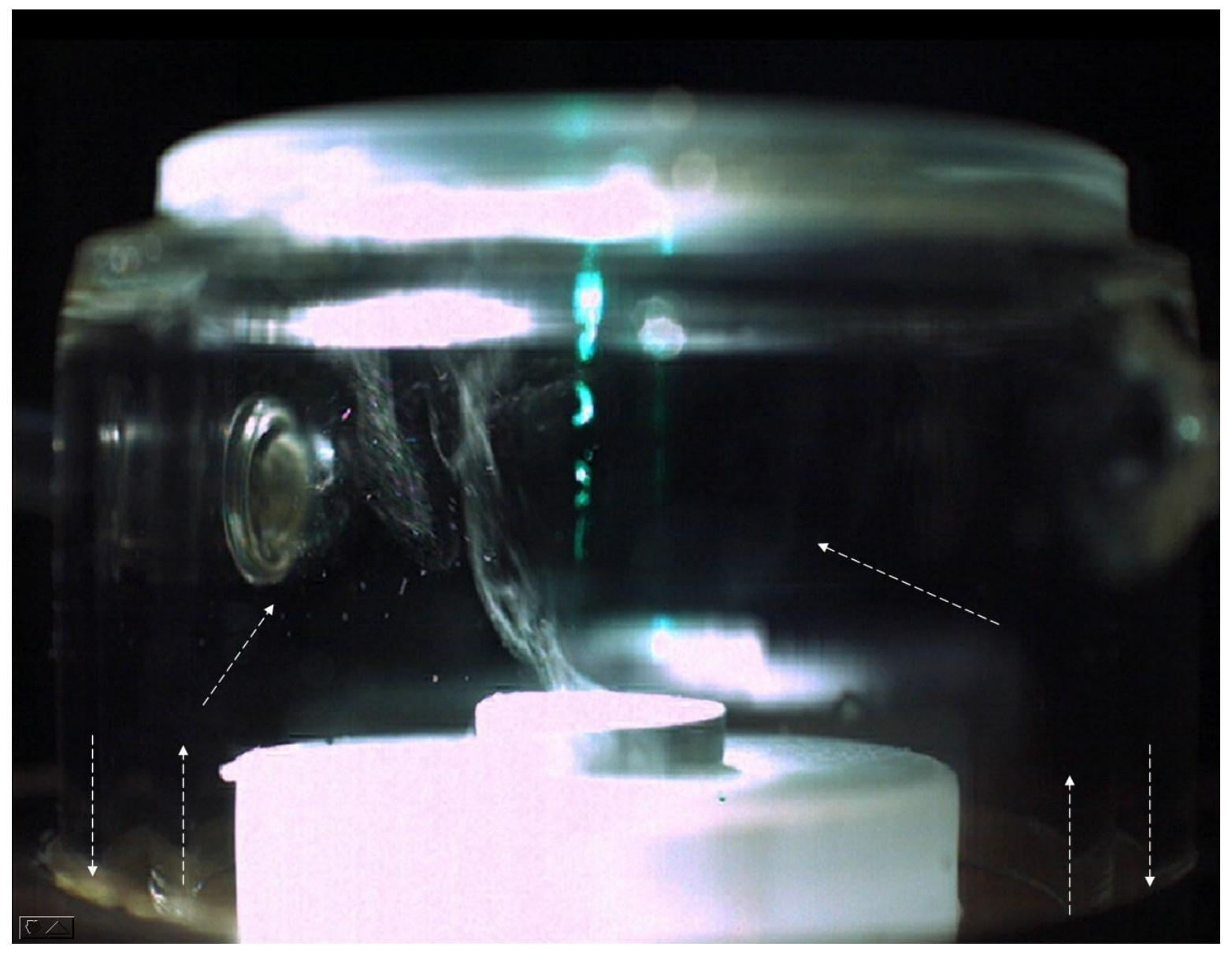

Figure 4. laser ablation cell. A laser pulse $(532 \mathrm{~nm})$ strikes a pressed pellet of yttrium oxide powder. This double-walled ablation cell is similar to designed to the CETAC LSX-100 ablation cell. The ablated material consists of many large particles that are swept toward the sample outlet on the left wall by argon flow. Arrows denote approximate gas flow directions. The pellet diameter is $\sim 13 \mathrm{~mm}$. 


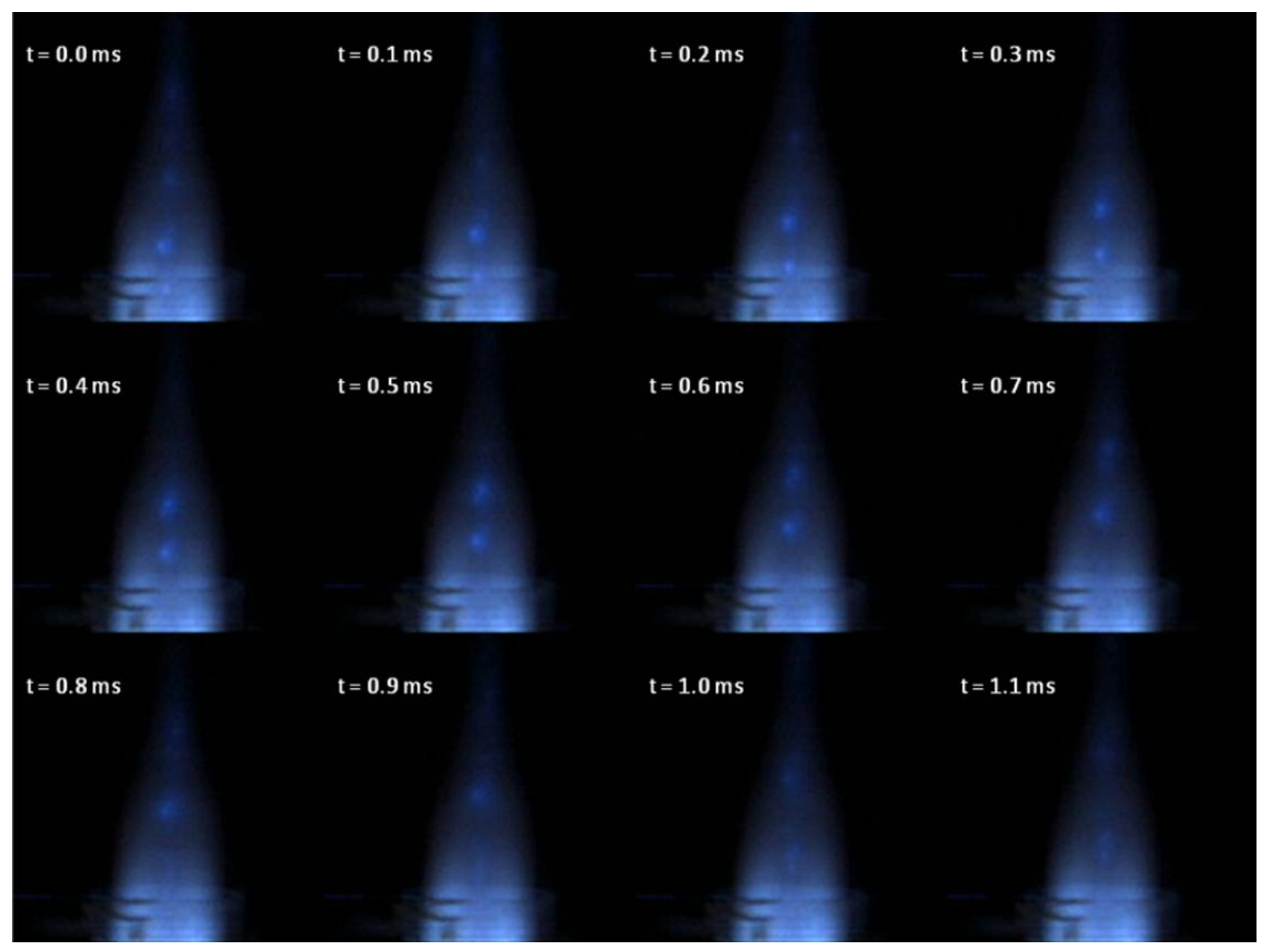

Figure 5. Consecutive images of the ICP during introduction of aerosol generated by ablation of a hand-pressed yttrium oxide pellet. Frame rate is $10,000 \mathrm{fps}$. The many visible particles behave similarly. Observations are made regarding the bright particle just approaching the end of the torch at $\mathrm{t}=0.0 \mathrm{~ms}$, chosen because it is visible in all twelve frames. 


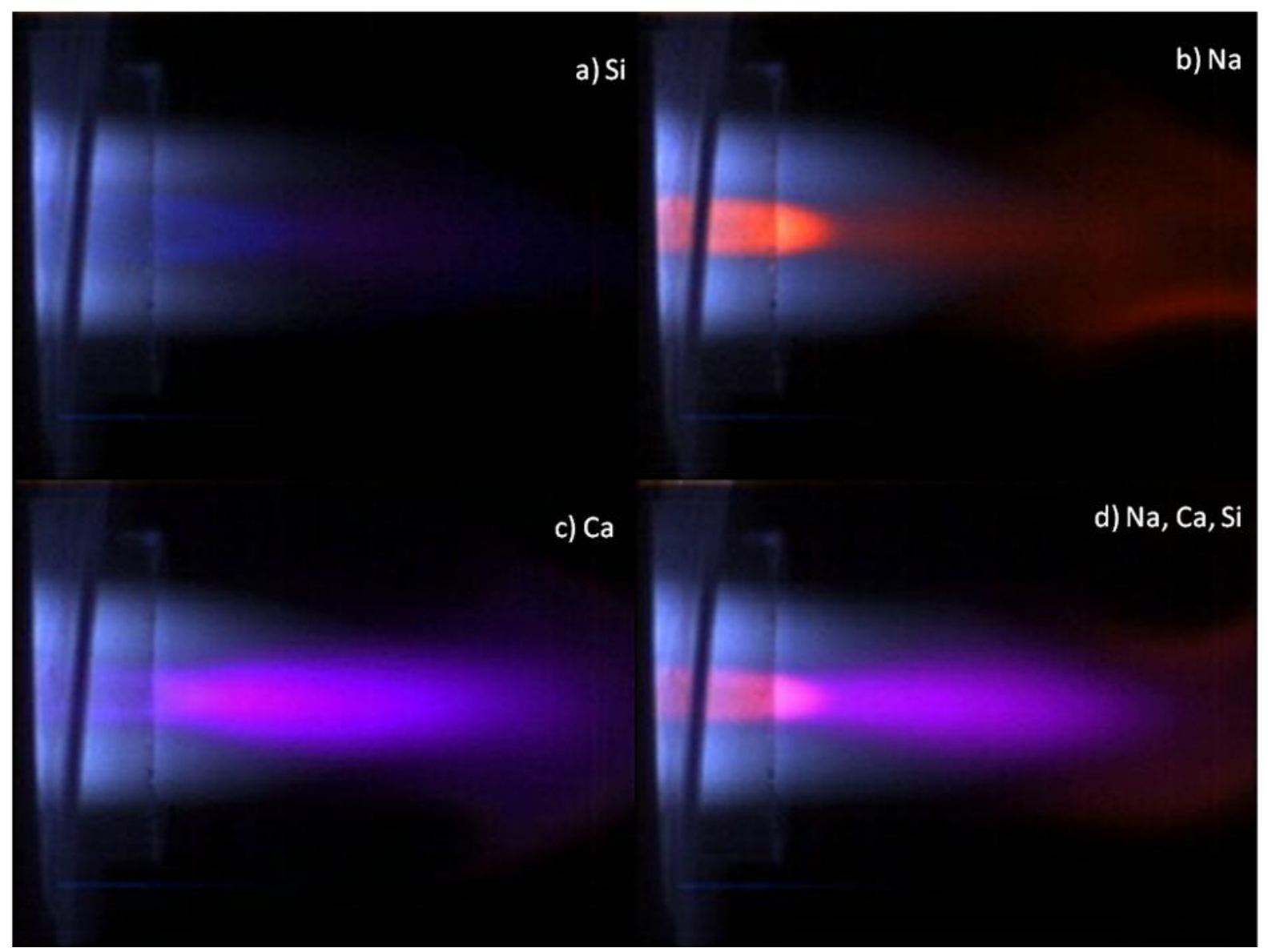

Figure 6. High speed photographs of the ICP during the rinse out of 10,000 ppm a) Si, b) Na, c) $\mathrm{Ca}$, and d) 3,300 ppm Si, Na \& Ca solution. Samples are introduced by ultrasonic nebulizer. Frame rate is 5,000 fps. 


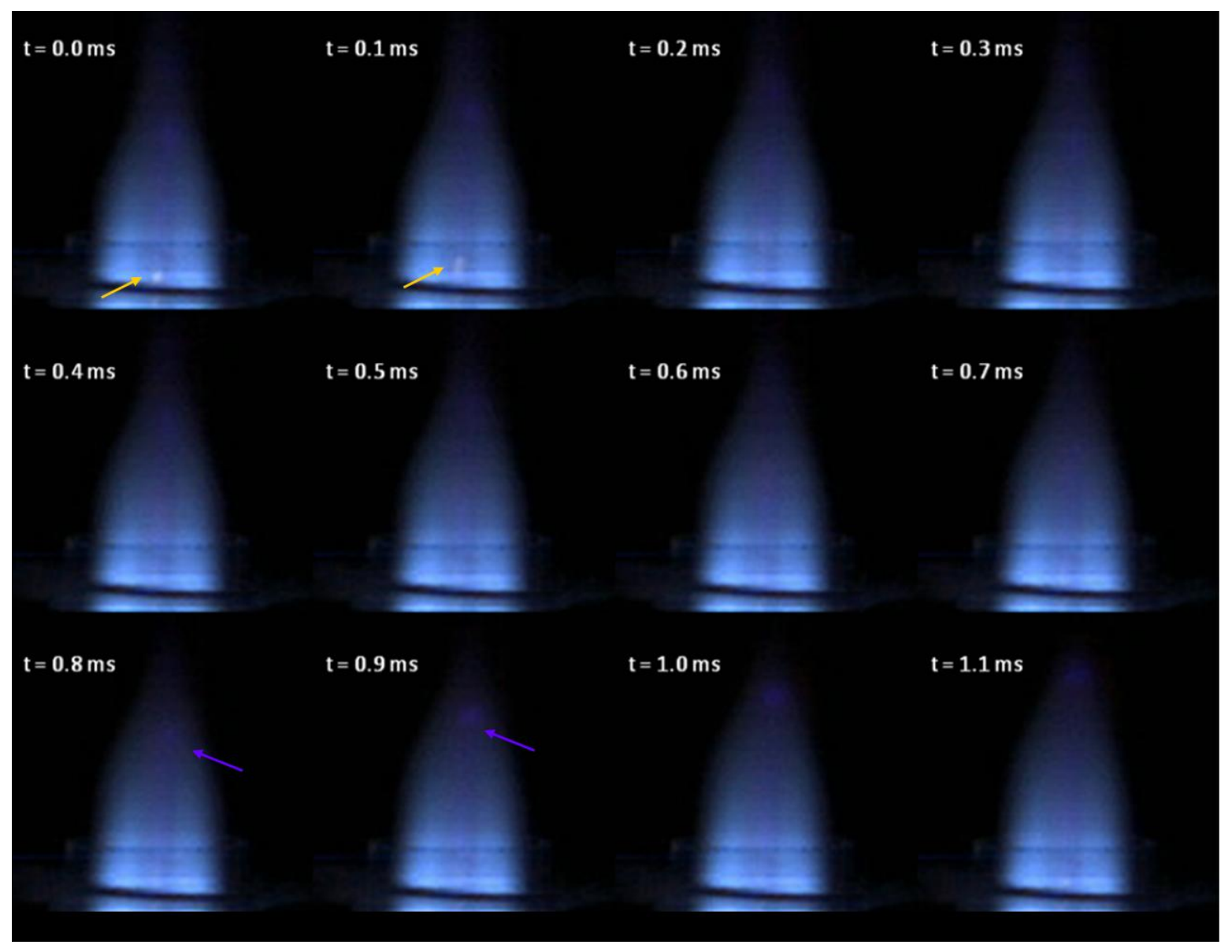

Figure 7. Consecutive frames showing large particle generated by ablation of NIST 610 glass. Frame rate is 10,000 fps. Yellow-orange arrow denotes sodium emission, purple arrow denotes $\mathrm{Ca}$ emission from same particle further downstream. Notice the distinct emission regions of $\mathrm{Na}$ and $\mathrm{Ca}$ from the particle cloud -sodium emission occurs from $\mathrm{t}=0.0$ to $\mathrm{t}=0.2$ $\mathrm{ms}$ and calcium emission from $\mathrm{t}=0.8$ to $\mathrm{t}=1.1 \mathrm{~ms}$. The particle cloud is not discernible for a period of 400-500 $\mu \mathrm{s}$. This contrasts the elemental emission zones during solution introduction, where sodium and calcium emission overlap. 


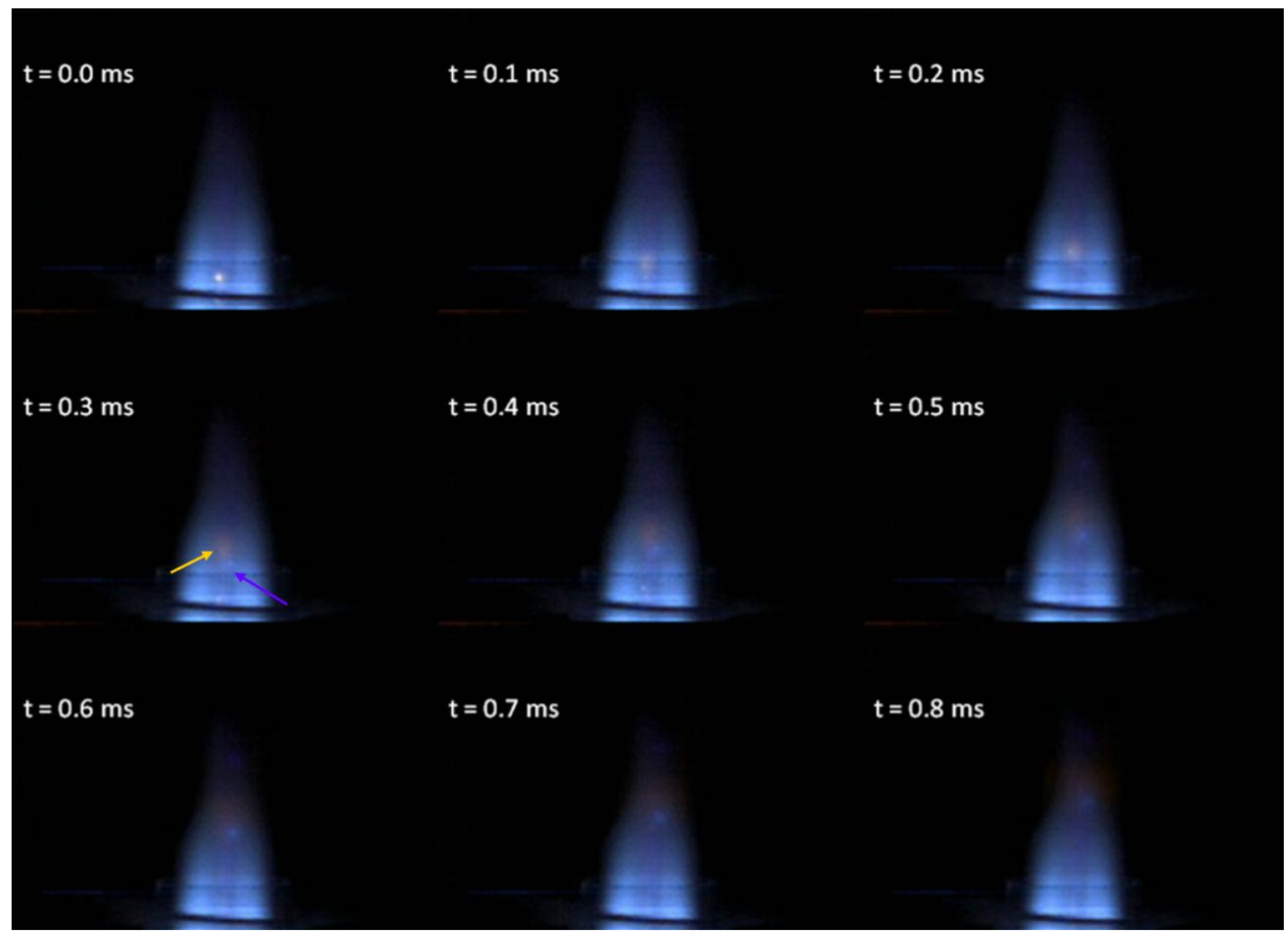

Figure 8a. Consecutive frames of the ICP during laser ablation of NIST 610 glass. Frame rate is $10,000 \mathrm{fps}$. A particle cloud exhibiting sodium emission $(0.3 \mathrm{~ms}$, yellow-orange arrow) is just ahead of a second particle exhibiting calcium emission (purple arrow) for the entire course through the plasma. This is a clear demonstration of fractionation. 


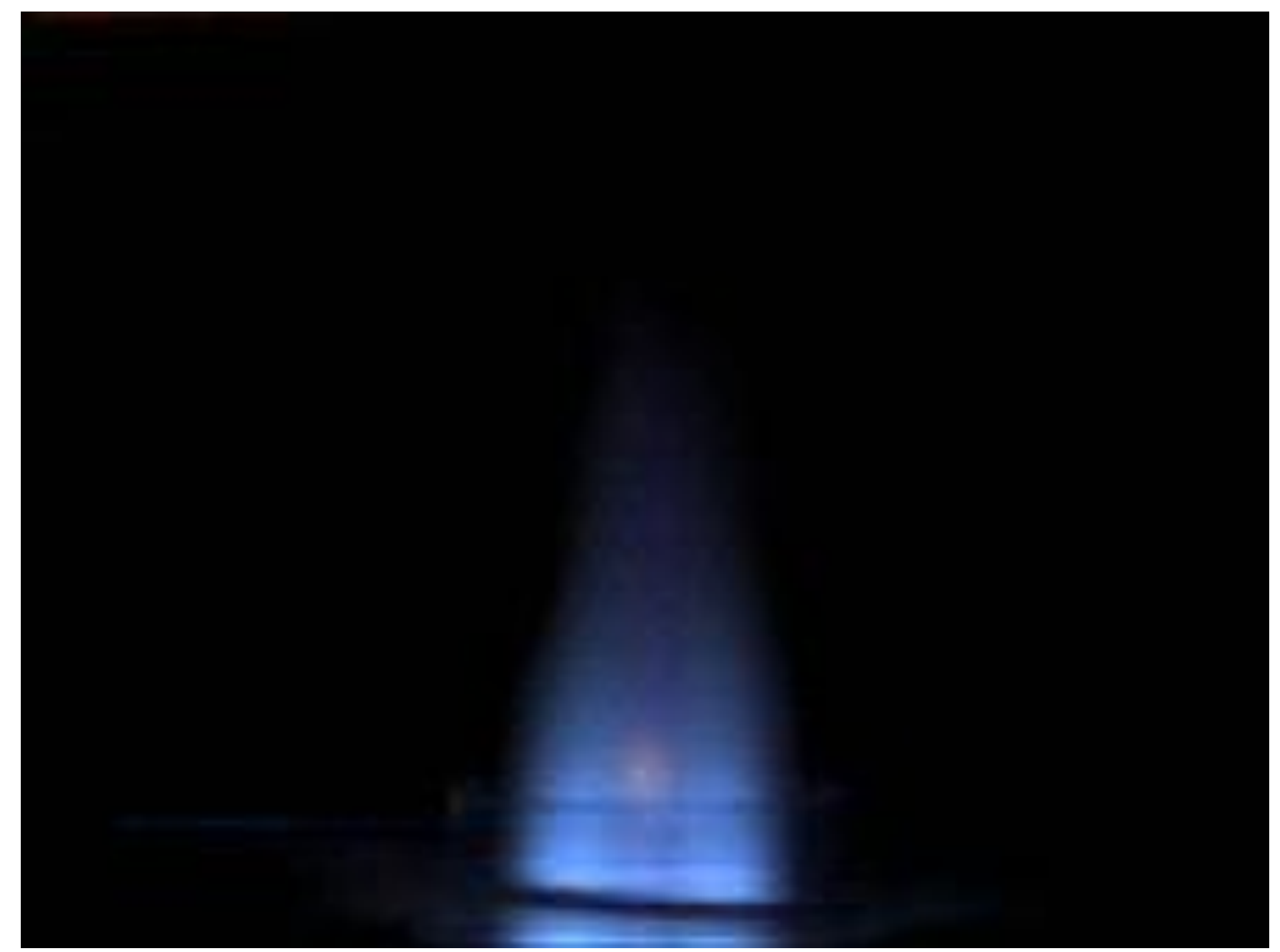

Figure 8b. Single image of a particle cloud during the ablation of NIST 610 glass. The brightest emission surrounding the particle is off-center from the larger cloud, signifying the cloud has drifted since it vaporized from the particle. 


\title{
Chapter 3. Digital photographic studies of vaporization and atomization in the inductively coupled plasma with fast shutter speed and high framing rate. Part II: Effects of solid particles from laser ablation at $266 \mathrm{~nm}$ with $10 \mathrm{~ns}$ and 150 fs pulses using helium and argon carrier gas.
}

A manuscript submitted for publication in The Journal of Analytical Atomic Spectroscopy

Chris H. Ebert, Nathan J. Saetveit, Daniel S. Zamzow, David P. Baldwin, Stanley J. Bajic, and R. S. Houk

\begin{abstract}
The emission behavior of particles generated by UV (266 nm) laser ablation (LA) of NIST 610 silicate glass and introduced to an inductively coupled plasma (ICP) is studied using a digital camera with fast shutter speed and high frame rate. Silicate glass is of particular interest because particles generated in this manner exhibit distinguishable calcium and sodium emission in the ICP. During typical ablation with a $20 \mathrm{~Hz}$ nanosecond laser and argon carrier gas, the plasma contains little visible background emission from the sample; emission is limited to discrete particle clouds. These clouds from ablated glass particles evince distinct regions of sodium emission first, followed by $\mathrm{Ca}$ emission well downstream. This behavior is attributed to sequential, spatially segregated vaporization of the two elements. With helium sample gas, the particle clouds are much larger and brighter and calcium emission is observed much earlier in the plasma. Femtosecond ablation at high repetition rate $(1000 \mathrm{~Hz})$ reduces the number of individual particles and produces intense
\end{abstract}


steady-state emission in the IRZ and NAZ. Implementing helium carrier gas with fs ablation further reduces the number of individual particles observed.

\section{Introduction}

LA-ICP-mass spectrometry (MS) is an established technique for the trace elemental analysis of solid samples ${ }^{1-4}$. The method is attractive because it is highly sensitive, it requires very little sample preparation, it is minimally destructive, and it can measure spatial images of the elemental composition of solids. The accuracy of determined concentration ratios in LA-ICP-MS is limited by fractionation, defined here as the difference between elemental concentration ratios measured from MS signals and the actual concentration ratios in the sample. Studying the behavior of laser-generated particles in the ICP could contribute to the development of strategies to alleviate fractionation and improve laser ablation as a sampling $\operatorname{method~}^{5,6}$.

In an accompanying study ${ }^{7}$, large droplets, individual particles, and aerosols produced by a green ns laser were introduced to an open ICP. Emission clouds from these species were observed by a high-speed digital camera $(0.1 \mathrm{~ms}$ temporal resolution) that captures separate images of a particle or droplet during its entire trip through the ICP, which was not possible in previous studies ${ }^{6,8,9}$. Clouds surrounding droplets of yttrium solution exhibit an emission gradient from the center of the cloud to the outside, with emission from YO molecules in the core of the cloud, neutral yttrium emission in an intermediate shell and $\mathrm{Y}^{+}$ions in an outer shell. Often, large particles and droplets did not completely succumb to the high temperatures for the entire length of the plasma - i.e., some $20 \mathrm{~mm}$ downstream from the torch end, well past the usual sampling point for ICP-MS experiments. Emission observed during 
introduction of laser-generated aerosols was produced extensively from discrete particles, with little steady-state emission from the initial radiation zone (IRZ) and normal analytical zone (NAZ). Large particles produced during ablation of NIST 610 glass showed signs of fractionation, exhibiting first sodium and then calcium emission in very different axial positions. This is attributed to the sequential vaporization of sodium and calcium from large particles.

The present work is intended to supplement the accompanying study by focusing only on LA with newer lasers and helium carrier gas and observing the changes in particle behavior that ensue. Previous studies have demonstrated that ablation in helium atmosphere reduces fractionation and improves the analytical performance of LA-ICP-MS ${ }^{10,11}$. Helium has a higher thermal conductivity than argon, which cools the laser-vaporized sample as it recondenses and creates an aerosol with a more uniform particle distribution ${ }^{12,13}$. The higher thermal conductivity of helium also helps cool the sample during ablation, which reduces sample melting and preferential vaporization of volatile elements. Ablating in helium also reduces fractionation because the laser-induced plasma is less extensive than that created during ablation in an argon atmosphere, reducing the non-stoichiometric redeposition of material $^{14}$. Subsequent removal of such previously-ablated, altered material is one cause of fractionation.

Reducing the laser pulse length has also proven to reduce fractionation ${ }^{15}$. When the pulse length is in the femtosecond range, more laser energy contributes to sample vaporization and less energy is converted to heat than with a nanosecond laser ${ }^{16}$. Chichkov et al. ${ }^{17}$ used scanning electron microscopy to observe craters left after ablation of steel with ns, ps, and fs lasers. They found extensive sample melting by ns pulses and reduced melting 
with shorter pulses. Russo et al. ${ }^{18}$ found the same effects, and determined elemental ratios to be more accurate and precise when laser heating of the sample was reduced by use of a fs laser.

Furthermore, fs laser ablation produced fewer large, micrometer-sized particles than ns laser ablation ${ }^{19}$, although Neimax et al. reported that at fluence above $5 \mathrm{~J} / \mathrm{cm}^{2}$ large particles were still plentiful during fs LA ${ }^{20}$. Günther et al. found that aerosols produced by ns LA exhibited a bimodal particle size distribution, while the distribution for fs LA produced aerosol was unimodal ${ }^{21}$. Nanosecond ablation produced an aerosol with a correlation between particle size and particle composition - large particles were less representative of the original sample than small particles. This non-stoichiometric effect was alleviated (but not completely eliminated) during femtosecond ablation ${ }^{22}$.

The present study contains high-speed images and movie clips of the ICP during the introduction of laser generated aerosols, with individual particle clouds visible in many successive frames. These photographs are used to draw qualitative conclusions about laser ablation and fractionation. Ablation is accomplished with either fs or ns lasers. The particle behavior using helium or argon as carrier gases are compared.

\section{Methods}

The ICP device used in this study is the same instrument used in Part 1 of this study (RF Plasma Products ICP-16L, 40 MHz). The plasma flows vertically; images are sometimes rotated for formatting considerations. The operating parameters of the ICP were the same as the previous study. Once again, all experiments were performed using an open plasma, with no extraction system or mass spectrometer. 
Some laser ablation experiments were done in a helium atmosphere rather than argon. For such experiments, the helium flow was $1.0 \mathrm{~L} / \mathrm{min}$ and no argon gas was added to the sample gas beyond the ablation cell. Usually when ablation is carried out in helium, makeup argon is added before the plasma to help stabilize the plasma. This plasma remained stable with $100 \%$ helium in the axial channel, so no makeup argon was added. Thus, the effect of helium in the axial channel is exacerbated and differences in emission behavior are more easily observed.

Nanosecond laser ablation was carried out with a Q-switched laser ablation system (LSX-500, CETAC Technologies, Omaha, NE). This is a Nd:YAG laser that is frequency quadrupled to $266 \mathrm{~nm}$ wavelength. Femtosecond ablation was achieved using a Libra laser (Coherent, Inc., Santa Clara, CA) with a home-built enclosed ablation system. This is a Ti:Sapphire laser, frequency tripled to $266 \mathrm{~nm}$ using a harmonic box (HGS-T, Coherent Inc.).

The laser parameters are reported in Table 1. For each laser, the parameters used are typical for their operation during LA-ICP-MS. Most notably, the laser repetition rate for the fs laser is $1000 \mathrm{~Hz}$, much higher than that for the ns laser $(20 \mathrm{~Hz})$. There is no simple way to reduce the repetition rate for the fs laser; this must be considered while comparing the behaviors of aerosols created by each laser. Laser power was adjusted on the ns laser by controlling the flash lamp current through the software. On the fs laser, laser pulse energy was controlled by inserting one of a series of neutral density filter between the harmonic box and ablation cell.

All ablation experiments were $\sim 15$ second raster analyses. The same ablation cell, from the LSX-100, was used with both lasers. The ablated aerosol particles were transported through approximately $6 \mathrm{~m}$ of tygon tubing $(4.76 \mathrm{~mm}$ ID) to the plasma torch. 
An Olympus i-Speed2 video camera recorded videos of the plasma during the introduction of laser-ablated particles. A Navitron $25 \mathrm{~mm}$ focal length lens was implemented to focus light from the axial channel on the camera. All images were recorded with an exposure time of $50 \mu \mathrm{s}$. At 10,000 fps, particles generated by laser ablation are typically observed in eight to twelve consecutive frames before emission ceases or the particle leaves the plasma. The image sizes are 224 by 168 pixels. All videos included in this publication were recorded during the steady-state introduction of sample after the rinse-in and before the rinse-out.

NIST 610 silicate glass is the only solid sample used in this study. This standard contains $33.7 \%$ silicon, $10.4 \%$ sodium, and $8.6 \%$ calcium by mass. The appearance of the plasma during the introduction of these elements by solution nebulization is discussed in the adjoining study ${ }^{7}$.

\section{Results and discussion}

As in Part $1^{7}$, the figures and videos discussed below are selected to best illustrate interesting phenomena seen in many such video measurements. Space considerations preclude a description of every photographic experiment done. In the text of this study, particles are described as 'large' if they generate a particle cloud that is distinguishable from steady-state background emission. The term 'large' does not imply a specific threshold for particle diameter.

Solution emission profiles of $\mathrm{Si}, \mathrm{Na}$, and $\mathrm{Ca}$

The emission profiles of the ICP during the introduction of silicon, sodium, and calcium solutions are displayed in Figure 6 of the accompanying paper $^{7}$. The visible emission 
from sodium and calcium are easily distinguishable by the camera and the human eye. Sodium emission ( $\mathrm{Na}$ (I) $589 \mathrm{~nm}$ ) appears orange and is generally limited to the IRZ. Calcium emission (Ca (II) 393 and $396 \mathrm{~nm}$ and Ca (I) $422 \mathrm{~nm}$ ) appears purple or blue-purple, and occurs in both the IRZ and the NAZ. During simultaneous introduction of calcium and sodium, the resulting combination of lines in the IRZ appears magenta to the eye. This color is readily distinguishable from sodium emission alone and from calcium emission alone. Silicon undergoes only faint emission in the visible region. In this study, orange light is attributed to $\mathrm{Na}$ I emission. Purple light is attributed to calcium emission, mainly $\mathrm{Ca}$ (II) lines. $\mathrm{Na}, \mathrm{Ca}$ and $\mathrm{Si}$ and $\mathrm{O}$ make up $98 \%$ of the material in NIST 610 silicate glass ${ }^{23}$.

\section{Nanosecond laser ablation in argon}

The particles generated by LA from glass are generally no larger than several $\mu \mathrm{m}$ in diameter, too small to be observed directly by the camera. Instead, emission emanates from the cloud of material that is steadily vaporized from the particle. During the ablation of NIST 610 silicate glass standard by the nanosecond UV laser, the regions of sodium and calcium emission in the ICP are significantly different than those observed during solution introduction.

Video A shows the ICP during introduction of NIST 610 by ns laser ablation. There is an occasional orange flash in the IRZ from $\mathrm{Na}$ (I) emission followed by a diffuse purple cloud of Ca (II) emission in the NAZ. We attribute this behavior to a large particle. Figure 1 shows twelve consecutive frames of the first particle in Video A. This particle cloud exhibits distinct emission zones of first $\mathrm{Na}$ (I) (orange cloud and arrow), then little emission for several frames (about $1 \mathrm{~cm}$ or $500 \mu \mathrm{s}$ ), then Ca (II) emission (purple cloud and arrow). This phenomenon is also observed with a green nanosecond laser and was reported in the 
adjoining study ${ }^{7}$. There is little steady-state analyte emission from the NAZ during ablation with the ns laser, so clearly there is no visible emission from the particle cloud in the hiatus. During the transitional period between sodium and calcium emission, the plasma looks no different than when material is not being ablated at all. In our opinion, the lack of emission for a number of frames occurs because a) the $\mathrm{Na}$ from the particle has been lost and any residual $\mathrm{Na}$ has been ionized and does not emit, and b) the particle is not hot enough for $\mathrm{Ca}$ to be vaporized. This is a clear demonstration of fractionation.

Changing the pulse energy of ns laser ablation does not impact the behavior of the ablated particles. Reducing the laser flash lamp power by $25 \%, 50 \%$ and $75 \%$ did not change the lack of steady-state emission (data not shown). The only observable change during the reduction of laser power was the corresponding reduction in the number of individual particles. Table 2 lists the average frequency of discrete particles observed in the plasma during ablation of glass at different laser energies. These rates are determined by manually counting visible particle clouds for $\sim 2500$ consecutive frames during a period of time well after the onset of particles and before the laser ablation ended.

\section{Nanosecond laser ablation in helium}

When NIST 610 glass is ablated by the ns laser in helium rather than argon, the visible emission is again limited to discrete particle clouds - the IRZ and NAZ contain little discernible emission except when a particle is passing through. The particle clouds themselves behave quite differently in helium. Video B shows such a plasma; large particle clouds are less prominent than when using Ar carrier gas. Of the few particles seen, Figure 2 displays one prominent cloud from a particle formed during ns laser ablation and carried to the plasma by helium. The particle cloud is much brighter and wider than typical particle 
clouds observed in an argon center channel. Furthermore, the particle cloud exhibits purple $\mathrm{Ca}$ (II) emission very early in the plasma. Calcium starts to evolve off the particle by the time it reaches the ICP-MS sampling point several millimeters downstream from the end of the torch, so even such a large particle would yield $\mathrm{Ca}^{+}$ions in an ICP-MS experiment. Apparently, helium facilitates the heating of particles more than argon does. Consequently, the photos show that vaporization and ionization are more extensive and occur farther upstream in helium than argon, especially for large particles.

Figure 2 and Video B show that sodium emission is never observed alone during ablation in helium, unlike the situation in argon. The particle cloud might undergo simultaneous emission from calcium and sodium for the first 3 or 4 frames of Figure 2 . The core of the particle cloud in these early images does have a pink or magenta tint, similar to the color of the IRZ during introduction of $\mathrm{Na}$ and $\mathrm{Ca}$ together in solution ${ }^{7 \text {, figure } 6 \mathrm{~d}}$. If so, calcium and sodium are vaporized concurrently. Subsequent views of this particle show only a purple cloud with no magenta core, characteristic of Ca emission only. Vaporizing and ionizing a greater portion of the laser-generated aerosol is expected to reduce fractionation, although use of He carrier gas may not totally eliminate it.

Particle velocity is not appreciably different with helium carrier gas rather than argon. Particle velocities for both carrier gases are approximately $20 \mathrm{~m} / \mathrm{s}$, measured using the known diameter of the torch as reference to determine the distance a particle moved each frame, and the frame rate of $10,000 \mathrm{fps}$.

\section{Femtosecond laser ablation in argon}

During the introduction of NIST 610 by fs laser ablation, the emission observed in the ICP is considerably different than during ablation by the ns laser. Video $\mathrm{C}$ and Figure 3 
display images of the plasma during the introduction of fs LA generated aerosol. For this particular clip, few discrete particles are observed. Unlike ns laser ablation, the center channel exhibits continuous, steady-state emission of sodium and calcium. The IRZ, while thinner and not as sharply defined as during solution introduction, contains the orange-pink color characteristic of the superposition of emission from both neutral sodium and calcium. The NAZ primarily exhibits $\mathrm{Ca}(\mathrm{II})$ emission, similar to the introduction of the multi-element solution observed in the accompanying paper ${ }^{7}$, Fig. $6 \mathrm{~d}$. This is evidence that material introduced to the plasma during fs LA undergoes more extensive vaporization before it enters the field of view of the camera than material generated by ns LA. This will generate more a stable, analytically desirable signal. If ICP-MS experiments are carried out with the sampler cone at the tip of the IRZ, both sodium and calcium are vaporized and ionized prior to reaching the cone, so the measured mass spectrum will more accurately represent the composition of the sample aerosol.

Along with this continuous emission, fs LA occasionally generates particles that are large enough to produce discrete emission clouds. Figure 4 shows a sequence with one such particle, which is not fully vaporized before it comes into view. It is difficult to ascertain the behavior of this particle because steady-state emission from the IRZ and NAZ competes with emission from the particle cloud at times. In the first two frames in Fig. 4, the particle cloud appears magenta to the eye, i.e. a combination of yellow $\mathrm{Na}$ (I) and $\mathrm{Ca}$ (II) lines. The particle cannot be distinguished from emission in the NAZ until at least $\mathrm{t}=0.6 \mathrm{~ms}$, where it is barely discernible from the background. For the last 2 to 3 frames, the particle cloud is exiting the plasma and exhibits calcium emission. 
In the course of several thousand frames (i.e., approximately $3 \mathrm{~s}$ ), several similar large particles were produced by fs LA. Not one of these particles exhibited discrete calcium emission above the background for the period between the tip of the IRZ and a spot $\sim 20 \mathrm{~mm}$ downstream of the torch - i.e., the first position when this purple particle cloud is visible again in Fig. 4. This leads to the conclusion that the largest particles created in fs laser ablation still undergo spatially segregated vaporization of sodium and calcium, although this behavior is much less common than for the particles created in nanosecond laser ablation. Judging from these observations, fs LA-ICP-MS analyses would produce a steady baseline signal from material that is fully vaporized and ionized well before the sampler cone. This signal would fairly accurately represent the composition of the laser produced aerosol, and plasma-induced fractionation would be minimal. However, on top of that steady signal there would be occasional transient spikes from particles too large to be fully processed before reaching the sample cone. The determined elemental ratios from these spikes may differ from the baseline signal; specifically the refractory elements may be underrepresented. This explanation is consistent with literature reports by several groups ${ }^{24-27}$. So while plasma-induced fractionation may be improved by using fs laser ablation rather than ns ablation, it is not fully eliminated so long as even a few of these larger particles persist.

Figure 5 contains images of the plasma during fs LA at various laser pulse energies. Increasing or decreasing the laser energy changes the intensity of steady-state emission from the IRZ and NAZ. There is little change in the spatial location of $\mathrm{Na}$ and $\mathrm{Ca}$ emission. When decreasing the laser energy, there is a slight reduction in the number of large, unvaporized particles that pass through the plasma (Table 2). The overall number of distinguishable particles is much lower for fs ablation than ns ablation. 


\section{Femtosecond laser ablation in helium}

Video D and Figure 6 are recorded during the introduction of aerosol generated in $\mathrm{He}$ by fs LA. During fs ablation of NIST 610 glass in a helium atmosphere, as seen in Video D, discernible individual particles are even less frequent. The axial channel of the plasma is very diffuse; the IRZ and NAZ are ill-defined. All visible analyte emission occurs as continuous radiation from the center channel. To the extent that the IRZ is perceivable, it contains emission from both sodium and calcium.

Using helium as the carrier gas reduces the number of large, unvaporized particles for a number of reasons: a) ablation in helium generally produces aerosols of narrower particle size distribution, b) helium is lighter than argon and cannot transport the largest particles to the plasma, and c) with helium in the axial channel of the ICP the large particles are more completely vaporized and ionized before they enter the camera's field of view.

\section{Conclusion}

Short laser pulse lengths and helium carrier gas have beneficial effects on the ICP emission behavior of aerosol generated by laser ablation of NIST 610 glass. Using helium in the axial channel causes particle clouds to diffuse more quickly and to vaporize and ionize earlier in the plasma. If so, helium is expected to not only improve laser-induced fractionation, as reported extensively, but also improve ICP-induced fractionation.

Ablating with a femtosecond laser at high repetition rate reduces the number of discrete particles compared to nanosecond ablation. Femtosecond ablation induces intense steady-state emission in the IRZ and NAZ of the plasma. At the tip of the IRZ during fs laser ablation, overlapping sodium and calcium emission are visible - just like during the 
introduction of $\mathrm{Na}$ and $\mathrm{Ca}$ solution. Thus, during fs-LA-ICP-MS experiments, the sample cone can be placed at the tip of the IRZ and extraction of both elements will be efficient. Performing ICP-MS by fs laser ablation in helium is expected to improve precision and accuracy when compared to ns ablation in argon due to the juxtaposition of several beneficial effects.

\section{Acknowledgements}

Research at the Ames Laboratory was supported by the U.S. Department of EnergyNational Nuclear Security Agency under contract number DE-AC02-07CH11358. The Coherent Libra femtosecond laser was obtained through funding provided by the U.S. Department of Energy, Office of Nuclear Nonproliferation (NA-22). 


\section{References}

1. R. S. Houk, V. A. Fassel, G. D. Flesch, H. J. Svec, A. L. Gray and C. E. Taylor, Anal. Chem., 1980, 52, 2283-2289.

2. Gray, Analyst, 1985, 110, 551-556.

3. J. Koch and D. Guenther, Appl. Spectrosc., 2011, 65, 155A-162A.

4. D. Guenther and B. Hattendorf, Trends Anal. Chem., 2005, 24, 255-265.

5. L. Flamigni, J. Koch, H. Wiltsche, R. Brogioli, S. Gschwind and D. Guenther, J. Anal. At. Spectrom., 2012, 27, 619-625.

6. D. B. Aeschliman, S. J. Bajic, D. P. Baldwin and R. S. Houk, J. Anal. At. Spectrom., 2003, 18, 1008-1014.

7. C. H. Ebert, N. J. Saetveit, D. S. Zamzow, S. J. Bajic and R. S. Houk, J. Anal. At. Spectrom., 2012, Submitted.

8. R. K. Winge, J. S. Crain and R. S. Houk, J. Anal. At. Spectrom., 1991, 6, 601-604.

9. R. S. Houk, R. K. Winge and X. Chen, J. Anal. At. Spectrom., 1997, 12, 1139-1148.

10. D. Guenther and C. A. Heinrich, J. Anal. At. Spectrom., 1999, 14, 1363-1368.

11. S. M. Eggins, L. P. J. Kinsley and J. M. G. Shelley, Appl. Surf. Sci., 1998, 127-129, 278-286.

12. R. Hergenroeder, J. Anal. At. Spectrom., 2006, 21.

13. I. Horn and D. Guenther, Appl. Surf. Sci., 2003, 207, 144-157.

14. J. Koch, S. Schlamp, T. Rosgen, D. Fliegel and D. Guenther, Spectrochim. Acta Part $B, 2007,62,20-29$.

15. V. Margetic, A. Pakulev, A. Stockhaus, M. Bolshov, K. Niemax and R.

Hergenroeder, Spectrochim. Acta Part B, 2000, 55, 1771-1785.

16. R. E. Russo, X. Mao, J. J. Gonzalez and S. S. Mao, J. Anal. At. Spectrom., 2002, 17, 1072-1075.

17. B. N. Chichkov, C. Momma, S. Nolte, F. von Alvensleben and A. Tuennermann, Appl. Phys. A, 1996, 63, 109-115.

18. F. Poitrasson, X. Mao, S. S. Mao, R. Freydier and R. E. Russo, Anal. Chem., 2003, 75, 6184-6190. 
19. C. Y. Liu, X. L. Mao, S. S. Mao, X. Zeng, R. Greif and R. E. Russo, Anal. Chem., 2004, 76, 379-383.

20. J. Koch, A. von Bohlen, R. Hergenroeder and K. Niemax, J. Anal. At. Spectrom., 2004, 19, 267-272.

21. V. Mozna, J. Pisonero, M. Hola, V. Kanicky and D. Guenther, J. Anal. At. Spectrom., 2006, 21, 1194-1201.

22. N. J. Saetveit, S. J. Bajic, D. P. Baldwin and R. S. Houk, J. Anal. At. Spectrom., 2008, 23, 54-61.

23. K. P. Jochum, U. Weis, B. Stoll, D. Kuzmin, Q. Yang, I. Raczek, D. E. Jacob, A. Stracke, K. Birbaum, D. A. Frick, D. Guenther and J. Enzweiler, Geostand. Geoanal. Res., 2011, 35, 397-429.

24. D. C. Perdian, S. J. Bajic, D. P. Baldwin and R. S. Houk, J. Anal. At. Spectrom., 2008, 23, 336-341.

25. D. C. Perdian, S. J. Bajic, D. P. Baldwin and R. S. Houk, J. Anal. At. Spectrom., 2008, 23, 325-335.

26. M. Guillong, J. Anal. At. Spectrom., 2002, 17, 831-837.

27. B. Kozlov, A. Saint and A. Skroce, J. Anal. At. Spectrom., 2003, 18, 1069-1075. 
Table 1. Laser and Ablation Parameters

\begin{tabular}{|c|c|c|}
\hline Laser & CETAC LSX-500 & Coherent Libra \\
\hline Laser wavelength & $266 \mathrm{~nm}$ & $266 \mathrm{~nm}$ \\
\hline Pulse width & $10 \mathrm{~ns}$ & $90 \mathrm{fs}$ \\
\hline Repetition Rate & $20 \mathrm{~Hz}$ & $1000 \mathrm{~Hz}$ \\
\hline Pulse Energy & $560 \mu \mathrm{J}$ & $75 \mu \mathrm{J}$ \\
\hline Power & $11.2 \mathrm{~mW}$ & $75 \mathrm{~mW}$ \\
\hline Spot Size & $100 \mu \mathrm{m}$ & $\sim 100 \mu \mathrm{m}$ \\
\hline Fluence & $1.78 \mathrm{~J} / \mathrm{cm}^{2}$ & $0.23 \mathrm{~J} / \mathrm{cm}^{2}$ \\
\hline Raster Speed & $100 \mu \mathrm{m} / \mathrm{sec}^{2}$ & $100 \mu \mathrm{m} / \mathrm{sec}^{\mathrm{n}}$ \\
\hline Beam homogenized & $\mathrm{yes}$ & $\mathrm{no}$ \\
\hline
\end{tabular}

Table 2. Influence of laser power on number of unvaporized particles observed per second

\begin{tabular}{|c|c|c|}
\hline Pulse Length & Laser Pulse Energy $(\boldsymbol{\mu J})$ & Particles/sec \\
\hline $10 \mathrm{~ns}$ & 560 & 1271 \\
\hline $10 \mathrm{~ns}$ & 374 & 1189 \\
\hline $10 \mathrm{~ns}$ & 182 & 876 \\
\hline $10 \mathrm{~ns}$ & 44 & 55 \\
\hline $90 \mathrm{fs}$ & 171 & 134 \\
\hline $90 \mathrm{fs}$ & 76 & 89 \\
\hline $90 \mathrm{fs}$ & 36 & 30 \\
\hline
\end{tabular}




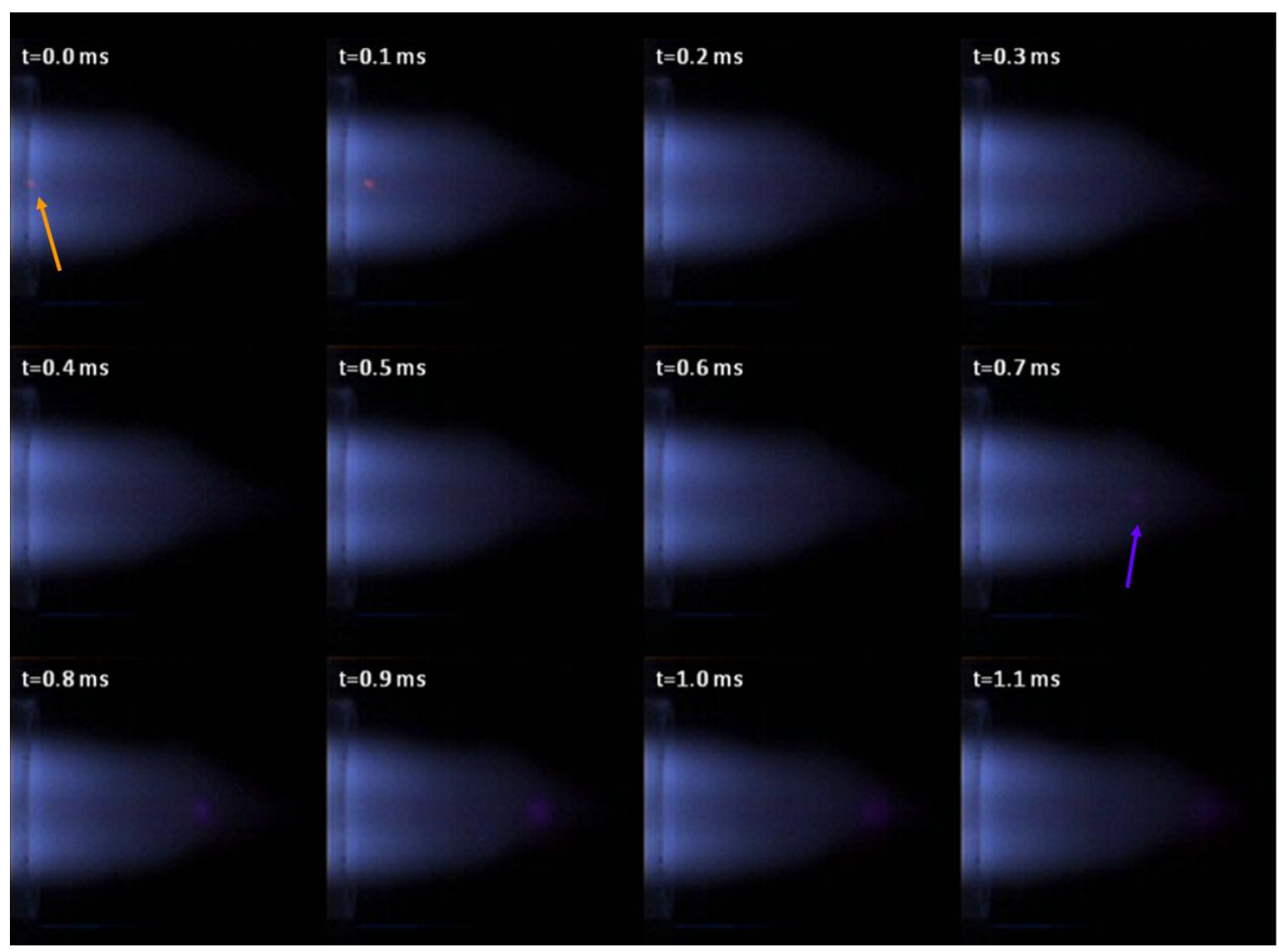

Figure 1. Consecutive images of the ICP during nanosecond ablation of NIST 610 glass with argon sample gas. This individual particle cloud exhibits sodium emission at $t=0.0$ to $t=0.2$ $\mathrm{ms}$ and calcium emission from $\mathrm{t}=0.8$ to $\mathrm{t}=1.1 \mathrm{~ms}$. No visible emission occurs for a distance of about $1 \mathrm{~cm}$ between the zones of $\mathrm{Na}$ and $\mathrm{Ca}$ emission. The orange arrow indicates the first visible $\mathrm{Na}$ emission; the purple arrow shows the initial location of $\mathrm{Ca}$ emission. 


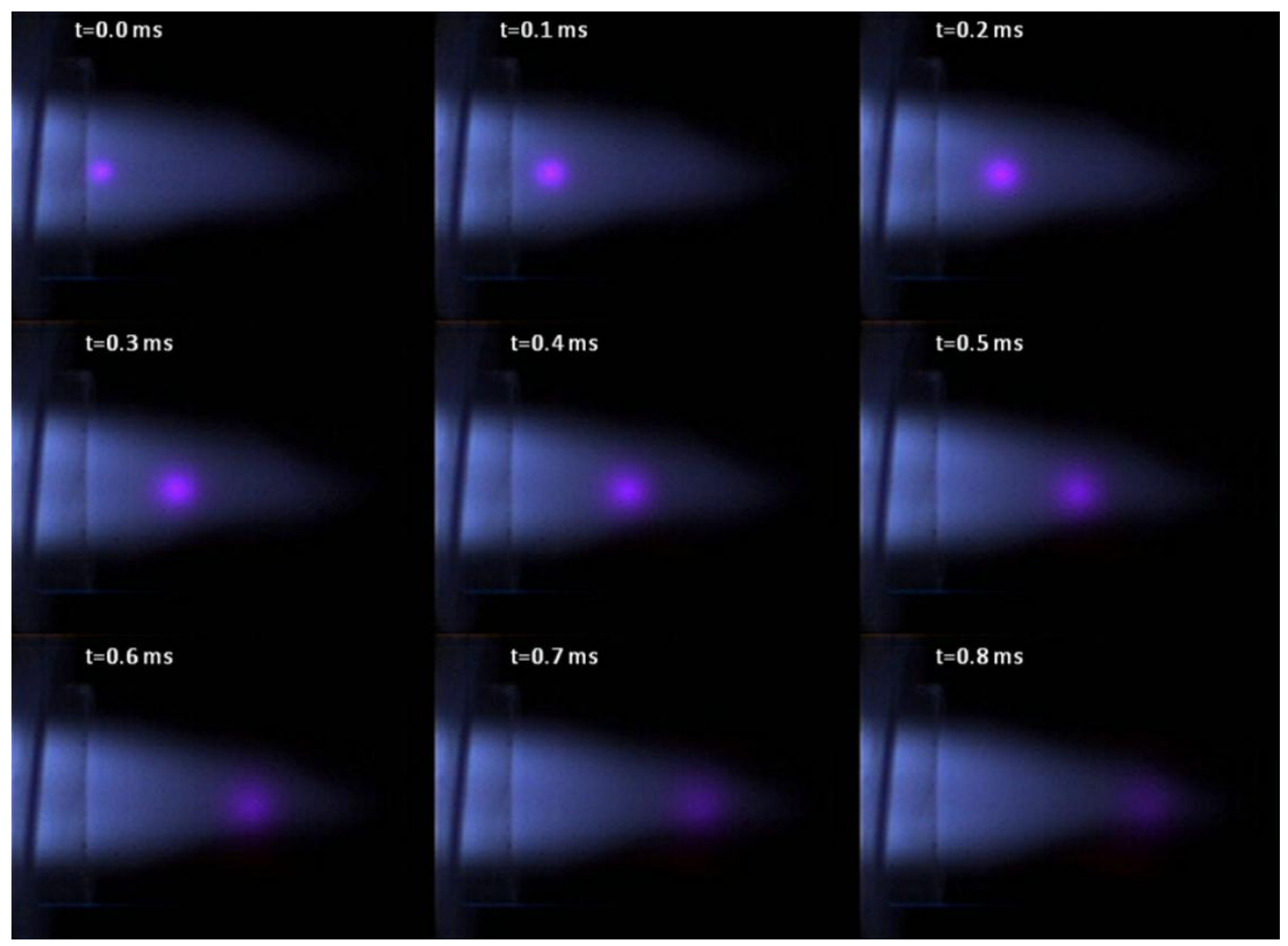

Figure 2. Consecutive images of the ICP during nanosecond laser ablation of NIST 610 glass with helium sample gas. 


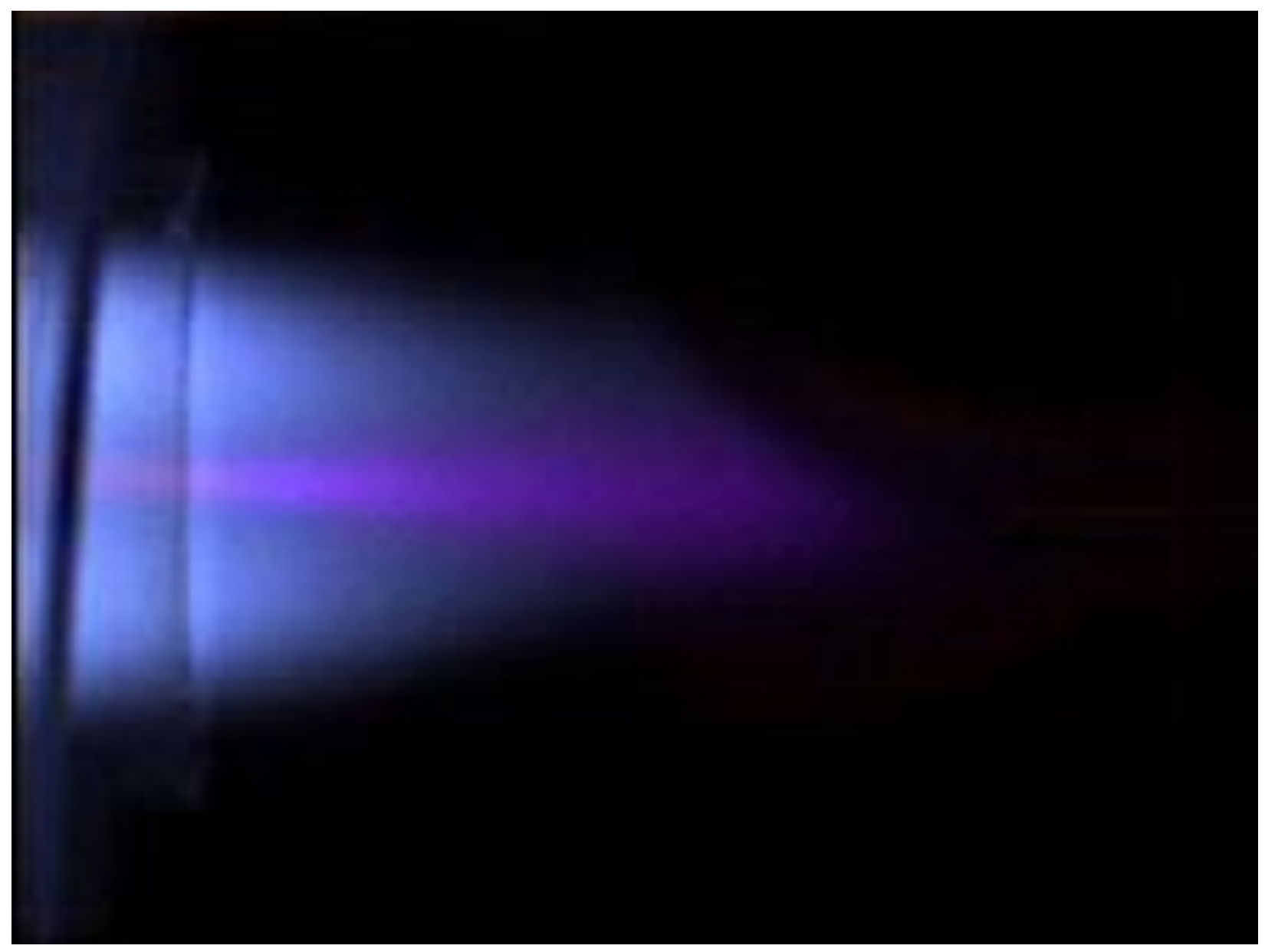

Figure 3. High speed photograph of the ICP during femtosecond laser ablation of NIST 610 glass in argon. This image is representative of the steady-state emission from fs LA when no discrete particle is traversing the plasma. 


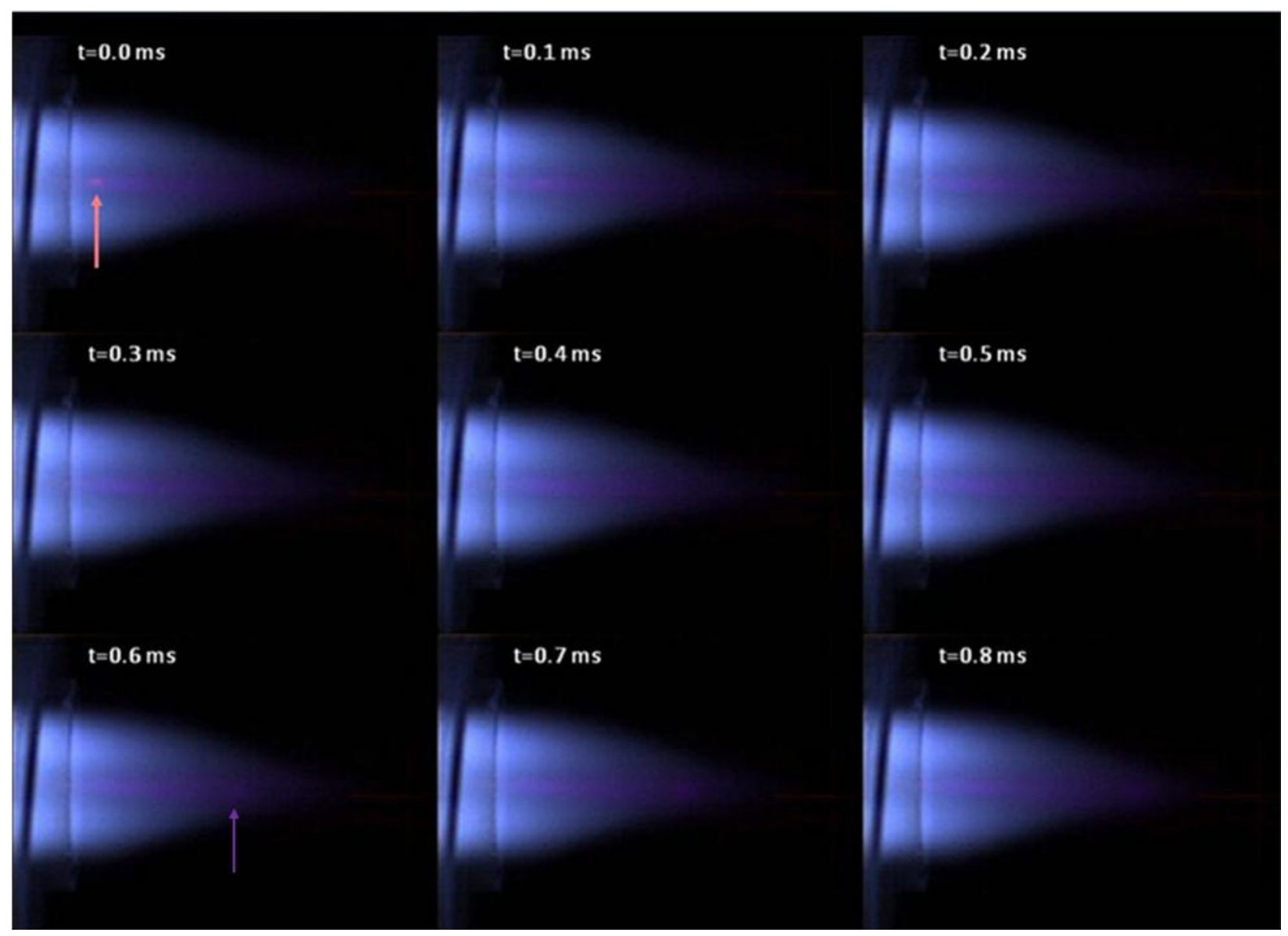

Figure 4. Consecutive images of the plasma during femtosecond laser ablation of NIST 610 glass in argon. A discrete particle cloud (mauve arrow) is visible before $\mathrm{t}=0.2 \mathrm{~ms}$ and after $\mathrm{t}=0.6 \mathrm{~ms}$, but it is not distinguishable for the intervening $400 \mu \mathrm{s}$. 
a)

Figure 5. High speed photographs of the steady-state emission during femtosecond ablation of NIST 610 glass in Ar with laser pulse energies of a) $0 \mu \mathrm{J}$, b) $36 \mu \mathrm{J}$, c) $76 \mu \mathrm{J}$ and d) $171 \mu \mathrm{J}$. 


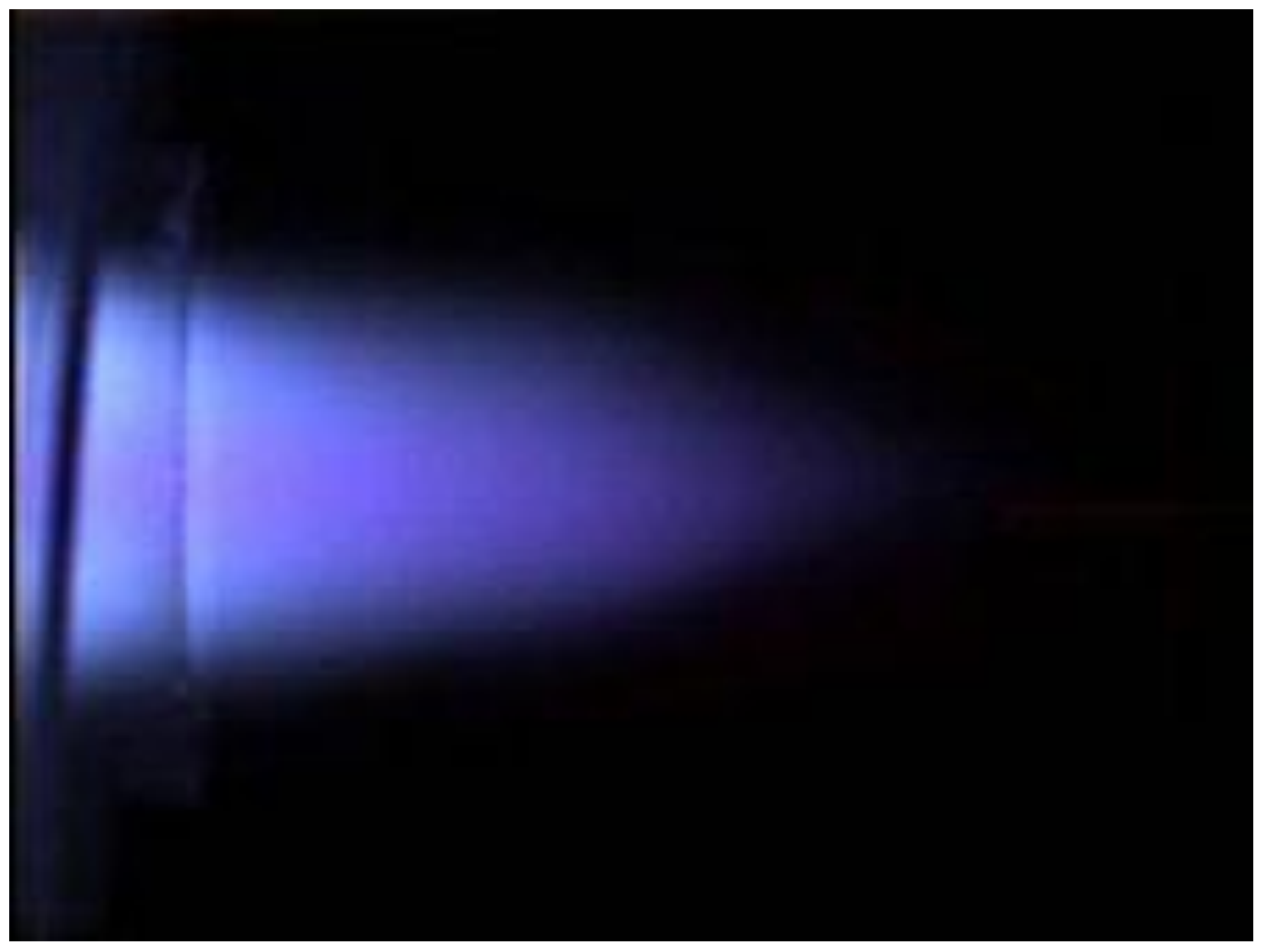

Figure 6. High speed image of the ICP during the introduction of femtosecond laser ablation generated aerosol of NIST 610 glass with helium sample gas. 


\title{
Chapter 4. Investigation into the behavior of metal-argon polyatomic ions $\left(\mathrm{MAr}^{+}\right)$in the extraction region of inductively coupled plasma-mass spectrometry
}

\author{
A manuscript accepted for publication in Spectrochimica Acta Part B: Atomic Spectrosopy \\ Chris H. Ebert, Travis M. Witte, R.S. Houk
}

\begin{abstract}
The abundances of metal-argon polyatomic ions $\left(\mathrm{MAr}^{+}\right)$are determined in inductively coupled plasma-mass spectrometry (ICP-MS). The ratios of $\mathrm{MAr}^{+}$abundance to that for $\mathrm{M}^{+}$ions are measured experimentally. These ratios are compared to expected values, calculated for typical plasma conditions using spectroscopic data. For all metals studied (Ti, V, Cr, Mn, Fe, Co, Ni, Cu, and Zn), the measured ratios are significantly lower than the calculated ratios. Increasing the plasma potential (and thereby increasing the ion kinetic energy) by means of a homemade guard electrode with a wide gap further reduces the $\mathrm{MAr}^{+} / \mathrm{M}^{+}$ratio. Implementing a skimmer cone designed for high transmission of light ions increases the $\mathrm{MAr}^{+}$abundance. Considering this evidence, the scarcity of $\mathrm{MAr}^{+}$ions is attributed to collision induced dissociation (CID), likely due to a shock wave at the tip of or in the throat of the skimmer cone.
\end{abstract}

\section{Introduction}

ICP-MS is a robust, highly sensitive technique for trace elemental analysis. It is widely used in a broad array of applications ${ }^{1-5}$. The ICP is a successful ion source because it 
is efficient at atomization and ionization, but polyatomic ions still persist in small amounts in accordance with thermodynamic principles ${ }^{6}$. These polyatomic ions cause poor accuracy during the determination of analyte ions of the same nominal mass. A thorough understanding of the origins of these polyatomic ions could reveal tactics to remove them and thus improve the analytical capabilities of ICP-MS.

Several methods are currently in use to attenuate polyatomic interferences. Desolvating the sample aerosol ${ }^{7}$, using a chemical reaction or kinetic energy discrimination in a collision cell ${ }^{8-10}$, running in 'cool plasma' mode ${ }^{11}$, or adding alternative gases to the central channel ${ }^{12}$ reduces the abundance of some polyatomic ions. As a more direct approach, high resolution instruments ${ }^{13}$ can physically separate polyatomic from monatomic ions. However, none of these strategies completely remove polyatomic ions from the ion beam without negatively impacting the analytical capabilities of the technique. They generally involve a loss of sensitivity, desolvation can increase memory for some elements, and collision cells can create new polyatomic interferences. Further research into the behavior of polyatomic ions could improve these methods or produce new methods of controlling them. In 2001 Houk et $a l .{ }^{6}$ published a method to calculate a theoretical ratio between the abundance of a polyatomic ion and the most likely monatomic ion resulting from its dissociation. By assuming the ions and background gas are at equilibrium, they employ thermodynamic equations for the dissociation reaction of the polyatomic ion and physical characteristics of the involved species to determine the expected extent of atomization at typical plasma temperature and conditions. In subsequent studies, poor agreement is observed between calculated and experimentally determined ion ratios for some polyatomic ions. Some of these ions are overabundant, including $\mathrm{Ar}_{2}{ }^{+}, \mathrm{COH}^{+}$, and $\mathrm{ArH}^{+6,14-17}$. Others 
like $\mathrm{NO}^{+}, \mathrm{ArO}^{+}, \mathrm{OH}^{+}$, and numerous $\mathrm{MAr}^{+}$ions are underrepresented in the mass spectrum $^{16,18-20}$.

If ions achieve equilibrium at the sampling position in the plasma, these deviations from calculated distributions must result from the creation or removal of polyatomic ions further downstream. Two likely locations for such events to transpire are during the supersonic expansion as the plasma proceeds past the sample cone and during the transmission of ions through the skimmer cone. This intermediate stage seems the most likely place for changes in the abundance of polyatomic ions because there is still enough background gas from the ICP for the analyte stream to undergo many collisions and because the gas kinetic temperature in this region is expected to be much lower than in the plasma itself $^{21}$.

Several labs study supersonic jets and the expansion and extraction processes of ICP-MS ${ }^{21-24}$. It is a crucial stage of ICP-MS that delivers the analyte ions from the atmospheric pressure plasma to the high vacuum necessary for mass analysis. In an ideal expansion, ions and background gas travel with approximately the same velocity, determined by the gas kinetic temperature $\left(\mathrm{T}_{\text {gas }}\right)$ in the plasma at the position sampled ${ }^{25}$. In such an expansion, collisions between ions and background gas are of low energy, and large changes in the abundance of polyatomic ions would not be expected.

However, evidence suggests that the expansion may not be ideal due to a shock wave at the tip of or inside the skimmer cone $e^{26-28}$. The presence and nature of a shock wave in the skimming region evidently depends on the geometry of the skimmer, the skimmer orifice diameter, the sampler-skimmer distance, and the interface pressure ${ }^{29-31}$. Collisions between high kinetic energy ions from the plasma and this cold gas could be sufficiently energetic to 
cause dissociation of weakly-bound polyatomic ions. Such collision induced dissociation (CID) is observed in during the ion extraction process in electrospray ionization MS, especially when ions are accelerated by a potential applied to the skimmer ${ }^{32}$.

The extent of polyatomic dissociation also depends on the magnitude of ion kinetic energy, which directly contributes to the energy of collisions in the expansion/extraction region. The ion energy is determined by two properties: a) the high temperature of the plasma, which imparts more kinetic energy to heavier ions than lighter ones, and b) the positive potential of the plasma, which contributes the same magnitude of kinetic energy to all singly-charged ions ${ }^{25,30}$. The plasma potential on modern instruments is generally low, partially due to the use of shielded load coils ${ }^{33,34}$ which are meant to eliminate the secondary discharge and reduce the spread of ion kinetic energies.

Of the various types of polyatomic ions, argon adduct ions $\left(\mathrm{MAr}^{+}\right)$could be particularly affected by the expansion and extraction processes. They typically have much lower binding energies than oxides or hydroxides so they are most vulnerable to collisioninduced dissociation, and they are most likely to be produced during extraction because argon comprises well over $90 \%$ of the background gas ${ }^{21}$. Witte and Houk ${ }^{20}$ measured $\mathrm{MAr}^{+} / \mathrm{M}^{+}$signal ratios during laser ablation (LA) of pure metals. They determined the $\mathrm{T}_{\text {gas }}$ values necessary to achieve the measured ratios; these temperatures ranged from 8000 to $200,000 \mathrm{~K}$. The high temperatures between species show that the $\mathrm{MAr}^{+}$ions are being removed somewhere during ion extraction. The variable temperatures between different $\mathrm{MAr}^{+}$species show that they are not removed by an equilibrium process. This previous work suggested CID as a possible cause of the loss of $\mathrm{MAr}^{+}$ions. 
The purpose of the present work is to investigate the behavior of $\mathrm{MAr}^{+}$ions during solution introduction, and to determine how the extraction conditions - specifically the cone geometry, the extraction voltage, and the plasma potential - affect the abundance of argon

adducts. The results here provide additional evidence that CID causes the loss of $\mathrm{MAr}^{+}$ions.

\section{Method - Calculations}

Expected $\mathrm{M}^{+} / \mathrm{MAr}^{+}$signal ratio

Houk and Praphairaksit ${ }^{6}$ describe how to calculate a theoretical ratio between the abundance of a polyatomic ion and the monatomic ion resulting from its dissociation by the high temperatures and energetic collisions in an ICP. The normal dissociation of a diatomic ion will have one neutral atom and one monatomic ion. As the first ionization energy of argon $(15.75 \mathrm{eV})$ is significantly higher than metals (typically $6-9 \mathrm{eV}$ ), calculations in this paper will exclusively assume the charge is on the metal product and the argon is neutral. Therefore the dissociation reaction and dissociation constant are:

$\mathrm{MAr}^{+} \rightleftharpoons \mathrm{M}^{+}+\mathrm{Ar} \quad \Delta \mathrm{H}=\mathrm{D}_{\mathrm{o}}\left(\mathrm{M}^{+}-\mathrm{Ar}\right) \quad \mathrm{K}_{\mathrm{d}}=n_{\mathrm{Ar}} * n_{\mathrm{M}}+/ n_{\mathrm{MAr}}+$

where $n$ is the number density of the gas or ion in the plasma at the sampling position and $\mathrm{D}_{\mathrm{O}}$ is the dissociation energy of the polyatomic ion. In a dry plasma, neutral argon atoms are by far the most abundant species, so $n_{\mathrm{Ar}}$ can be determined easily from the ideal gas law. The number density ratio $n_{\mathrm{M}}+/ n_{\mathrm{MAr}}+$ is determined from the signal ratio of the corresponding species in the mass spectrum.

The dissociation constant can also be derived from statistical thermodynamic principles: 


$$
K_{d}=\frac{Z_{A r} Z_{M^{+}}}{Z_{M A r^{+}}} * e^{-D_{O} / k_{b} T_{\text {gas }}}
$$

where $\mathrm{k}_{\mathrm{b}}$ is the Boltzman constant; $\mathrm{T}_{\text {gas }}$ is the gas kinetic temperature at the tip of the sampler cone (in $\mathrm{K}$ ); and $\mathrm{Z}$ is the total partition function of each species, derived from the electronic, vibrational, rotational, and translational partition functions. This equation is converted to

$$
\begin{aligned}
& \log K_{d}=0.5 \log T_{\text {gas }}-\frac{5040 D_{O}}{T_{\text {gas }}}+1.5 \log \frac{M_{A^{+}} M_{B}}{M_{A B^{+}}}+\log \left(z_{A^{+}} z_{\mathrm{B}}\right)+ \\
& \log \left(1-10^{-\frac{0.625 \omega}{T_{\text {gas }}}}\right)+\log \frac{B}{g}+20.432
\end{aligned}
$$

where $\mathrm{M}$ is the mass of each species ( $\mathrm{g} / \mathrm{mole})$; $\omega$ is the vibrational constant $\left(\mathrm{cm}^{-1}\right)$; $\mathrm{B}$ is the rotational constant $\left(\mathrm{cm}^{-1}\right) ; \mathrm{z}$ is the electronic partition function ${ }^{35}$ at the plasma temperature $(\mathrm{K})$; $\mathrm{g}$ is the statistical weight of the ground electronic state, determined by the term symbol of the polyatomic ion; and $\mathrm{D}_{\mathrm{O}}$ is in $\mathrm{eV}$. The constant 20.432 is correct only for a heteronuclear diatomic ion ${ }^{36}$. Also this equation only holds if the polyatomic ion is in its ground electronic state. If the polyatomic ion has low-energy electronic levels that are populated, further corrections must be made to the calculations ${ }^{19}$. Note that adjusting for low excited electronic levels would increase the expected abundance of polyatomic ions. Thus, the measured scarcity of metal-argon ions reported previously ${ }^{20}$ and below cannot be explained by the omission of these excited state populations from calculations.

By combining equations (1) and (3) and inserting necessary spectroscopic data ${ }^{20}$, the expected ratio $n_{\mathrm{M}}+/ n_{\mathrm{MAr}}+$ becomes a function of plasma temperature. Comparing this expected ratio to the experimentally measured abundances of $\mathrm{M}^{+}$and $\mathrm{MAr}^{+}$reveals if argide 
ions are being apparently created or removed during the expansion and extraction process or if they are present in quantities similar to those expected in the plasma itself.

\section{Mass bias corrections}

Between the sampling point of the plasma and the detector, space-charge repulsion and ion focusing lenses impact the ion beam. Usually, light ions are under-represented in the mass spectrum. Consequently, the $\mathrm{M}^{+} / \mathrm{MAr}^{+}$signal ratio as measured is inaccurate, as $\mathrm{MAr}^{+}$ ions outweigh their $\mathrm{M}^{+}$partners by a large amount (40 Da). To distinguish between these effects, which impact monatomic and polyatomic ions alike, and the creation or removal of polyatomic ions by other phenomena, a mass bias ratio is employed to adjust measured ion signals.

The response of 10 elements from ${ }^{7} \mathrm{Li}$ to ${ }^{151} \mathrm{Eu}$ at known concentrations produces a curve used to correct for mass bias effects (Figure 1). The matrix of the standard is matched to the samples used during the experiment, and the responses are adjusted for ionization

efficiency $^{23}$ and isotopic abundance. A $2^{\text {nd }}$ degree polynomial curve is fit to the data, and the mass bias correction ratio is determined by the masses of the analyte ions. The general shape of this plot is similar to many others reported previously ${ }^{37}$. A different mass bias curve is generated for each experimental setup, since some changes made to the plasma conditions and interface are expected to cause a change in the mass bias curve.

\section{Correction for background monatomic ions}

Polyatomic ions are typically said to interfere with monatomic ions of the same nominal mass. A more difficult problem arises when a polyatomic ion is, in fact, the ion of interest and a monatomic ion, typically from an impurity element, obstructs its measurement. Interfering monatomic ions produce much more signal than polyatomic ions (relative to the 
culprit's concentration in solution), so special care must be taken to account for their presence when trying to measure polyatomic ions of low abundance.

Blank subtraction was generally found wanting as a method to account for monatomic interferences. As little as one part-per-trillion difference between the blank and standard of a possible interfering ion is enough to impact the results of this investigation. Such a small amount of contamination could occur from the elemental standards used, even if crosscontamination and leaching from the solution bottles are avoided.

Therefore, interferences from monatomic ions were generally corrected by isotopic subtraction. Using chromium as a typical case, ${ }^{52} \mathrm{CrAr}^{+}$had monatomic interferences ${ }^{92} \mathrm{Zr}^{+}$ and ${ }^{92} \mathrm{Mo}^{+}$. While determining $\mathrm{Cr}^{+}$and $\mathrm{CrAr}+$ signals, ${ }^{91} \mathrm{Zr}^{+},{ }^{95} \mathrm{Mo}^{+}$and ${ }^{97} \mathrm{Mo}^{+}$were also measured. ${ }^{91} \mathrm{Zr}^{+},{ }^{95} \mathrm{Mo}^{+}$and ${ }^{97} \mathrm{Mo}^{+}$signals were then adjusted for isotopic abundance and mass bias corrections to find how much signal at $\mathrm{m} / \mathrm{z}=92$ were zirconium and molybdenum; then this was subtracted to determine how much signal was actually ${ }^{52} \mathrm{CrAr}^{+}$.

There was one exception to this method. Net $\operatorname{TiAr}^{+}$signals were determined by blank subtraction because none of its isotopes could be adjusted for atomic ion interferences by isotopic subtraction. The titanium standard used has a $10 \mathrm{ppt}$ zirconium contamination, sufficient to make ${ }^{50} \mathrm{TiAr}^{+}$undetectable. The isotopic pattern of ${ }^{86} \mathrm{Sr},{ }^{87} \mathrm{Sr}$, and ${ }^{88} \mathrm{Sr}$ is too similar to the isotopic pattern of ${ }^{46} \mathrm{Ti},{ }^{47} \mathrm{Ti}$, and ${ }^{48} \mathrm{Ti}$ to make satisfactory adjustments, and ${ }^{84} \mathrm{Sr}^{+}$signal was too low to be used dependably for accurate isotopic subtraction. Finally, ${ }^{89} \mathrm{Y}^{+}$is monoisotopic. ${ }^{46} \mathrm{TiAr}^{+},{ }^{47} \mathrm{TiAr}^{+},{ }^{48} \mathrm{TiAr}^{+}$, and ${ }^{49} \mathrm{TiAr}^{+}$were therefore blank subtracted, and as long as the ratios between them were reasonable this had to be sufficient. $\mathrm{The}^{48} \mathrm{TiAr}^{+}$ was typically three to five times higher than the blank signal at $\mathrm{m} / \mathrm{z}=88$. That was high enough to consider the data reportable, and the precision of $\mathrm{MAr}^{+} / \mathrm{M}^{+}$signal ratios 
(represented by $95 \%$ confidence intervals) is not appreciably worse for titanium than for other elements.

\section{Determination of plasma potential}

The kinetic energy of ion-argon collisions in the expansion and extraction region of ICP-MS directly impacts the extent of collision-induced dissociation or creation of polyatomics. The average kinetic energy is given by:

$$
\mathrm{KE}_{\text {ion }}=\frac{\mathrm{m}_{\text {ion }}}{\mathrm{m}_{\mathrm{Ar}}}\left(\frac{5}{2} \mathrm{k}_{\mathrm{B}} \mathrm{T}_{\mathrm{gas}}\right)+\mathrm{V}_{\mathrm{P}}
$$

where $\mathrm{V}_{\mathrm{P}}$ is the plasma potential and $\mathrm{KE}$ is reported in $\mathrm{eV}^{30}$. In the present work, the kinetic energies of ions of various masses are measured by attenuating the ions with increasingly positive DC bias on the quadupole mass filter, generating a stopping curve $\mathrm{e}^{38}$. The refocusing effect of increasing the pole bias makes determining the average ion kinetic energy unreliable, so the maximum kinetic energy is reported. The maximum KE is the DC quadrupole bias voltage when $99 \%$ of the analyte has been lost; the average kinetic energy is presumably several $\mathrm{eV}$ lower. The stopping potential is recorded for singly-charged ions of several $\mathrm{m} / \mathrm{z}$ values, and the slope and $\mathrm{y}$-intercept of the fit line are inserted into equation (4) to determine the potential and temperature of the plasma. A typical stopping curve is discussed in the Results and Discussion section.

\section{Method - Instrumentation}

\section{ICP-MS device}

Experiments are conducted with an XSeries 2 quadrupole ICP-MS (Thermo Fisher Scientific, Inc., Bremen, Germany), the same instrument used for our previous studies of 
$\mathrm{MAr}^{+}$ions ${ }^{20}$. Typical operating parameters of the ICP are reported in Table 1 . The sample gas flow and ion lens voltages are adjusted for a balance between maximum sensitivity and minimum metal-oxide ion formation and varied from day-to-day. The instrument includes a hexapole collision cell, but no collision gas was added and the cell was used only to transmit ions. The detector is cross-calibrated between analog and counting modes using a multielement standard.

The sample is introduced with a PFA-400 $\mu \mathrm{L}$ nebulizer and APEX desolvation system (Elemental Scientific Inc., Omaha, NE). Efficient solvent removal is helpful in the present research because at times $\mathrm{MAr}^{+}$ion signal is very low and accounting for interfering $\mathrm{MO}^{+}, \mathrm{MOH}^{+}$, and $\mathrm{MO}_{\mathrm{x}}{ }^{+}$ions would introduce severe complications and deteriorate accuracy and precision. With this introduction system the solvent load is $\sim 12 \mu \mathrm{L} / \mathrm{min}$, as determined by the difference in mass gained by the drain solution and mass lost by the sample solution over three hours of analysis.

\section{Shielded load coil}

On an ICP with an unbalanced load coil and no shield, the plasma potential is high relative to the grounded sampler cone due to capacitive coupling between free electrons in the plasma and the voltage gradient of the load $\operatorname{coil}^{21}$. The shield is a grounded, slotted metal cylinder inserted between the load coil and torch; free electrons in the metal shield prevent the voltage gradient on the coil from reaching the plasma. In Thermo instruments, the shield is often referred to as a guard electrode. The benefits of using a shield include the reduction of multiply-charged ions and the avoidance of a secondary discharge or 'pinch' between the plasma and the sample cone ${ }^{33}$. 
As described by $\mathrm{Gray}^{34}$, a small gap is necessary in the shield. If it were a complete cylinder, electrons in the metal would revolve completely around the cylinder due to the electromagnetic field induced by the current on the load coil. This would rapidly heat the shield and melt it. We suggest that widening this gap would expose the underlying plasma to more of the load coil, reduce the extent of shielding, and thus increase the plasma potential. The XSeries 2 typically employs a silver shield with a narrow slot of only $\sim 2 \mathrm{~mm}$ wide, just enough to prevent arcing across the gap and melting. For some experiments, this standard guard electrode is replaced with a homemade aluminum electrode with a larger gap approximately $6 \mathrm{~mm}$ wide, Fig. 2 . This homemade guard electrode is otherwise identical in shape to the standard guard electrode: $16 \mathrm{~mm}$ in length, long enough to cover the entire length of the load coil, and with a grounding arm that reaches back to a grounding pin near the middle of the torch. The guard electrode is grounded during all measurements.

\section{Skimmer geometry}

Ions are extracted through the same sampling cone in all experiments. Either an Xt or an Xs nickel skimmer cone (Thermo Fisher Scientific Inc.) ${ }^{39}$ is used. The Xt cone is designed for matrix tolerance, while the Xs cone is designed for softer extraction and higher sensitivity for low mass ions. The same nickel sampler cone is used for all measurements. Experiments are conducted with a positive (+4 volts) or high negative voltage ( -100 to -250 volts, optimized for sensitivity) on the extraction lens. When the extraction lens is positive, the response is decreased from the optimum sensitivity by approximately 40 -fold and the precision for some $\mathrm{MAr}^{+}$ions deteriorates as their response approaches the background. 


\section{Samples}

$\mathrm{MAr}^{+} / \mathrm{M}^{+}$signal ratios are determined using $1 \mathrm{ppm}$ or $10 \mathrm{ppm}$ single-element standards diluted from 1,000 ppm stock solutions (Plasma Chem Associates, Inc.) in 2\% nitric acid. Stopping curve plots and mass bias curves are generated using a $10 \mathrm{ppb}$ multielement standard in $2 \%$ nitric acid. This multielement standard includes cerium, which is used for optimization of ICP operating conditions and for estimation of $\mathrm{T}_{\text {gas }}$ using the signal ratio $\mathrm{CeO}^{+} / \mathrm{Ce}^{+}$.

\section{Results and Discussion}

Measured $\mathrm{MAr}^{+} / \mathrm{M}^{+}$signal ratios under standard operating conditions

Table 2 contains the $\mathrm{MAr}^{+} / \mathrm{M}^{+}$signal ratios with $95 \%$ confidence intervals for $\mathrm{Ti}, \mathrm{V}$, $\mathrm{Cr}, \mathrm{Mn}, \mathrm{Fe}, \mathrm{Co}, \mathrm{Ni}, \mathrm{Cu}$, and $\mathrm{Zn}$ during analysis with the $\mathrm{Xt}$ skimmer cone and standard guard electrode. All signal ratios in this work are presented in ppm, i.e., a measured $\mathrm{MAr}^{+} / \mathrm{M}^{+}$ratio of $31 \mathrm{ppm}$ means the actual signal ratio is $31 \times 10^{-6}$. The confidence interval was determined from five repetitions of data recorded on five separate days. These intervals include imprecision caused by the day-to-day variation of the instrument. Signal ratios within a given day's experiment are much more precise.

These ion ratios during the introduction of solutions are comparable to those measured during laser ablation of pure metals by Witte et al. ${ }^{20}$ They measured $\mathrm{MAr}^{+} / \mathrm{M}^{+}$ ratios during $n s$ laser ablation of pure metals with the same instrument and operating parameters as the present study. Seven of their nine measurements were within the $95 \%$ confidence interval reported in the present study. 
Table 2 also reports the calculated values for the abundance of $\mathrm{MAr}^{+}$ions at $6000 \mathrm{~K}$. For all nine metals studied, the expected $\mathrm{MAr}^{+} / \mathrm{M}^{+}$ion ratio is more than double the upper bound of the $95 \%$ confidence interval of the experimentally determined $\mathrm{MAr}^{+} / \mathrm{M}^{+}$ratio. The bond energy of these polyatomics is very low, but these measured ratios are still far lower than expected. The plasma temperatures necessary to achieve these measured $\mathrm{MAr}^{+} / \mathrm{M}^{+}$ ratios in the ICP range from 8000 to more than $100,000 \mathrm{~K}^{20}$; these values are not realistic physically. If the analyte ions leave the plasma at equilibrium, some process(es) reduce the abundance of $\mathrm{MAr}^{+}$during or after their extraction.

A trend is observed between the dissociation energy of the $\mathrm{MAr}^{+}$ion and the discrepancy between the expected and measured $\mathrm{MAr}^{+} / \mathrm{M}^{+}$ratio. For the weakest bound species $\left(\mathrm{FeAr}^{+}, \mathrm{MnAr}^{+}, \mathrm{ZnAr}^{+}\right.$, and $\left.\mathrm{CrAr}^{+}\right)$the fraction of 'missing' $\mathrm{MAr}^{+}$ions are highest, over $99 \%$ in all cases. For the stronger bound argon adducts, the measured ratio is closer to albeit still well below - the calculated ratio. This correlation merits consideration; such a trend would be observed if CID is the cause of the scarcity of $\mathrm{MAr}^{+}$ions. That is, a strongerbound ion requires a more energetic collision to dissociate than a weaker-bound ion. Therefore, when an ensemble of ions undergo collisions of a range of energies, a larger fraction of weakly-bound $\mathrm{MAr}^{+}$ions will dissociate than the more strongly-bound $\mathrm{MAr}^{+}$ions. This observation led us to investigate the possibility that CID removes most of these polyatomic ions.

\section{Effect of skimmer cone on $\mathrm{MAr}^{+} / \mathrm{M}^{+}$ratios}

The Xs skimmer cone for the XSeries2 instrument is designed for higher transmission of light analyte ions ${ }^{39}$. Table 3 contains the $\mathrm{MAr}^{+} / \mathrm{M}^{+}$ratios measured using the $\mathrm{Xs}$ cone. For all nine metals, the $\mathrm{MAr}^{+} / \mathrm{M}^{+}$signal ratios are higher during analysis with the $\mathrm{Xs}$ skimmer 
than with the Xt skimmer. For eight of nine cases with the $\mathrm{Xs}$ cone, the $\mathrm{MAr}^{+}$ion abundance is outside the $95 \%$ confidence intervals during analysis with the Xt cone (see Table 2). The skimmer cone does not influence the equilibrium between $\mathrm{M}^{+}$and $\mathrm{MAr}^{+}$ions in the ICP. Instead, analysis with the Xs cone results in higher $\mathrm{MAr}^{+}$abundance because more MAr ${ }^{+}$ ions survive the extraction process with the Xs cone than with the $\mathrm{Xt}$ cone.

Taylor and Fansworth ${ }^{31}$ demonstrate that many different commercially available skimmer cones produce a shock wave (although they did not study the Xt or Xs cones specifically). Furthermore, they found the extent of the shock wave depends on the geometry of the skimmer cone. The presence and intensity of a shock wave is a likely explanation for the difference in $\mathrm{MAr}^{+} / \mathrm{M}^{+}$ratios for the Xs and Xt cones.

Effect of plasma potential and ion kinetic energy on $\mathrm{MAr}^{+} / \mathrm{M}^{+}$ratios

If CID causes the loss of $\mathrm{MAr}^{+}$ions, then increasing the plasma potential and the ion kinetic energy should attenuate them further. To that end, the usual silver guard electrode with a $2 \mathrm{~mm}$ slot was replaced by a homemade aluminum shield with a $6 \mathrm{~mm}$ slot. Figure 3 compares the stopping curves for ${ }^{115} \mathrm{In}^{+}$during analysis with the standard and homemade guard electrodes. The median $\mathrm{In}^{+}$kinetic energy, determined by the quadrupole bias voltage at which the $\mathrm{In}^{+}$signal falls to $50 \%$ of the maximum signal, is approximately $3 \mathrm{eV}$ higher with the homemade guard electrode than with the standard guard electrode. The stopping potential is also much higher with the homemade guard electrode, $9.8 \mathrm{~V}$ compared to $5.8 \mathrm{~V}$. The stopping voltages for several ions are plotted against their isotope masses in Figure 4. The plasma potential (i.e., the y-intercept) is several volts higher with the homemade guard electrode than with the standard guard electrode. 
Table 4 presents the $\mathrm{MAr}^{+} / \mathrm{M}^{+}$ratios measured with the homemade guard electrode. For all nine metals, this guard electrode reduces $\mathrm{MAr}^{+}$abundance. For seven out of nine metals, the $\mathrm{MAr}^{+} / \mathrm{M}^{+}$ratio with the homemade guard electrode is below the $95 \%$ confidence interval for the $\mathrm{MAr}^{+} / \mathrm{M}^{+}$ratio with the standard guard electrode, despite the wide range of the latter values. This observation suggests that collision induced dissociation is a likely mechanism for the deficiency of metal argon ions. Increasing the gap in the guard electrode causes an increase in the plasma potential, which in turn increases the kinetic energy of ions leaving the plasma. Then, a greater portion of $\mathrm{MAr}^{+}$ions have sufficient kinetic energy to dissociate when they collide with argon gas.

Changing the guard electrode could admittedly change the plasma temperature, the effects of which must not be disregarded. The temperature of the plasma can be estimated by the determined signal ratio $\mathrm{CeO}^{+} / \mathrm{Ce}^{+6} . \mathrm{CeO}^{+}$has a bond energy of $8.81 \mathrm{eV}$, making it far less susceptible to $\mathrm{CID}$ than the $\mathrm{MAr}^{+}$ions studied in the present work. $\mathrm{CeO}^{+}$is generally considered a reliable polyatomic ion for the determination of $\mathrm{T}_{\mathrm{gas}}{ }^{16,19}$. Optimizing plasma operating conditions to achieve a consistent $\mathrm{CeO}^{+} / \mathrm{Ce}^{+}$ratio when each of the two guard electrodes are used should reproduce conditions at the sampling position fairly closely.

Table 5 contains the $\mathrm{CeO}^{+} / \mathrm{Ce}^{+}$and $\mathrm{Ce}^{2+} / \mathrm{Ce}^{+}$signal ratios determined with standard and homemade (i.e., wide-gap) guard electrodes. The $\mathrm{Ce}^{2+} / \mathrm{Ce}^{+}$ratio is 5-fold higher with the wider gap in the guard electrode, a clear indication that the plasma potential is higher with the homemade guard ${ }^{40}$. The $\mathrm{CeO}^{+} / \mathrm{Ce}^{+}$signal ratios are not significantly different for the two guard electrodes, and $\mathrm{T}_{\text {gas }}$ for each guard electrode only differs by $30 \mathrm{~K}$. This small temperature difference in the plasma would not induce the significant change in calculated $\mathrm{MAr}^{+} / \mathrm{M}^{+}$signal ratios. Therefore, the decrease in $\mathrm{MAr}^{+} / \mathrm{M}^{+}$ratios with the homemade guard 
electrode is attributed to the increase in ion kinetic energy and to more extensive CID. The $\mathrm{CeO}^{+} / \mathrm{Ce}^{+}$signal ratio is lower than the usual 1 to $3 \%$ because the aerosol was desolvated in these experiments.

\section{Effect of extraction lens voltage on $\mathrm{MAr}^{+} / \mathrm{M}^{+}$ratios}

On the instrument used in the study with the Xt skimmer cone, sensitivity is optimized with the extraction lens voltage between -100 and -250 volts; the optimum value varies from day to day. At this voltage, collisions between analyte ions and background gas at the extraction lens are far more energetic than collisions occurring at the tip of the skimmer cone. This makes the region between the skimmer tip and the entrance to the extraction lens a potential place for CID. Setting the extraction voltage near zero will greatly weaken the energy of collisions at the extraction lens, which in turn reduces the extent of CID.

Table 6 compares the measured $\mathrm{MAr}^{+} / \mathrm{M}^{+}$signal ratio with the extraction lens voltage optimized to that with the extraction lens voltage set to +4 volts. Data are included for both the Xt and Xs skimmer cones. For each skimmer cone, data were recorded sequentially without turning off the plasma in between measurements. With each skimmer cone, variations occur between the $\mathrm{MAr}^{+} / \mathrm{M}^{+}$ratios when the extraction lens is positive and negative. However, there is no consistent trend correlating the $\mathrm{MAr}^{+}$ion abundance to the extraction voltage.

If CID occurred extensively between the skimmer tip and the extraction lens, setting the extraction voltage near the plasma potential would be expected to dramatically reduce the energy of those collisions and cause an increase the $\mathrm{MAr}^{+} / \mathrm{M}^{+}$ratios. The lack of a large 
effect on measured $\mathrm{MAr}^{+} / \mathrm{M}^{+}$ratios by the extraction voltage suggests that the bulk of the CID process has occurred before the ions traverse this region.

\section{Conclusions}

During solution nebulization analysis with the XSeries2 ICP-MS, MAr ${ }^{+}$ions are present in far lower abundances than predicted by thermodynamic calculations using conditions in the ICP region being sampled. The data reported in this study suggest collision induced dissociation as a likely mechanism for the loss of $\mathrm{MAr}^{+}$. The abundance of $\mathrm{MAr}^{+}$ ions can be predictably increased or decreased in a manner agreeing with the known behavior of CID; two such manipulations are demonstrated in this work. First, using a skimmer cone designed for higher transmission increases the ratio of $\mathrm{MAr}^{+} / \mathrm{M}^{+}$ions, possibly by reducing the number of collisions that occur at the skimmer cone region. Second, increasing the kinetic energy of $\mathrm{MAr}^{+}$ions decreases the abundance of $\mathrm{MAr}^{+}$, because a larger fraction of collisions are sufficiently energetic to cause dissociation of the polyatomic ion.

The location of such CID process(es) is of some interest. While the present study does not thoroughly investigate this question, some conclusions can be drawn from the data here. There was no correlation observed between $\mathrm{MAr}^{+}$abundance and the extraction lens voltage. This means CID probably does not occur at the extraction lens, as changing the extraction voltage from $<-100$ volts to +4 volts would extensively reduce the collision energy and cause an increase in $\mathrm{MAr}^{+}$abundance. This observation indicates that background gas exists at a low pressure at the extraction lens and only a small fraction of ions undergo a collision there. Therefore, CID occurs in the short distance between the tip of the sampler cone, where $\mathrm{T}_{\text {gas }} \sim 6000 \mathrm{~K}$, and the region just behind the skimmer tip. 


\section{Acknowledgements}

Research at the Ames Laboratory was supported by the U.S. Department of EnergyNational Nuclear Security Agency under contract number DE-AC02-07CH11358. The XSeries2 instrument was obtained through funding provided by the U.S. Department of Energy, Office of Nuclear Nonproliferation (NA-22). The authors thank Elemental Scientific, Inc. for providing the APEX desolvator and PFA nebulizer. 


\section{References}

1. R. S. Houk, V. A. Fassel, G. D. Flesch, H. J. Svec, A. L. Gray and C. E. Taylor, Anal. Chem., 1980, 52, 2283-2289.

2. E. H. Evans, J. A. Day, C. D. Palmer and C. M. M. Smith, J. Anal. At. Spectrom., 2009, 24, 711-733.

3. D. Beauchemin, Mass Spectrom. Rev., 2010, 29, 560-592.

4. K. L. Linge and K. E. Jarvis, Geostand. Geoanal. Res., 2009, 33, 445-467.

5. J. Koch and D. Guenther, Appl. Spectrosc., 2011, 65, 155A-162A.

6. R. S. Houk and N. Praphairaksit, Spectrochim. Acta Part B, 2001, 56, 1069-1096.

7. L. C. Alves, D. R. Wiederin and R. S. Houk, Anal. Chem., 1992, 64, 1164-1169.

8. $\quad$ Z. Du and R. S. Houk, J. Anal. At. Spectrom., 2000, 15, 383-388.

9. B. Hattendorf and D. Guenther, J. Anal. At. Spectrom., 2000, 15, 1125-1131.

10. T. Arnold, J. N. Harvey and D. J. Weiss, Spectrochim. Acta Part B, 2008, 63, 666672.

11. S. D. Tanner, J. Anal. At. Spectrom., 1995, 10, 905-921.

12. J. S. Wang, E. H. Evans and J. Caruso, J. Anal. At. Spectrom., 1992, 7, 929-936.

13. N. M. Reed, R. O. Cairns, R. C. Hutton and Y. Takaku, J. Anal. At. Spectrom., 1994, 9, 884-896.

14. T. J. Cleland and F. R. Meeks, Spectrochim. Acta Part B, 1996, 51, 1487-1490.

15. E. H. Evans, L. Ebdon and L. Rowley, Spectrochim. Acta Part B, 2002, 57, 741-754.

16. J. W. Ferguson and R. S. Houk, Spectrochim. Acta Part B, 2006, 61, 905-915.

17. J. W. Ferguson, T. J. Dudley, K. C. Sears, S. M. McIntyre, M. S. Gordon and R. S. Houk, Spectrochim. Acta Part B, 2009, 64, 690-696.

18. S. M. McIntyre, J. W. Ferguson, T. M. Witte and R. S. Houk, Spectrochim. Acta Part $B, 2011,66,248-254$.

19. S. M. McIntyre, J. W. Ferguson and R. S. Houk, Spectrochim. Acta Part B, 2011, 66, 581-587.

20. T. M. Witte and R. S. Houk, Spectrochim. Acta Part B, 2012, 69, 25-31.

21. D. J. Douglas and J. B. French, J. Anal. At. Spectrom., 1988, 3, 743-747.

22. R. Campargue, J. Phys. Chem., 1984, 88, 4466-4474. 
23. H. Niu and R. S. Houk, Spectrochim. Acta Part B, 1996, 51, 779-815.

24. N. W. Radicic, J. B. Olsen, R. V. Nielson, J. H. Macedone and P. B. Farnsworth, Spectrochim. Acta Part B, 2006, 61, 686-695.

25. J. E. Fulford and D. J. Douglas, Appl. Spectrosc., 1986, 40, 971-974.

26. A. L. Gray, J. Anal. At. Spectrom., 1989, 4, 371-373.

27. J. E. Patterson, B. S. Duersch and P. B. Farnsworth, Spectrochim. Acta Part B, 1999, 54, 537-544.

28. H. Niu and R. S. Houk, Spectrochim. Acta Part B, 1994, 49, 1283-1303.

29. T. N. Olney, W. Chen and D. J. Douglas, J. Anal. At. Spectrom., 1999, 14, 9-17.

30. D. J. Douglas and S. D. Tanner, in Inductively Coupled Plasma Mass Spectrometry, ed. A. Montaser, Wiley-VCH, New York. 1998, pp. 615-679.

31. N. Taylor and P. B. Farnsworth, Spectrochim. Acta Part B, 2012, 69, 2-8.

32. B. B. Schneider and D. D. Y. Chen, Anal. Chem., 2000, 72, 791-799.

33. K. i. Sakata and K. Kawabata, Spectrochim. Acta Part B, 1994, 49, 1027-1038.

34. A. L. Gray, J. Anal. At. Spectrom., 1986, 1, 247-249.

35. L. De Galan, R. Smith and J. D. Winfordner, Spectrochim. Acta part B, 1968, 23, $521-525$.

36. R. S. Houk, Spectrochim. Acta Part B, 2006, 61, 235-236.

37. C. P. Ingle, B. L. Sharp, M. S. A. Horstwood, R. R. Parrish and D. J. Lewis, J. Anal. At. Spectrom., 2003, 18, 219-229.

38. J. A. Olivares and R. S. Houk, Appl. Spectrosc., 1985, 39, 1070-1077.

39. I. Thermo Scientific, Technical Note: 40717, 2007.

40. A. L. Gray, R. S. Houk and J. G. Williams, J. Anal. At. Spectrom., 1987, 2, 13-20. 
Table 1. ICP-MS operating parameters

\begin{tabular}{|l|l|}
\hline Forward power & $1400 \mathrm{~W}$ \\
\hline Outer gas flow & $13.0 \mathrm{~L} / \mathrm{min}$ \\
\hline Auxiliary gas flow & $0.7 \mathrm{~L} / \mathrm{min}$ \\
\hline Sample gas flow $(\operatorname{argon})$ & $0.9 \mathrm{~L} / \mathrm{min}$ \\
\hline Detector mode $\left(\mathrm{M}^{+}\right)$ & Analog \\
\hline Detector mode $\left(\mathrm{MAr}^{+}\right)$ & Counting \\
\hline
\end{tabular}




\begin{tabular}{|c|c|c|c|c|c|c|c|c|c|}
\hline 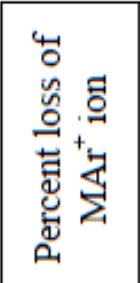 & $\stackrel{n}{2}$ & & חू & $\begin{array}{l}\circ \\
\stackrel{2}{ }\end{array}$ & $\begin{array}{l}+ \\
\infty \\
\infty\end{array}$ & $\frac{\dot{\sigma}}{\mathrm{a}}$ & ষั & $\begin{array}{l}n \\
\circ\end{array}$ & m. \\
\hline 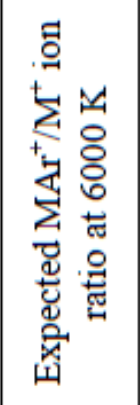 & $\vec{\infty}$ & ๙ூ & $\underset{\Delta}{\Delta}$ & $\underset{m}{\stackrel{\Delta}{m}}$ & $\vec{n}$ & $\frac{N}{n}$ & $\frac{n}{m}$ & તิ & nִ \\
\hline 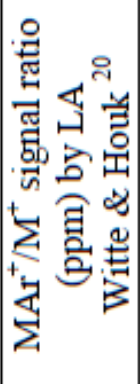 & $\begin{array}{l}\infty \\
\stackrel{0}{0} \\
\stackrel{0}{0}\end{array}$ & $\begin{array}{l}\circ \\
\stackrel{\infty}{-} \\
0\end{array}$ & 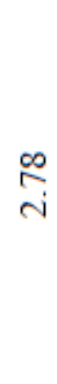 & ô & $\stackrel{2}{\stackrel{2}{a}}$ & $\begin{array}{l}n \\
\infty \\
m \\
0\end{array}$ & $\stackrel{n}{n}$ & $\begin{array}{l}8 \\
\text { m }\end{array}$ & $\begin{array}{l}\dot{+} \\
\dot{+}\end{array}$ \\
\hline 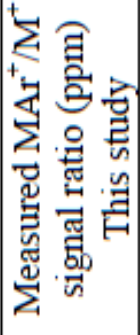 & 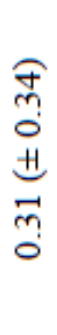 & 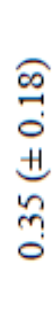 & 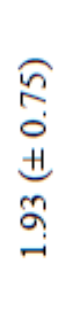 & 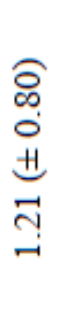 & 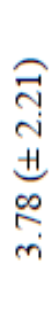 & 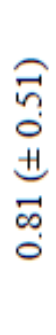 & 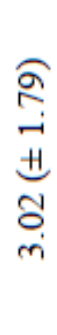 & 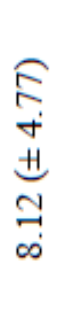 & 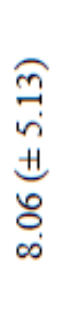 \\
\hline 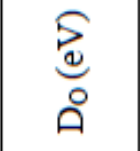 & $\stackrel{7}{\overrightarrow{0}}$ & $\frac{g}{\stackrel{+}{+}}$ & $\stackrel{n}{r}$ & 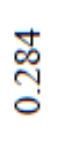 & $\vec{m}$ & $\begin{array}{l}\text { iे } \\
\text { m! } \\
\text { ? }\end{array}$ & $\begin{array}{l}\infty \\
\circ \\
0 \\
0\end{array}$ & $\begin{array}{l}\hat{n} \\
\hat{0}\end{array}$ & $\begin{array}{l}n \\
\tilde{n} \\
0\end{array}$ \\
\hline 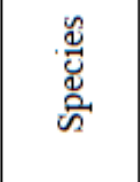 & 离 & ${ }^{+}$宗 & 忘 & 悹 & 过 & ${ }^{+}$ & 宽 & 离 & 空 \\
\hline
\end{tabular}


Table 3. $\mathrm{MAr}^{+} / \mathrm{M}^{+}$signal ratios with Xs skimmer cone and the relative increase when Xs cone replaces Xt cone. Measurements taken with 10 ppm solutions.

\begin{tabular}{|c|c|c|}
\hline Species & $\begin{array}{c}\mathrm{MAr}^{+} / \mathrm{M}^{+}(\mathrm{ppm}) \\
\text { with Xs skimmer cone }\end{array}$ & $\begin{array}{c}\text { Relative increase } \\
\text { compared to Xt cone }\end{array}$ \\
\hline $\mathrm{FeAr}^{+}$ & 0.51 & 1.6 \\
\hline $\mathrm{MnAr}^{+}$ & 1.12 & 3.2 \\
\hline $\mathrm{ZnAr}^{+}$ & 9.37 & 4.9 \\
\hline $\mathrm{CrAr}^{+}$ & 2.11 & 1.7 \\
\hline $\mathrm{TiAr}^{+}$ & 12.22 & 3.2 \\
\hline $\mathrm{VAr}^{+}$ & 4.69 & 5.8 \\
\hline $\mathrm{CoAr}^{+}$ & 41.05 & 13.6 \\
\hline $\mathrm{CuAr}^{+}$ & 19.42 & 2.4 \\
\hline $\mathrm{NiAr}^{+}$ & 42.32 & 5.3 \\
\hline
\end{tabular}


Table 4. $\mathrm{MAr}^{+} / \mathrm{M}^{+}$signal ratios with homemade aluminum guard electrode and percent of signal lost when homemade guard electrode replaces standard guard electrode. Measurements taken with 1 ppm solutions.

\begin{tabular}{|c|c|c|}
\hline Species & $\begin{array}{c}\mathrm{MAr}^{+} / \mathrm{M}^{+}(\mathrm{ppm}) \text { with } \\
\text { homemade GE }\end{array}$ & $\begin{array}{c}\text { Additional } \\
\mathrm{MAr}^{+} \text {loss(\%) with } \\
\text { wide slot }\end{array}$ \\
\hline $\mathrm{FeAr}^{+}$ & 0.08 & 75.4 \\
\hline $\mathrm{MnAr}^{+}$ & 0.12 & 67.0 \\
\hline $\mathrm{ZnAr}^{+}$ & 0.48 & 75.3 \\
\hline $\mathrm{CrAr}^{+}$ & 0.51 & 57.5 \\
\hline $\mathrm{TiAr}^{+}$ & 0.75 & 80.1 \\
\hline $\mathrm{VAr}^{+}$ & 0.26 & 67.8 \\
\hline $\mathrm{CoAr}^{+}$ & 1.01 & 66.7 \\
\hline $\mathrm{CuAr}^{+}$ & 3.11 & 61.7 \\
\hline $\mathrm{NiAr}^{+}$ & 2.63 & 67.3 \\
\hline
\end{tabular}

Table 5. $\mathrm{CeO}^{+} / \mathrm{Ce}^{+}$and $\mathrm{Ce}^{++} / \mathrm{Ce}^{+}$signal ratios and $\mathrm{T}_{\text {gas }}$ values determined by $\mathrm{CeO}^{+} / \mathrm{Ce}^{+}$with standard and homemade guard electrodes.

\begin{tabular}{|c|c|c|}
\hline & $\begin{array}{c}\text { Homemade Guard } \\
\text { Electrode }\end{array}$ & $\begin{array}{c}\text { Standard } \\
\text { Guard Electrode }\end{array}$ \\
\hline $\mathrm{Ce}^{++} / \mathrm{Ce}^{+}$ & $10.37 \%$ & $1.79 \%$ \\
\hline $\mathrm{CeO}^{+} / \mathrm{Ce}^{+}$ & $0.334 \%$ & $0.359 \%$ \\
\hline $\mathrm{T}_{\text {gas }}$ & $6230 \mathrm{~K}$ & $6200 \mathrm{~K}$ \\
\hline
\end{tabular}




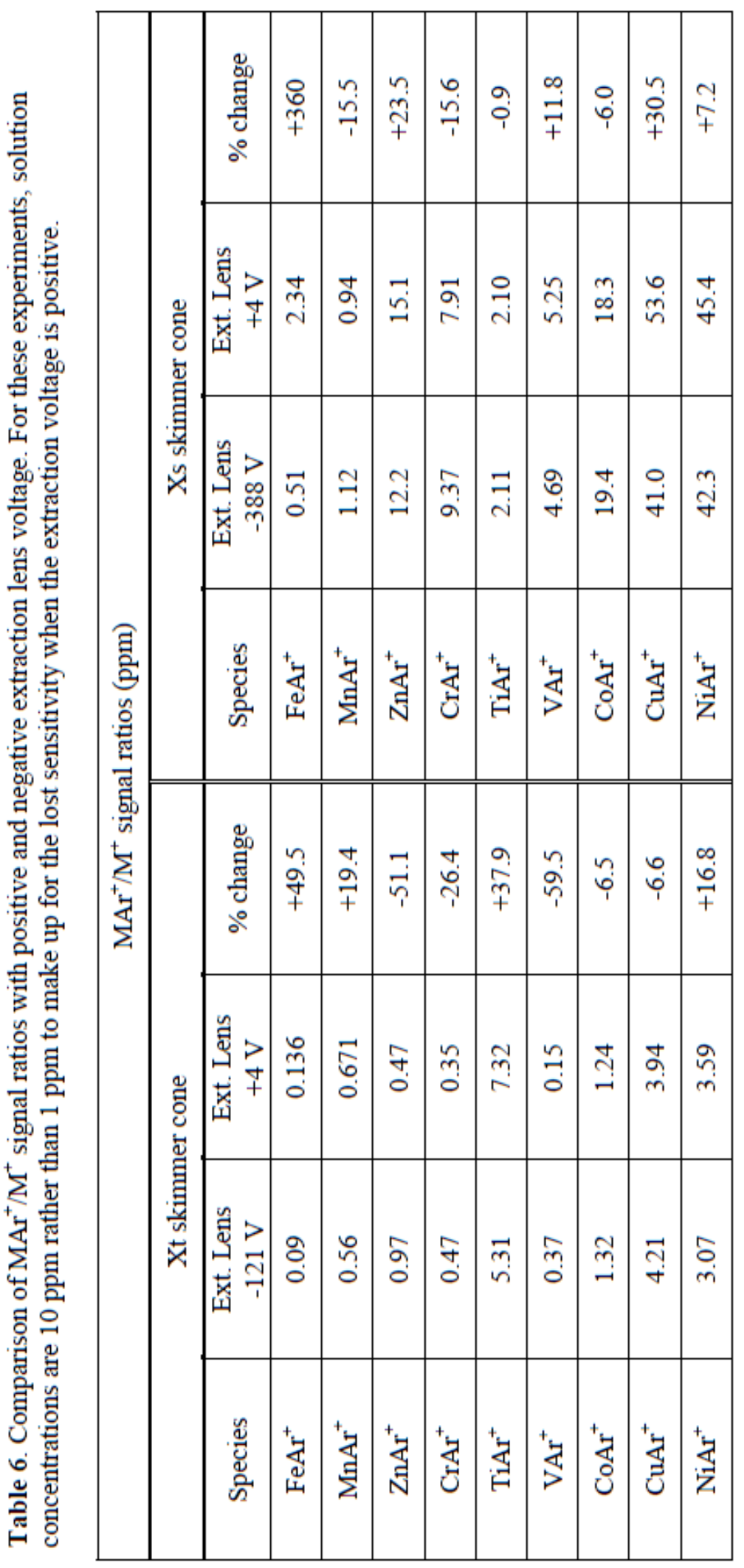




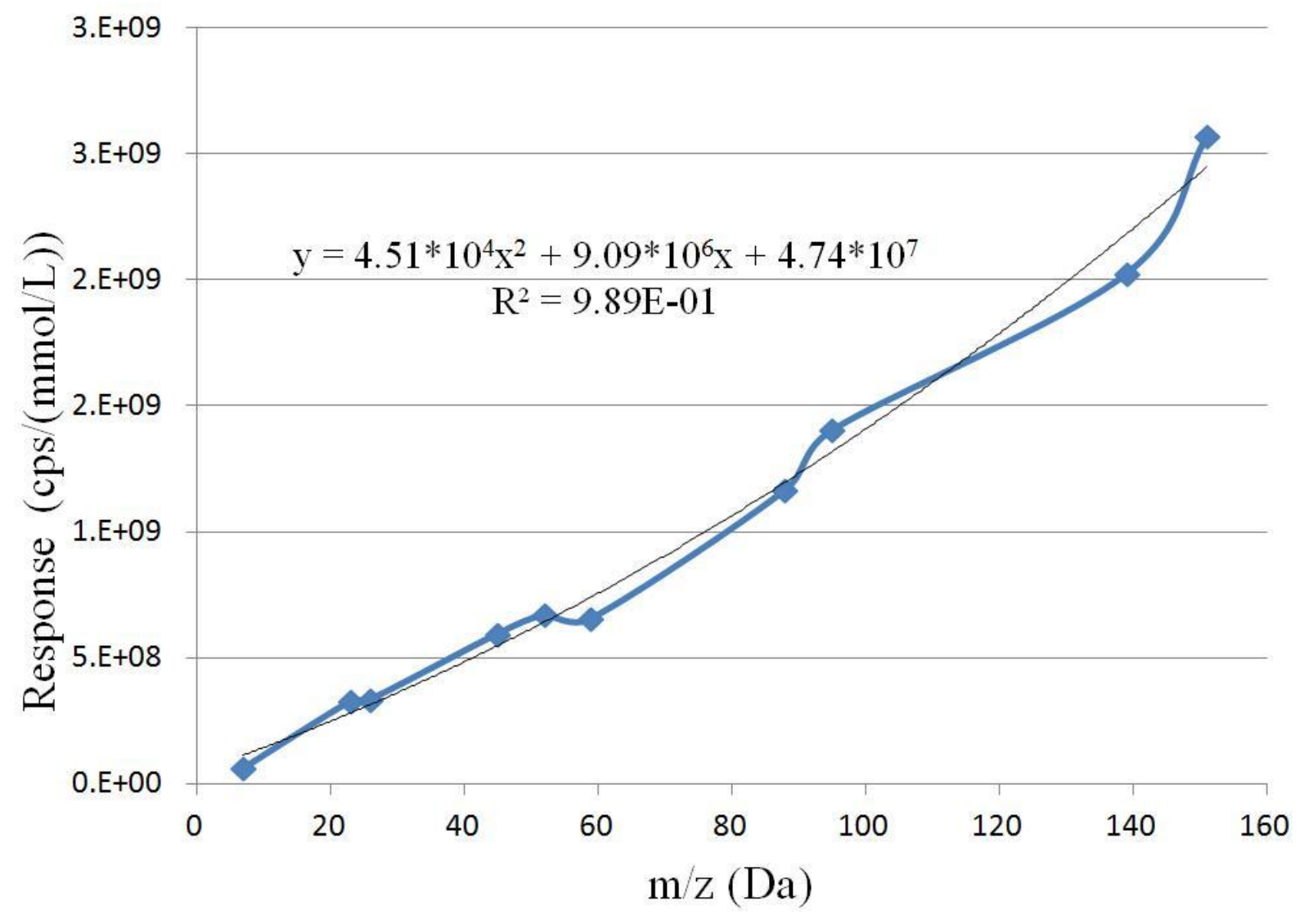

Figure 1. Instrument response curve used for mass bias corrections. This plot is generated with normal Xt skimmer cone, guard electrode, and negative extraction voltage. 


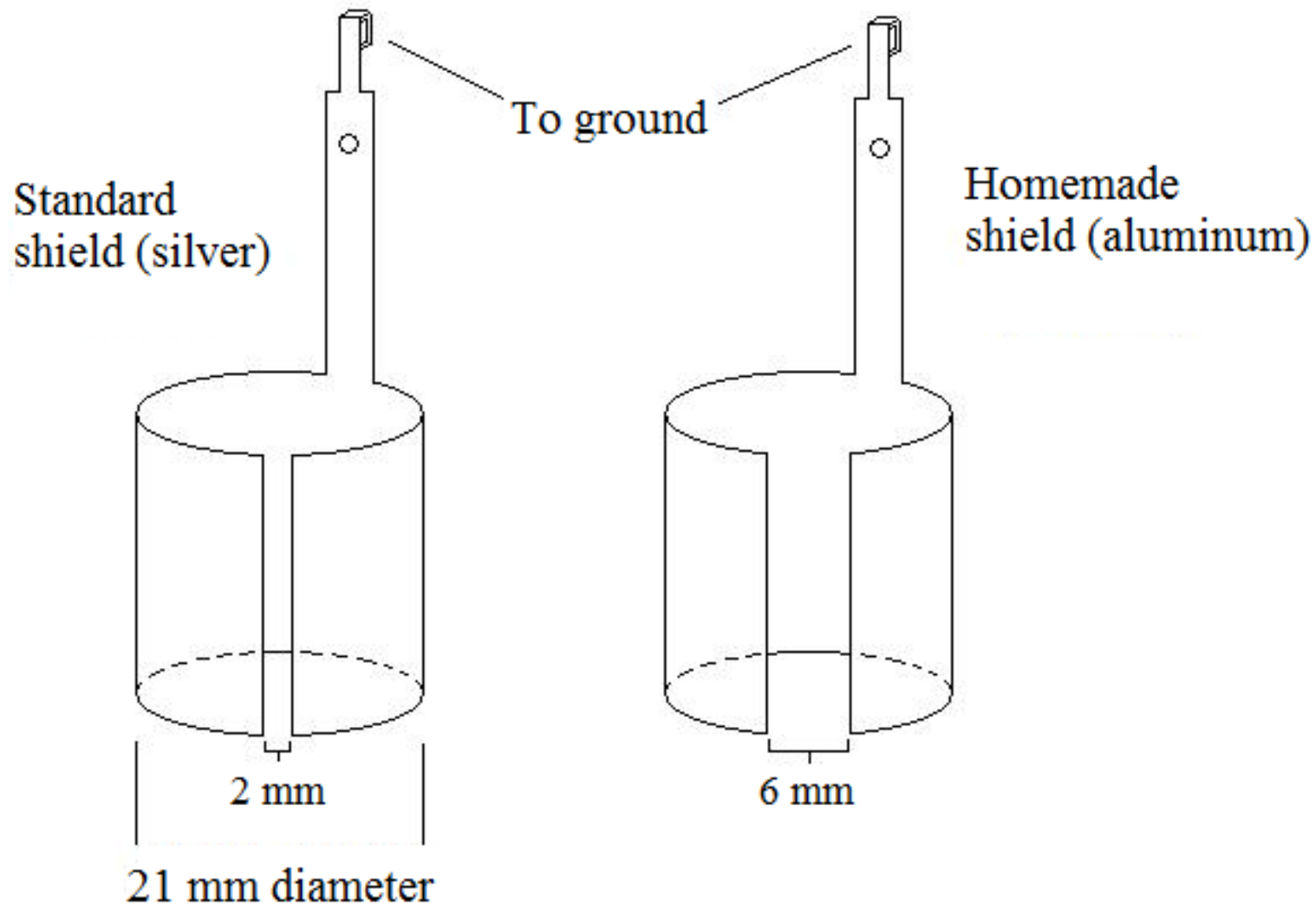

Figure 2. Depiction of standard and homemade guard electrodes. The only significant differences are material and slot width. 


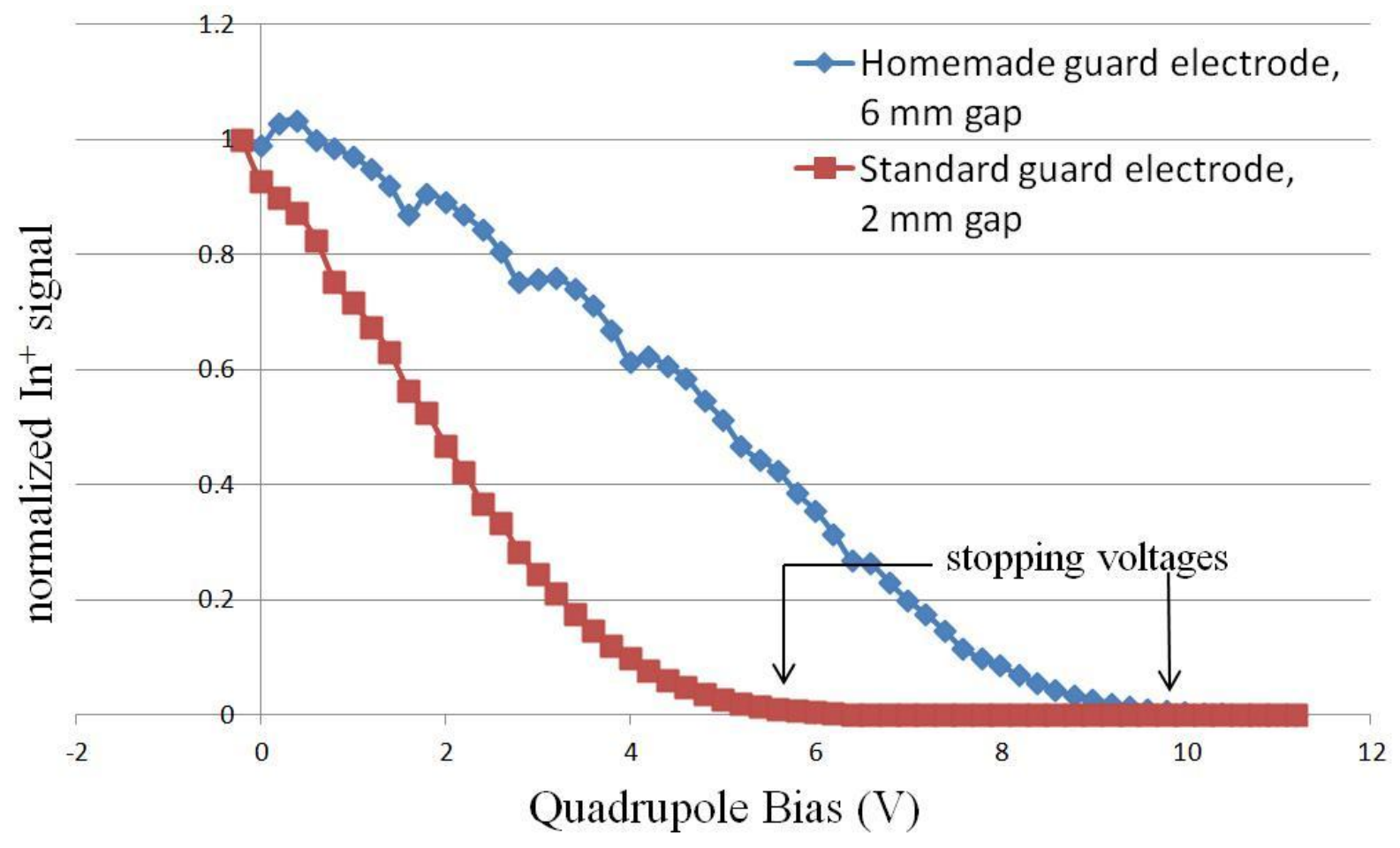

Figure 3. Stopping curves of $\mathrm{In}^{+}$ions with standard or homemade guard electrodes. 


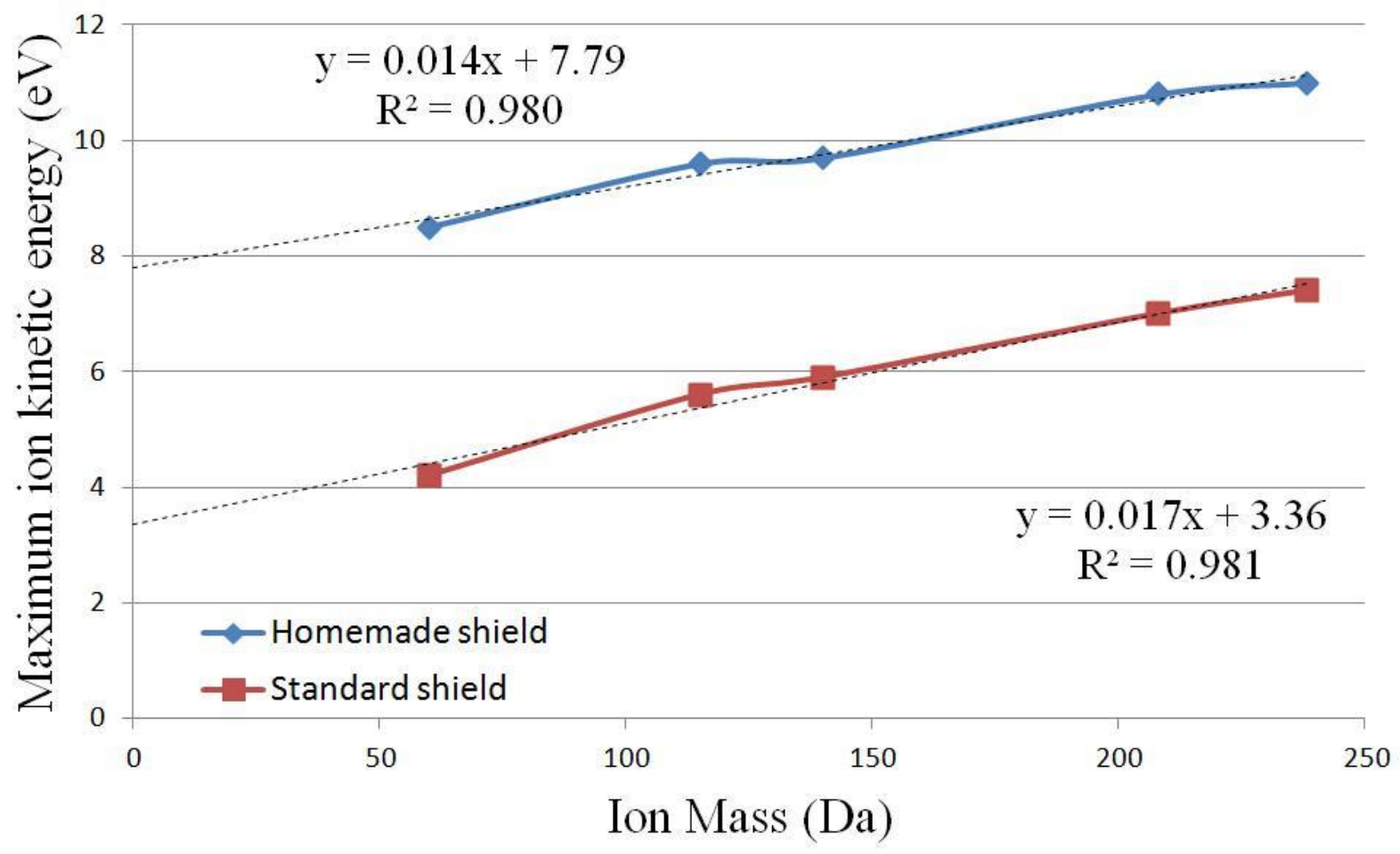

Figure 4. Maximum ion kinetic energy vs ion mass with homemade or standard guard electrode. Plasma potential and ion kinetic energies are much higher with homemade guard electrode. 


\section{Chapter 5. Elemental and isotopic analysis of uranium oxide and NIST glass standards by femtosecond-LA-ICP-MIC-MS}

A technical report for the US Department of Energy, report number IS-5194

Chris Ebert, Daniel S. Zamzow, Eddie H. McBay, Debra A. Bostick, Stanley J. Bajic, David P. Baldwin, and R. S. Houk

\section{Introduction}

The objective of the work was to test and demonstrate the analytical figures of merit of a femtosecond-laser ablation ( $f s$-LA) system coupled with an inductively coupled plasmamulti ion collector-mass spectrometer (ICP-MIC-MS). The mobile $f s$-LA sampling system was designed and assembled at Ames Laboratory and shipped to Oak Ridge National Laboratory (ORNL), where it was integrated with an ICP-MIC-MS. The test period of the integrated systems was February 2-6, 2009.

Spatially-resolved analysis of particulate samples is accomplished by 100 -shot laser ablation using a $f s$-pulsewidth laser and monitoring selected isotopes in the resulting ICP-MS transient signal. The capability of performing high sensitivity, spatially resolved, isotopic analyses with high accuracy and precision and with virtually no sample preparation makes $f s$-LA-ICP-MIC-MS valuable for the measurement of actinide isotopes at low concentrations in very small samples for nonproliferation purposes. Femtosecond-LA has been shown to generate particles from the sample that are more representative of the bulk composition, thereby minimizing weaknesses encountered in previous work using nanosecond-LA

$(n s-\mathrm{LA})^{1-3}$. The improvement of $f s$ - over $n s$-LA sampling arises from the different 
mechanisms for transfer of energy into the sample in these two laser pulse-length regimes. The shorter duration $f s$-LA pulses induce less heating and cause less damage to the sample than the longer $n s$ pulses. This results in better stoichiometric sampling (i.e., a closer correlation between the composition of the ablated particles and that of the original solid sample), which improves accuracy for both intra- and inter-elemental analysis.

The primary samples analyzed in this work are a) solid uranium oxide powdered samples having different ${ }^{235} \mathrm{U}$ to ${ }^{238} \mathrm{U}$ concentration ratios, and b) glass reference materials (NIST 610, 612, 614 and 616). Solid uranium oxide samples containing ${ }^{235} \mathrm{U}$ in depleted, natural and enriched abundances were analyzed as particle aggregates immobilized in a collodion substrate. The uranium oxide samples were nuclear reference materials (CRMs U0002, U005-A, 129-A, U015, U030-A, and U050) obtained from New Brunswick Laboratory-USDOE.

\section{Experimental}

Femtosecond-LA sampling was accomplished using a Coherent Libra $f s$-laser system with UV harmonic generation. The Libra laser system was placed on a 1.83-m x 0.91-m steel cart along with its ancillary components (e.g., power supplies and water recirculator). The 266-nm output from the Libra was directed through a beam tube into an interlocked enclosure, which was also located on the cart. The enclosure housed optics, an electronic shutter, gas lines, and valves for the argon carrier gas, an $x-y-z$ translation stage, and the ablation cell. Since the entire laser beam path was enclosed in beam tubes and an interlocked enclosure, laser ablation sampling was performed in a Class-I laser hazard mode. Class-I signifies that the LA system is considered safe from any potential laser exposure hazards to 
operators. Having the $f_{s}$-LA system on a cart allowed the system to be moved into a separate room where it could be operated in a non-Class-I mode safely during initial set-up and optimization at ORNL.

The Ti:Sapphire output from the Libra laser was frequency-tripled to a wavelength of $266 \mathrm{~nm}$, with an energy of $180 \mu \mathrm{J}$ per pulse, a pulse with of approximately $100 \mathrm{fs}$, and a repetition rate of $1 \mathrm{kHz}$. The laser beam spot size used in these tests was approximately $35 \mu \mathrm{m}$. A programmable shutter was used to control the number of laser pulses for a particular ablation event. A 100-ms shutter-open duration was used (i.e., 100 laser shots) for the uranium oxide measurements. The shutter-open duration was varied from $10-\mathrm{ms}$ to 500-ms for the single-spot analyses of the glass reference samples. Only results using 100-ms shutter-open duration are reported here.

The ICP-MS instrument used at ORNL was a Thermo Finnigan NEPTUNE ICP-MS quipped with a multi-ion collector (MIC) detector array and a Faraday cup detector array. The MIC array configuration used during the test period is shown in Table 1. Table 2 shows the Faraday cup configuration used. Thorium-232 was added to the Faraday cup array during some of the testing to detect Th for the inter-element measurement of the glass reference samples. The detector integration time was 131-ms for all transient measurements, generally using 400 points ( 52 s) for each LA run. The ICP-MIC-MS was operated in low resolution mode for maximum sensitivity. Other instrumental laser ablation and ICP-MS parameters were optimized daily. ICP-MS operating conditions were chosen to maximize $\mathrm{U}^{+}$signal from a nebulized aqueous solution of $\sim 100 \mathrm{ppb} \mathrm{U}$.

Samples for laser ablation sampling were prepared by spreading very small amounts of uranium oxide powder onto an acrylic disk, which had a 2-cm diameter with a 2-mm deep 
depression on one face. The powder was suspended in a less than $200-\mu \mathrm{m}$ layer of collodion, at a loading of approximately 5-mg of uranium oxide per disk. Single-spot analyses of the samples were restricted to an approximate $35-\mu \mathrm{m}$ diameter area for each run, the diameter of the focused laser beam. This was the beam diameter selected for these tests, but not the minimum size for this instrument.

\section{Results and discussion}

\section{Uranium isotope ratios}

Figure 1 shows representative transient signals acquired from a 100-shot $f s$-LA-ICP-MIC-MS analysis of a $1.5 \%$ enriched uranium oxide sample (U015). The ${ }^{234} \mathrm{U}$, ${ }^{235} \mathrm{U},{ }^{236} \mathrm{U}$, and ${ }^{238} \mathrm{U}$ signal intensities are plotted on a logarithmic scale for clear visualization. (The observed gaps in the plotted traces at low signal intensities are due to occasion negative values, which cannot be plotted on a logarithmic scale.) From these traces, the ${ }^{235} \mathrm{U} /{ }^{238} \mathrm{U}$ ratios were determined for the set of depleted, natural, and enriched uranium oxide samples. Since pure uranium oxide samples were analyzed to establish the analytical figures of merit for the state-of-the-art $f s$-LA-ICP-MIC-MS system, strong ${ }^{238} \mathrm{U}$ intensities

(>10 volts) were commonly observed during these tests. The strong ${ }^{238} \mathrm{U}$ signals required measurement of these samples using Faraday cups rather than the more sensitive electro multiplier available on this instrument. The ion collectors have an upper voltage threshold of $\sim 3 \mathrm{mV}$ and would be readily saturated and the data useless for such larger ion concentrations. No measureable uranium background was detected for the collodion or acrylic substrate.

The results from the 100-shot $f s$-LA-ICP-MIC-MS for two days of analyses of the uranium oxide samples are shown in Table 3. There is excellent agreement between the 
measured 100-shot laser ablation values and the certified values of the CRMs. The measured ratios include small corrections for mass bias; details of the method for such corrections can be obtained from the authors. The relative standard deviation (RSD) for the two data sets is less than $0.75 \%$ for the multiple runs done for each of the uranium oxide samples. These results demonstrate the significant improvement in precision and accuracy that this state-ofthe-art $f s$-LA-ICP-MIC-MS provides over a more conventional commercial $n s$-LA-ICP-MS system $^{4}$.

Table 4 shows results for the analysis of the same uranium oxide samples using both a commercial $n s$ laser for ablation sampling (CETAC LSX-500) and the $f_{s}$-LA system used during the site test, coupled with a sequential-scanning ICP-MS (Thermo Finnigan Element) at Ames Laboratory. Please note that this is not data generated using the ICP-MIC-MS at ORNL. Even though the $f s$-LA system generally provides better results than the $n s$-LA system, poorer accuracy and precision are observed for either LA system when integrated to a sequential-scanning ICP MS compared to the results obtained with the $f s$-LA-ICP-MIC-MS setup used during the site test.

A least-squares fit of the entire dataset was performed and the results are shown in Figure 2. (Figure 3 shows an expanded view of the fit around natural isotope abundance uranium.) The measured 100-shot $f_{s}$-LA-ICP-MIC-MS data for the uranium oxide samples are plotted against their known values. The $95 \%$ prediction and confidence intervals and the literature value for ${ }^{235} \mathrm{U} /{ }^{238} \mathrm{U}$ in natural uranium, $0.725 \%$, are also plotted. The linearregression fit to the data yielded a correlation coefficient of $\mathrm{R}=0.99999$. From the data, one can determine that a single ablation measurement that yielded a value of $0.725 \%{ }^{235} \mathrm{U} /{ }^{238} \mathrm{U}$ (natural abundance) would be $95 \%$ likely to lie in the prediction range of 0.707 to $0.742 \%$. 
The $95 \%$ prediction interval from the previous study for the same hypothetical natural abundance sample, performed with a conventional commercial $n s$-LA unit and sequential ICP, was 0.611 to $0.826 \%{ }^{4}$. This demonstrates a distinct improvement in precision (over six times more precise), due to the incorporation of $f s$-laser sampling and the multi-ion collector MS, thus meeting one of the project's most significant goals. The much higher precision obtained with the tested state-of-the-art system means that error contributions from the plasma or laser are now the most significant limitation to improved accuracy, sensitivity, and precision. These error contributions may be addressed by more frequent renormalization of the measured system response to isotopic standards. For example, the analytical protocol would likely be modified to perform normalization between each sample or after every third sample, rather than once per sample set as was done for the site test data, by performing a mass-bias correction. (Additional normalization data were not collected during the site test because of time limitations.)

The least-squares fit in Figure 2 shows that a known natural abundance sample would yield a measurement within a 0.723 to $0.728 \%$ confidence range $95 \%$ of the time, determined from this calibration dataset. The same hypothetical natural abundance sample yielded a measurement within a 0.718 to $0.745 \%$ confidence range $95 \%$ of the time, in the previous study with poorer precision ${ }^{4}$. The confidence intervals are significantly improved with the $f s$-LA-ICP-MIC-MS system (0.005\% versus $0.027 \%)$. Thus, much smaller enrichment or depletion levels can be accurately measured using the $f s$-LA-ICP-MIC-MS system.

\section{Thorium/uranium concentration ratios}

Measurement of the Th/U signal ratio is a convenient way to determine if the particles produced by the LA process are small enough to be effectively converted into atoms and ions 
in the ICP. A measured Th/U ratio less than the known concentration ratio in the sample indicates that the particles are too large to be completely atomized and ionized in the plasma, leading to low results for Th (Since Th is not as readily atomized and ionized in the plasma). This study was conducted using NIST reference glass standards; the Th/U concentration ratios for these samples are near unity (see Tables 5 and 6).

Measurements were taken by both scanning the laser over the sample surface and sampling at a single spot. Results of the $f s$-LA-ICP-MIC-MS analyses during the site test were compared to similar analyses of the reference standards performed with a) a commercial $n s$-LA system connected to a sequential-scanning ICP at Ames Laboratory and with b) the same $f s$-LA system connected to the sequential-scanning ICP-MS. The results are shown in Table 5 for scanning LA sampling and in Table 6 for single-spot LA sampling.

It should be noted that the reported ${ }^{232} \mathrm{Th} /{ }^{238} \mathrm{U}$ values for the sequential-scanning ICP-MS were obtained after the instrument was optimized with a $100 \mathrm{ppb} \mathrm{U}$ tuning solution for maximum signal intensity. The results are presented to illustrate the improvement in accuracy and precision obtained with the state-of-the-art $f s$-LA-ICP-MIC-MS system. Experiments in our lab have shown that varying the scanning ICP-MS operating parameters, such as gas sample flow, can readily affect the measured ${ }^{232} \mathrm{Th} /{ }^{238} \mathrm{U}$ values. Adjusting various plasma and MS parameters affects the mass bias observed in these measurements. These tests illustrate that independent ratios obtained at optimized signal levels are much closer to the certified values using $f s$-LA compared to $n s$-LA. They are close enough that accurate interelemental ratios may be obtained with little optimization or with non-matrix-matched standards. We still need to perform tests to determine whether any residual mass bias 
observed using $f s$-LA could be corrected using liquid standards for normalization, something that could not be done previously with $n s$-LA sampling.

Since $f s$-LA greatly minimizes fractionation during sampling, measurements taken with the $f s$-LA-ICP-MIC_MS system yield ${ }^{232} \mathrm{Th} /{ }^{238} \mathrm{U}$ values much closer to the certified stoichiometric ratios for these samples. This is readily illustrated in Tables 5 and 6 . The precision obtained for both single-spot LA and laser scanning analyses are significantly improved with the state-of-the-art system compared to the commercial $n s$-LA and scanning ICP-MS system, as shown in Tables 5 and 6.

\section{Conclusions}

This study demonstrated significant improvement in the precision and accuracy in the measurement of uranium oxide using a state-of-the-art $f s$-LA-ICP-MIC-MS system compared to a conventional commercial $n s$-LA-ICP-MS system. A six-fold increase in precision was observed during the site test due to the incorporation of $f s$-laser sampling and the multi-ion collector MS, meeting one of this project's most significant goals. There is excellent agreement between the measured 100 -shot ablation ${ }^{235} \mathrm{U}^{238} \mathrm{U}$ values and the certified values. With the exception of the analysis of one depleted uranium oxide sample, the differences between the measured values and the certified values were less than $0.5 \%$.

Thus single-shot LA-ICP-MS can readily differentiate between very small samples of depleted, natural and enriched uranium samples. From the reported data, a known natural abundance sample particle would yield a measurement within a 0.723 to $0.728 \%$ confidence range $95 \%$ of the time. Similarly, a sample that resulted in a measured value of $0.725 \%{ }^{235} \mathrm{U}$ 
would be $95 \%$ likely to lie in the prediction range of 0.707 to $0.742 \%$, based on the calibration and standards used during the test at ORNL.

This study also demonstrated that $f s$-LA greatly minimizes fractionation during sampling, thereby improving inter-elemental ratio analyses of samples. Measurements taken with the $f_{s}$-LA-ICP-MIC-MS system yielded ${ }^{232} \mathrm{Th} /{ }^{238} \mathrm{U}$ values much closer to the certified stoichiometric ratios for these samples, compared to the results obtained previously for $n s$-LA-ICP-MS. 


\section{References}

1. C. Y. Liu, X. L. Mao, S. S. Mao, X. Zeng, R. Greif and R. E. Russo, Anal. Chem., 2004, 76, 379-383.

2. Z. Wang, B. Hattendorf and D. Guenther, J. Anal. At. Spectrom., 2006, 21, 11431151.

3. J. Pisonero and D. Guenther, Anal. Bioanal. Chem., 2007, 387, 149-153.

4. J. Messerly, N. Saetveit, S. J. Bajic, D. P. Baldwin and R. S. Houk, Ames Laboratory Report IS-5174, 2005. 
Table 1. Multi-ion collector array configuration used during the ORNL test. IC\# = designation of ion counter.

\begin{tabular}{|c|c|c|c|c|c|c|c|}
\hline IC2 & IC3 & IC4 & IC5 & IC6 & IC7 & L4 & IC8 \\
\hline${ }^{231} \mathrm{~Pa}$ & ${ }^{232} \mathrm{Th}$ & ${ }^{233} \mathrm{U}$ & ${ }^{234} \mathrm{U}$ & ${ }^{235} \mathrm{U}$ & ${ }^{236} \mathrm{U}$ & $\mathrm{m} / \mathrm{z} \mathrm{237}$ & ${ }^{238} \mathrm{U}$ \\
\hline
\end{tabular}

Table 2. Faraday cup configuration used during the ORNL test. L\# or H\# = designation of Faraday cup detector.

\begin{tabular}{|l|c|c|c|c|c|c|c|}
\hline & L1 & L2 & L3 & Center & H1 & H2 & H3 \\
\hline $\begin{array}{l}\text { Configuration for } \\
\text { uranium oxide } \\
\text { measurements }\end{array}$ & ${ }^{234} \mathrm{U}$ & ${ }^{235} \mathrm{U}$ & ${ }^{236} \mathrm{U}$ & $\begin{array}{c}\mathrm{m} / \mathrm{z} \\
237\end{array}$ & ${ }^{238} \mathrm{U}$ & ${ }^{239} \mathrm{Pu}$ & --- \\
\hline $\begin{array}{l}\text { Configuration for } \\
{ }^{232} \mathrm{Th} /{ }^{238} \mathrm{U} \text { measurements }\end{array}$ & ${ }^{232} \mathrm{Th}$ & ${ }^{233} \mathrm{U}$ & ${ }^{234} \mathrm{U}$ & ${ }^{235} \mathrm{U}$ & ${ }^{236} \mathrm{U}$ & $\begin{array}{c}\mathrm{m} / \mathrm{z} \\
237\end{array}$ & ${ }^{238} \mathrm{U}$ \\
\hline
\end{tabular}


Table 3. Measured ${ }^{235 / 238} \mathrm{U}$ for uranium oxide in collodion analyzed by $f s$-LA-ICP-MIC-MS

\begin{tabular}{|c||c|c|c|c||c|c|c|c|}
\hline & \multicolumn{4}{|c||}{ Day 2 } & \multicolumn{5}{c|}{ Day 1 } \\
\hline $\begin{array}{c}\text { Certified ratio } \\
\left({ }^{235 / 238} \mathrm{U}\right)\end{array}$ & Avg & \%RSD & Reps & \%Dif & Avg & \%RSD & Reps & \%Dif \\
\hline .0528 & 0.052906 & 0.33 & 4 & 0.20 & 0.052983 & 0.23 & 7 & 0.35 \\
\hline .0314 & 0.031396 & 0.41 & 4 & -0.01 & 0.031433 & 0.35 & 7 & 0.11 \\
\hline .0156 & 0.015669 & 0.73 & 5 & 0.44 & 0.015556 & 0.52 & 6 & -0.28 \\
\hline .00726 & 0.007289 & 0.43 & 6 & 0.40 & 0.007253 & 0.34 & 5 & -0.10 \\
\hline .00509 & 0.005101 & 0.54 & 4 & 0.21 & 0.005071 & 0.41 & 5 & -0.38 \\
\hline .000176 & 0.000174 & 0.52 & 5 & -1.17 & 0.000175 & 0.65 & 6 & -0.30 \\
\hline
\end{tabular}

Table 4. Uranium oxide in collodion measured on a scanning ICP-MS

\begin{tabular}{|c||c|c|c|c||c|c|c|c|}
\hline \multicolumn{1}{|c||}{} & \multicolumn{4}{c||}{$n s$-LA, scanning MS } & \multicolumn{4}{c|}{$f_{s}$-LA, scanning MS } \\
\hline $\begin{array}{c}\text { Certified ratio } \\
\left({ }^{235 / 238} \mathrm{U}\right)\end{array}$ & Avg & \%RSD & Reps & \%Dif & Avg & \%RSD & Reps & $\%$ Dif \\
\hline .0528 & 0.04878 & 7.25 & 5 & -7.61 & 0.04676 & 27.93 & 6 & -11.4 \\
\hline .0314 & 0.03359 & 19.87 & 5 & 6.97 & 0.03035 & 7.29 & 6 & -3.33 \\
\hline .0156 & 0.01862 & 33.25 & 5 & 19.4 & 0.01545 & 8.08 & 6 & -0.96 \\
\hline .00726 & 0.00502 & 50.18 & 5 & -30.9 & 0.00652 & 17.47 & 6 & -10.2 \\
\hline .00509 & 0.00414 & 23.67 & 5 & -18.5 & 0.00491 & 1.06 & 6 & -3.54 \\
\hline .000176 & 0.00017 & 23.07 & 5 & -4.91 & 0.00018 & 28.55 & 6 & -1.08 \\
\hline
\end{tabular}


Table 5. Measured ${ }^{232} \mathrm{Th} /{ }^{238} \mathrm{U}$ ratios obtained for scanning laser ablation on NIST glass standards

\begin{tabular}{|c||c|c|c|c|c|c||c|c|c|}
\hline \multirow{1}{*}{$\begin{array}{c}\text { LA, MS } \\
\text { system }\end{array}$} & \multicolumn{3}{|c|}{ NIST 610} & \multicolumn{3}{c||}{ NIST 612 } & \multicolumn{3}{c|}{ NIST 614} \\
\hline & Avg & \%RSD & \%Dif & Avg & \%RSD & \%Dif & Avg & $\%$ RSD & \%Dif \\
\hline $\begin{array}{c}n s \text {-LA, } \\
\text { scanning MS }\end{array}$ & 0.52 & 7.28 & -49.11 & 0.51 & 9.98 & -50.86 & 0.42 & 2.08 & -54.79 \\
\hline \begin{tabular}{c}
$f s$-LA, \\
scanning MS \\
\hline$s$-LA, MIC \\
MS
\end{tabular} & 0.86 & 2.20 & -15.75 & 0.91 & 0.93 & -12.91 & 0.80 & 2.94 & -14.07 \\
\hline $\begin{array}{c}\text { Certified } \\
\text { value }\end{array}$ & 1.02 & 0.83 & -6.30 & 0.96 & 1.59 & -7.38 & 0.86 & 0.93 & -7.59 \\
\hline
\end{tabular}

Table 6. Measured ${ }^{232} \mathrm{Th} /{ }^{238} \mathrm{U}$ ratios obtained by single-spot laser ablation on NIST glass standards

\begin{tabular}{|c||c|c|c|c|c|c||c|c|c|}
\hline $\begin{array}{c}\text { LA, MS } \\
\text { system }\end{array}$ & \multicolumn{3}{|c||}{ NIST 610} & \multicolumn{3}{c||}{ NIST 612 } & \multicolumn{3}{c|}{ NIST 614} \\
\hline & Avg & $\%$ RSD & $\%$ Dif & Avg & $\%$ RSD & \%Dif & Avg & $\%$ RSD & \%Dif \\
\hline $\begin{array}{c}n s \text {-LA, } \\
\text { scanning MS }\end{array}$ & 0.64 & 15.28 & -36.80 & 0.53 & 30.72 & -49.41 & 0.52 & 1.75 & -44.38 \\
\hline \begin{tabular}{c}
$f s$-LA, \\
scanning MS \\
\hline$s$-LA, MIC \\
MS
\end{tabular} & 1.02 & 10.72 & 0.18 & 0.97 & 18.87 & -6.69 & 0.94 & 16.82 & 1.02 \\
\hline $\begin{array}{c}\text { Certified } \\
\text { value }\end{array}$ & 1.02 & 1.16 & -2.84 & 0.99 & 1.87 & -4.90 & 0.91 & 4.03 & -2.46 \\
\hline
\end{tabular}




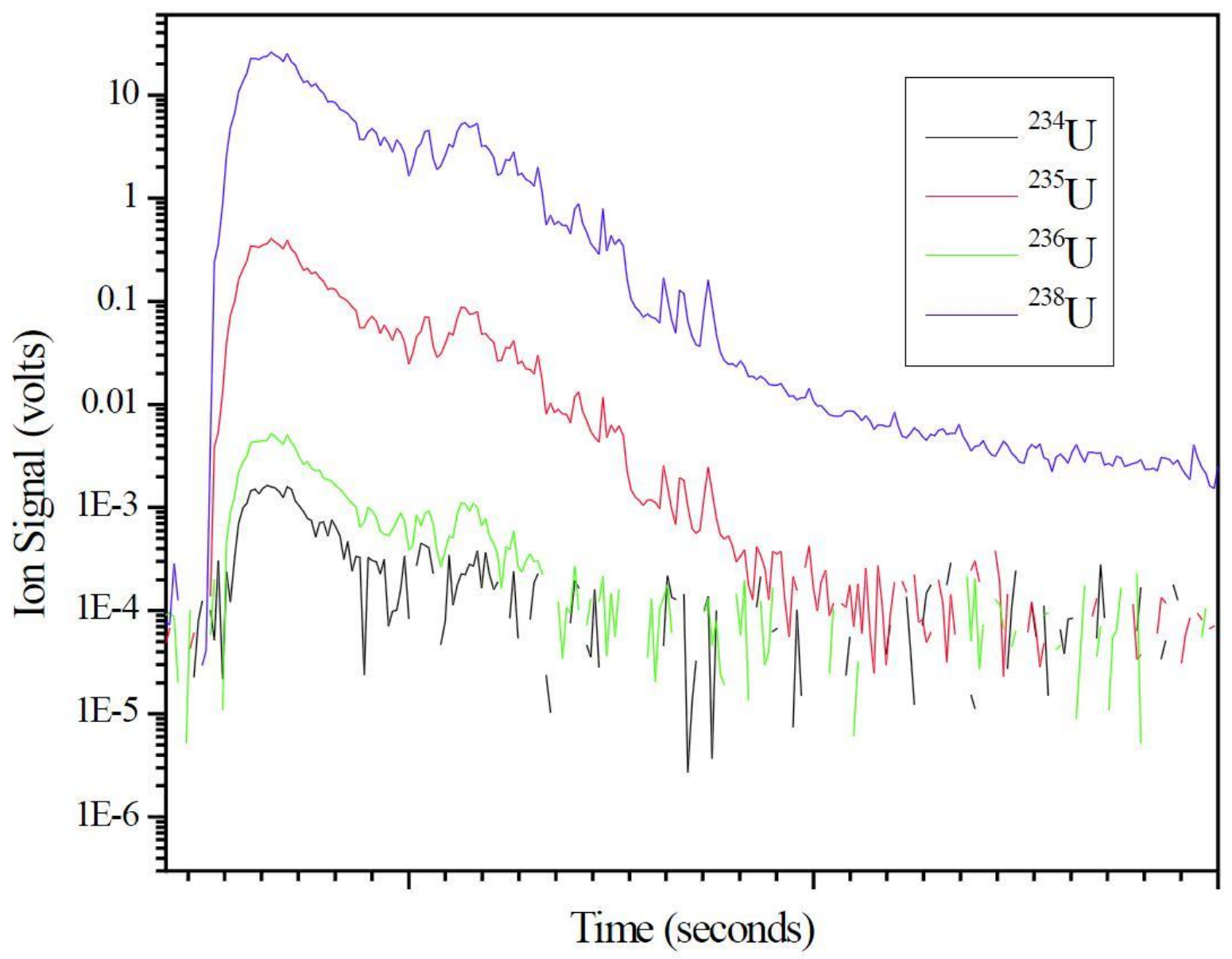

Figure 1. Typical transient signals from a single 100-shot $f s$-LA-ICP-MIC-MS analysis (Faraday cup data) of an enriched uranium oxide sample containing $1.5 \%{ }^{235} \mathrm{U}$. 


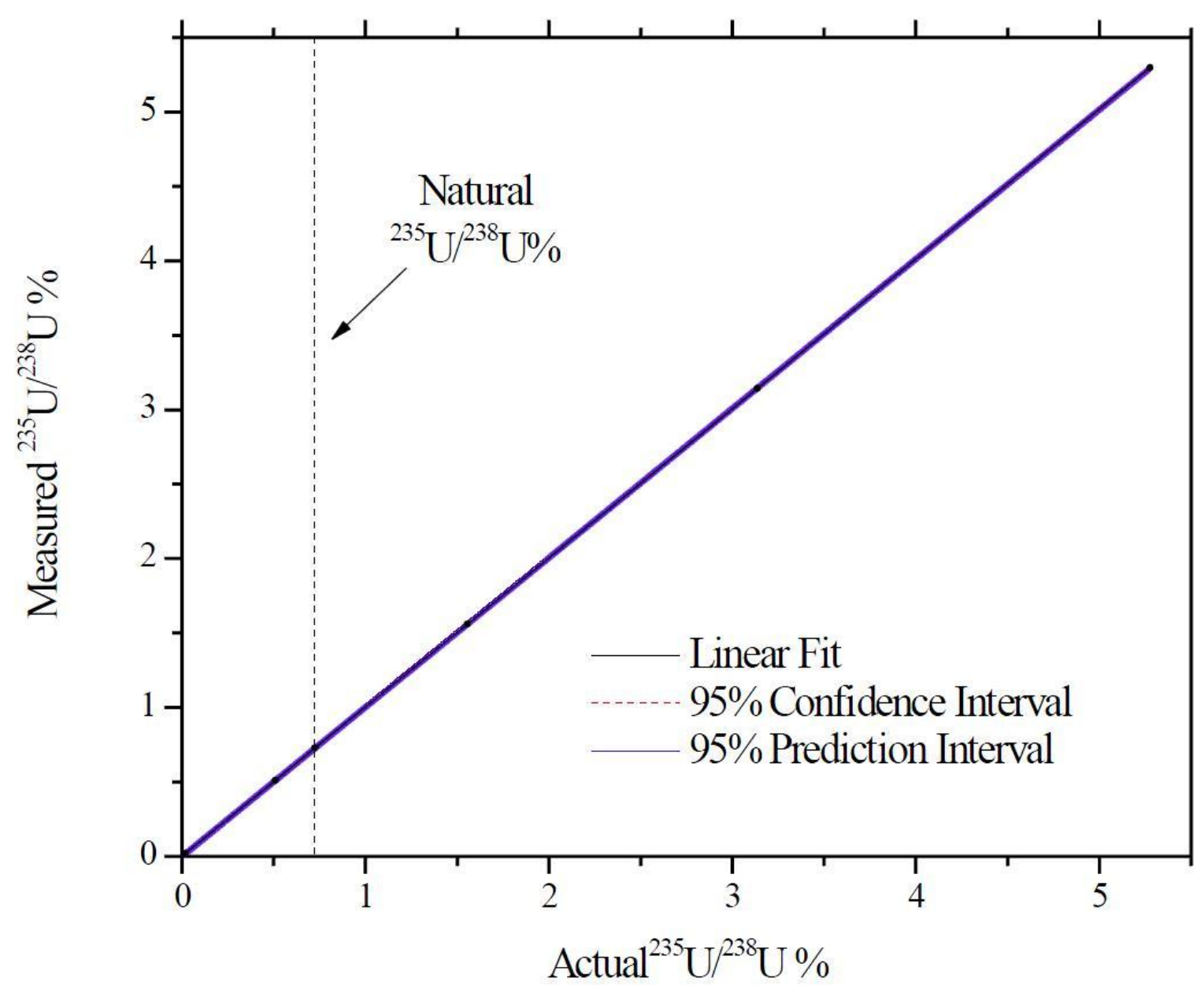

Figure 2. Linear-regression fit of the entire dataset of uranium oxide samples, analyzed by 100 -shot $f s$-LA-ICP-MIC-MS at ORNL (Faraday cup data). The 95\% upper and lower confidence intervals and the $95 \%$ upper and lower prediction intervals are plotted. 


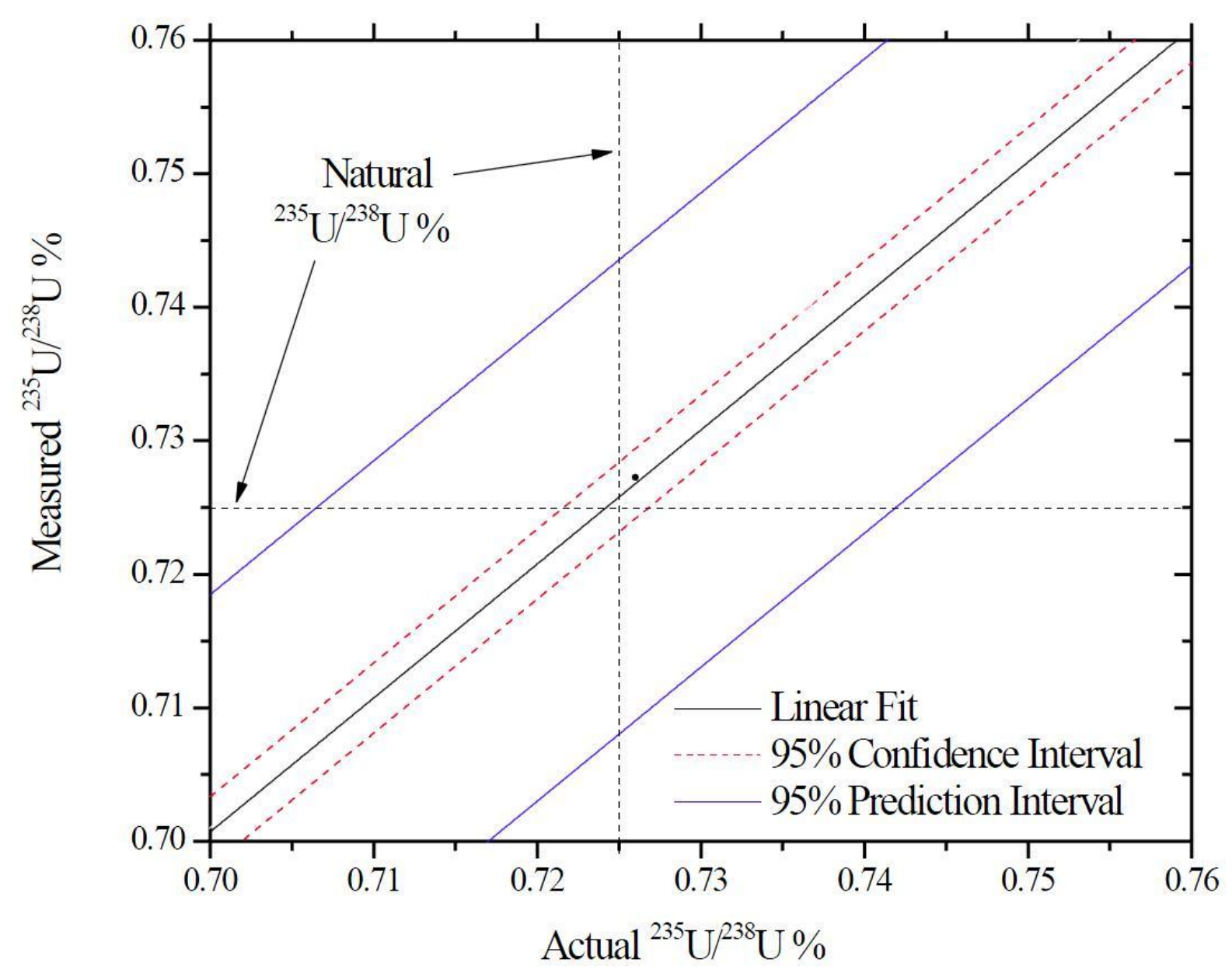

Figure 3. An expanded view (approximately centered around natural isotope abundance uranium) of the least-squares fit of the entire dataset acquired at ORNL. The 95\% upper and lower confidence intervals and the $95 \%$ upper and lower prediction intervals are plotted. The dashed vertical and horizontal lines represent natural abundance uranium ratio. 


\title{
Chapter 6: Laser ablation ICP-MS method developments for environmental contamination detection purposes
}

\author{
Material submitted to the US Department of Energy \\ Chris H. Ebert, Daniel S. Zamzow, Stanley J. Bajic, David P. Baldwin, R. S. Houk
}

\begin{abstract}
The suitability of laser ablation inductively coupled plasma mass spectrometry (LA-ICP-MS) for the removal and elemental analysis of individual dust or soil particles from two novel matrices is examined. These matrices are of particular interest for the purposes of environmental contamination monitoring. Femtosecond laser ablation is more successful than nanosecond laser ablation at removing soil particles from grease matrices. Determined ${ }^{235} \mathrm{U}^{+}{ }^{238} \mathrm{U}^{+}$signal ratios of analyzed soil particles are at natural abundance with greater than 95\% confidence. Femtosecond LA-ICP-MS is used to determine the thorium and uranium content of dust particles trapped in spider silk samples obtained from a site with known thorium contamination and from a neutral site. Particles found in spider silk from a known contamination site produced thorium signal more than an order of magnitude higher than particles contained in spider silk from a neutral site. ${ }^{232} \mathrm{Th}^{+}{ }^{238} \mathrm{U}^{+}$signal ratios of individual dust particles trapped in spider silk from the neutral site were approximately normally distributed, while particles trapped in spider silk from the contamination site produced ${ }^{232} \mathrm{Th}^{+} / 238 \mathrm{U}^{+}$signal ratios that were not normally distributed.
\end{abstract}




\section{Introduction}

Environmental analysis by atomic spectrometry is a widely studied area of instrumental chemistry $^{1,2}$. ICP-MS and LA-ICP-MS are particularly successful methods for the monitoring of concerning elemental species 1 (introduction), 3,4 . LA-ICP-MS is a competitive choice among sampling methods because it directly samples solid materials and can be used to analyze many samples and matrices ${ }^{5-7}$. LA is capable of selectively removing individual particles from a matrix for elemental analysis, which is often preferable to bulk analysis ${ }^{7-9}$. Researching the capability of LA to ablate particles out of additional matrices can help the efforts of environmental monitoring.

Without appropriate sample preparation, LA can liberate particles outside the ablation spot. Collodion is an established matrix used for the trapping of particles so they can be ablated individually ${ }^{9}$. Collodion is a solution of nitrocellulose dissolved in 1:1 ethanol:ether. When collodion is applied to a surface, it rapidly dries into a thin, translucent coating of plastic-like nitrocellulose. Applying collodion to a surface with particles of interest effectively contains those particles without obscuring them ${ }^{10}$. Laser ablation of a single particle in this matrix successfully removes the target particle without disturbing neighboring particles.

The present work evaluates LA-ICP-MS as a method for determining the uranium or thorium content in dust or soil particles trapped in two novel matrices. These matrices are common in production facilities, factories, and laboratories from which environmental contamination may originate. Nanosecond and femtosecond LA-ICP-MS is used to determine ${ }^{235} \mathrm{U}^{+} 2^{238} \mathrm{U}^{+}$signal ratios of soil particles contained in a collodion matrix. These results are compared to the ns and fs LA-ICP-MS determination of ${ }^{235} \mathrm{U}^{+} /{ }^{238} \mathrm{U}^{+}$signal ratios 
of the same soil contained in two grease matrices. A comparison between femtosecond and nanosecond lasers for the removal of soil particles from these greases by LA-ICP-MS is presented. LA-ICP-MS is also used to determine uranium and thorium in dust particles trapped in spider silk obtained from an area known to have thorium contamination. The resulting thorium and uranium signals are compared to those from dust particles trapped in spider silk obtained from a neutral site.

The research in this chapter is a compilation of data taken by the author and reported to our funding source in the form of various reports; additional data were included in such reports but were taken by other researchers so they are not included here.

\section{Methods}

Inductively coupled plasma mass spectrometry

ICP-MS experiments were performed on a quadrupole instrument (XSeries 2, Thermo Fischer Scientific Inc., Bremen, Germany). Experimental conditions are listed in Table 1. All gas flows were argon during these experiments. The ICP-MS was operated such that the quadrupole switched between $\mathrm{m} / \mathrm{z}$ values very quickly (10 ms dwell time). This was the optimal way to evaluate the signal ratio during a transient sample like an ablated soil or dust

particle without the use of a multichannel mass spectrometer ${ }^{11}$. Most particles produced data for approximately 3 to 5 seconds, but the mass spectrometer recorded data for a full twenty seconds. The ion signals reported in this chapter were the integrated signal over the full twenty seconds. 


\section{Laser ablation}

Ablation was carried out with a nanosecond laser (LSX-500, CETAC Technologies, Omaha, NE) or a femtosecond laser (Libra, Coherent Inc., Santa Clara, CA). General parameters for these lasers are reported in Chapter 3, Table 1. With each laser, an integrated camera was used to locate and target an individual soil or dust particle. Ablation was then carried out at this location; 20 laser pulses at $20 \mathrm{~Hz}$ were used during ns LA and 100 laser pulses were used at $1000 \mathrm{~Hz}$ during fs laser ablation. The camera on the fs LA system can detect a particle as small as $\sim 10 \mu \mathrm{m}$; the camera on the ns LA system can detect a particle as small as $\sim 3 \mu \mathrm{m}$.

\section{Samples}

The soil used in this work was collected from a non-contaminated site. Analysis by microwave digestion and subsequent ICP-emission spectroscopy determined this soil contains 5 ppm uranium. For this work, soil samples were prepared in two ways. By the first method, soil was spread across a clean cloth (ITW Texwipe, Mahwah, NJ), covered with collodion, and allowed to dry. This effectively trapped the soil particles and allowed the laser to selectively ablate a single soil particle without jarring other particles into the ambient argon stream and into the plasma. The second method of soil preparation was to spread soil across a surface and mix it with one of two grease matrices. The grease-soil mixture was then spread across a clean cloth.

Spider silk samples were collected from two sites. The first site was known to be contaminated with thorium; the second site was believed to be non-contaminated. Uranium is not a suspected contaminant at the first site, so ${ }^{238} \mathrm{U}$ was chosen as an internal standard to compare to thorium. Spider silk was collected by swiping a web with a clean cloth, then 
covered with collodion and allowed to dry. Preliminary testing with a Geiger counter revealed the spider silk obtained from the contaminated site emitted alpha radiation, while the spider silk from a neutral site did not. When observing these samples with the integrated camera on a laser ablation system, individual strands of spider silk and larger round particulates were observed (Figure 1). These large particulates were believed to be dust particles from the environment of the spider silk and were ablated for analysis.

The soil and dust particles selected for analysis were roughly 50 to $100 \mu \mathrm{m}$ in diameter, ideally just smaller than the laser spot size. Blank ablations of the clean cloths, dried collodion, and grease samples revealed no uranium or thorium above the argon blank while no ablation was performed ( $<3 \mathrm{cps})$.

\section{Results and Discussion}

When determining an elemental or isotopic ratio, counting error must be carefully considered as it can negatively impact the precision of ratio measurements. This is a danger if one or both species are very near the background level. To avoid this limit to precision, the data obtained during the ablation of a soil particles are only used to determine a ${ }^{235} \mathrm{U}^{+} / 238 \mathrm{U}^{+}$ ratio if the ${ }^{235} \mathrm{U}^{+}$signal was greater than $100 \mathrm{cps}$ for at least one full second. Signal lower than $100 \mathrm{cps}$ at peak is considered insufficient to determine a ratio. The ablation of some particles do not result in achieving this threshold because the particles did not contain sufficient uranium; however, in some cases the threshold is not reached because the particle is not completely ablated. This is an important distinction that arises during comparison between the grease and collodion matrices. 
No such threshold is implemented when determining ${ }^{232} \mathrm{Th}^{+} /{ }^{238} \mathrm{U}^{+}$signal ratios during the ablation of dust particles in a spider silk matrix. During this analysis, the full distribution of elemental ratios is desired rather than an aggregate ratio. In this situation, removing data points would introduce bias so counting error must be accepted.

\section{Ablation of soil particles in collodion matrix}

Table 2 contains the ${ }^{235} \mathrm{U}^{+} / 238 \mathrm{U}^{+}$signal ratio in soil particles removed from a collodion matrix by ns or fs LA and determined by ICP-MS. During ns LA, 7 out of 12 ablated particles resulted in ${ }^{235} \mathrm{U}^{+}$signal greater than $100 \mathrm{cps}$. During fs LA, 8 out of 13 particles were above this threshold. Since collodion is an established medium for the containment of particles and their removal by LA, this establishes that approximately $60 \%$ of the particles analyzed in this soil sample have sufficient uranium to determine a ratio. The ${ }^{235} \mathrm{U} /{ }^{238} \mathrm{U}$ ratio of natural uranium (atomic ratio $=0.00726$ ) is well within the determined $95 \%$ confidence interval for ablation by either the ns or fs laser.

\section{Ablation of soil particles in grease matrices}

Table 3 contains the ${ }^{235} \mathrm{U}^{+} 2^{238} \mathrm{U}^{+}$signal ratio in soil particles removed from grease matrices by ns or fs LA and determined by ICP-MS. During ns LA of soil particles in grease matrices, only 2 out of 12 ablated particles generated ${ }^{235} \mathrm{U}^{+}$signal greater than $100 \mathrm{cps}$. Nanosecond LA is significantly worse at removing particles from these matrices than removing particles from a collodion matrix. This problem is attributed to heating of the grease matrices by the ns laser. Greases are softer than collodion and more prone to melting. The particles are not entirely vaporized or ejected; rather they stick to the residual grease matrix in the ablation crater. Attempts to remove these particles with 100 laser pulses (rather than 20) were equally ineffective; these results are not included. 
During fs LA of the soil particles in greases matrices, 23 out of 32 ablated particles generated sufficient ${ }^{235} \mathrm{U}^{+}$to determine a ${ }^{235} \mathrm{U}^{+} /{ }^{238} \mathrm{U}^{+}$signal ratio. Approximately the same portion of ablation attempts generate sufficient signal during the analysis of soil in grease and collodion matrices. Vaporization of grease matrices is more efficient, less matrix heating occurs, and particles are more successfully vaporized or ejected during fs LA than ns LA.

\section{Ablation of dust particles in spider silk matrix}

Thorium and uranium were determined in 111 individual dust particles trapped in spider silk from a site of known thorium contamination and 98 individual dust particles trapped in spider silk from a neutral site by fs LA-ICP-MS. Figure 2 contains a histogram of the integrated thorium signal from each site. The average thorium signal of the analyzed particles from the contamination site is 318000 counts, more than an order of magnitude higher than the 1210 counts of those from the neutral site.

Although the difference between the determined thorium signals in particles from the two sites is considerable, a possibility remains that the particles chosen from the two sets are of vastly different size and the total concentration of thorium in the particles is not significantly different. To verify that thorium concentrations are different between the two groups of particles, the $\mathrm{Th}^{+}$signal from each particle was compared to that for $\mathrm{U}^{+}$. Figure 3 shows a histogram of ${ }^{232} \mathrm{Th}^{+} / 238 \mathrm{U}^{+}$signal ratios on a logarithmic scale for dust particles contained in spider silk from a neutral site as determined by fs LA-ICP-MS. The signal ratios of these particles fit a normal distribution with $\mathrm{R}^{2}=0.9346$. Figure 4 contains a histogram of ${ }^{232} \mathrm{Th}^{+}{ }^{238} \mathrm{U}^{+}$signal ratios on a logarithmic scale of dust particles contained in spider silk from the contamination site as determined by fs LA-ICP-MS. The signal ratios from this sample do not fit a normal distribution. Furthermore, the distribution of signal ratios from the 
contamination site is broader than that from the neutral site. The comparison between these two sets of data provides a clear demonstration that thorium contamination is prevalent at the site.

\section{Conclusions}

Two novel materials are introduced as possible matrices for the capture of particles for environmental monitoring. Femtosecond LA-ICP-MS is a suitable method for determining elements of interest in individual soil particles contained by grease matrices. Nanosecond LA-ICP-MS could not accomplish this task because ns laser pulses could not remove particles from the matrix, most likely due to sample heating and melting. Spider silks were found to be a possible source for detecting environmental contamination. Analysis of dust particles trapped in spider silk from a known contamination area by fs LA-ICP-MS revealed thorium content an elevated level compared to samples from a neutral area. 


\section{References}

1. O. T. Butler, W. R. L. Cairns, J. M. Cook and C. M. Davidson, J. Anal. At. Spectrom., 2012, 27, 187-221.

2. D. Beauchemin, Mass Spectrom. Rev., 2010, 29, 560-592.

3. J. S. Becker, C. Pickhardt and H.-J. Dietze, Int. J. Mass Spectrometry, 2000, 202, 283-297.

4. J. S. Becker, Int. J. Mass Spectrometry, 2005, 242, 183-195.

5. S. F. Boulyga and J. S. Becker, J. Anal. At. Spectrom., 2002, 17, 1143-1147.

6. S. F. Boulyga, D. Desideri, M. A. Meli, C. Testa and J. S. Becker, Int. J. Mass Spectrometry, 2003, 226, 329-339.

7. D. S. Zamzow, D. P. Baldwin, S. J. Weeks, S. J. Bajic and A. P. D'Silva, Environ. Sci. Technol., 1994, 28.

8. J. Messerly, N. Saetveit, S. J. Bajic, D. P. Baldwin and R. S. Houk, Ames Laboratory Report IS-5174, 2005.

9. C. H. Ebert, D. S. Zamzow, E. H. McBay, D. A. Bostick, S. J. Bajic, D. P. Baldwin and R. S. Houk, Ames Laboratory Report IS-5194, 2009.

10. T. M. Witte, D. S. Zamzow, C. Hexel, D. A. Bostick, E. H. McBay, S. J. Bajic, D. P. Baldwin and R. S. Houk, Ames Laboratory Report USI-0001, 2010.

11. D. C. Perdian, S. J. Bajic, D. P. Baldwin and R. S. Houk, J. Anal. At. Spectrom., 2008, 23, 325-335. 
Table 1. ICP parameters

\begin{tabular}{|c|c|}
\hline Operating parameter & Standard setting \\
\hline Forward power & $1400 \mathrm{~W}$ \\
\hline Cooling gas flow & $13.0 \mathrm{~L} / \mathrm{min}$ \\
\hline Auxiliary gas flow & $0.80 \mathrm{~L} / \mathrm{min}$ \\
\hline Sample gas flow & $\begin{array}{c}\sim 0.90 \mathrm{~L} / \mathrm{min} \text {, adjusted for } \\
\text { optimum sensitivity }\end{array}$ \\
\hline
\end{tabular}

Table 2. ${ }^{235} \mathrm{U}^{+} /{ }^{238} \mathrm{U}^{+}$signal ratios with $95 \%$ confidence intervals determined during the analysis of individual particles trapped in collodion matrix by ns and fs LA-ICP-MS.

\begin{tabular}{|c|c|c|}
\hline & Nanosecond laser & Femtosecond laser \\
\hline${ }^{235} \mathrm{U}^{+}{ }^{238} \mathrm{U}^{+}$signal ratio & $0.00756 \pm 0.00043$ & $0.00725 \pm 0.00034$ \\
\hline Number of particles & 7 & 8 \\
\hline
\end{tabular}

Table 3. ${ }^{235} \mathrm{U}^{+} / 238 \mathrm{U}^{+}$signal ratios with $95 \%$ confidence intervals determined during the analysis of individual particles trapped in grease matrices by ns and fs LA-ICP-MS.

\begin{tabular}{|c|c|c|}
\hline & Nanosecond laser & Femtosecond laser \\
\hline${ }^{235} \mathrm{U}^{+} /{ }^{238} \mathrm{U}^{+}$signal ratio & $0.00715 \pm 0.00024$ & $0.00736 \pm 0.00032$ \\
\hline Number of particles & 2 & 23 \\
\hline
\end{tabular}




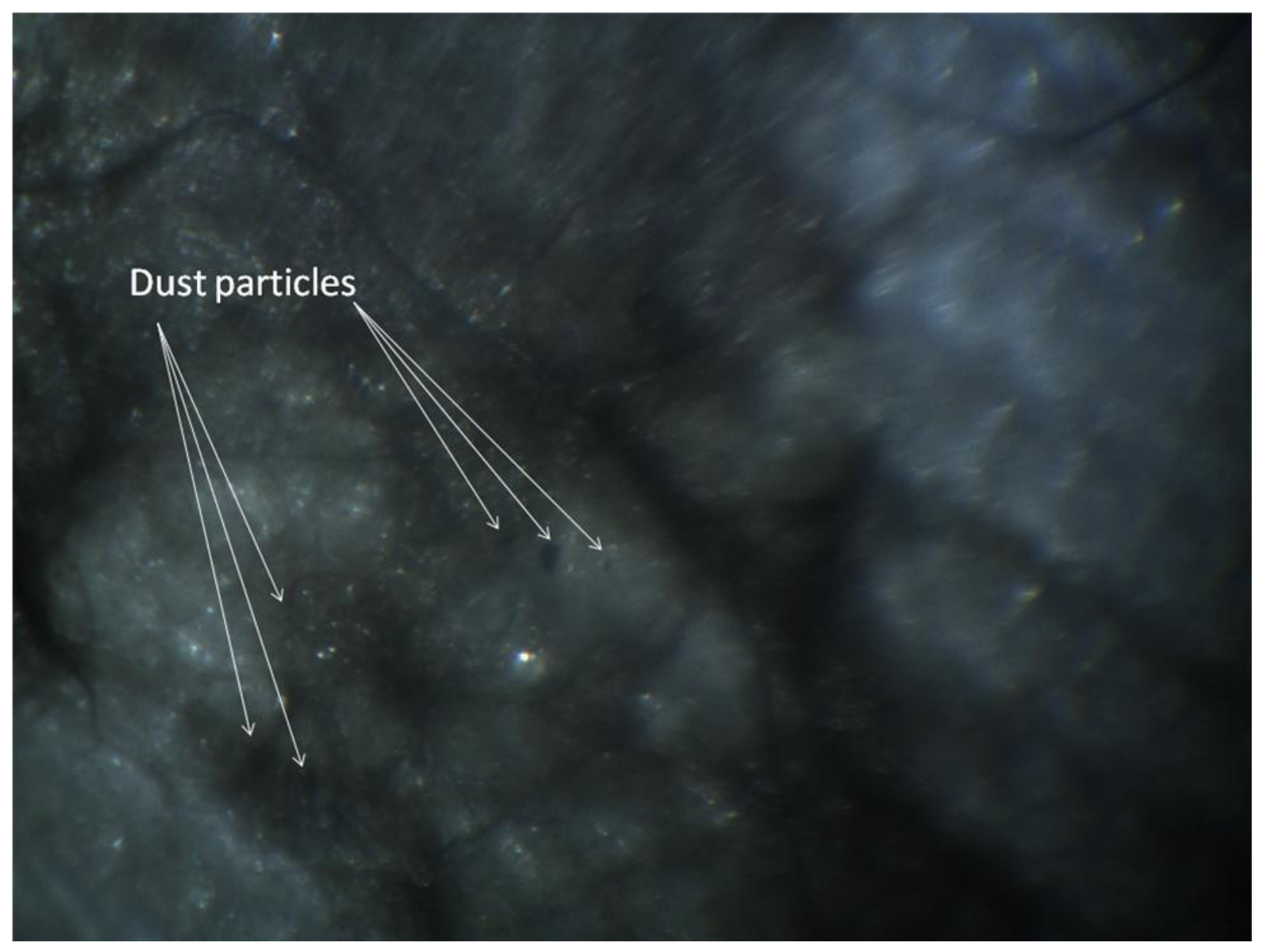

Figure 1. Image of spider silk captured on a clean cloth and covered in collodion. Individual silk fibers and individual dust particles are visible. The large grey area in the upper left is a matted clod of spider silk. 
Histogram of thorium content in ablated dust particles

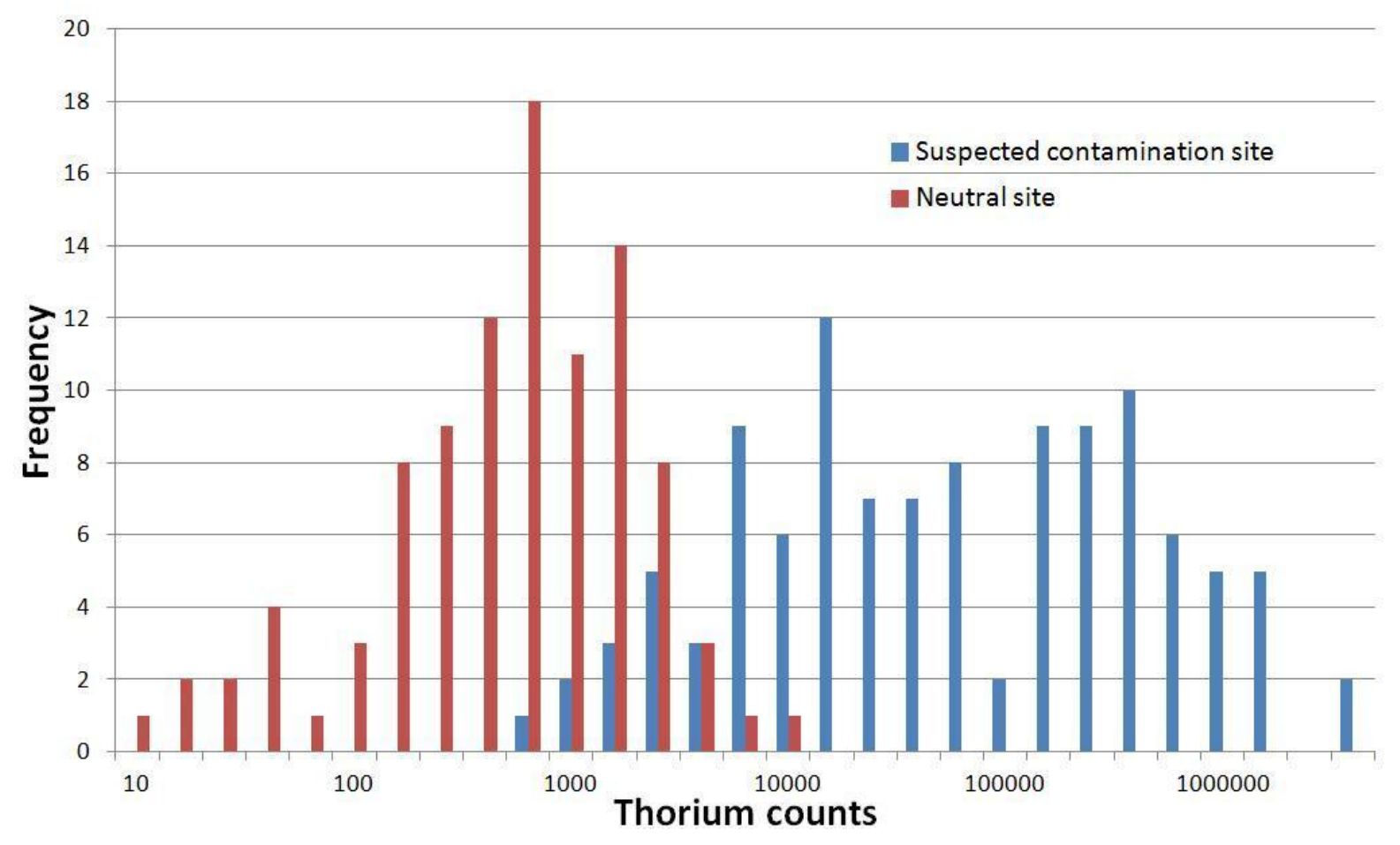

Figure 2. Histogram of the determined thorium signal generated by laser ablation of individual dust particles trapped in spider silk gathered from a known contamination site and a neutral site. 


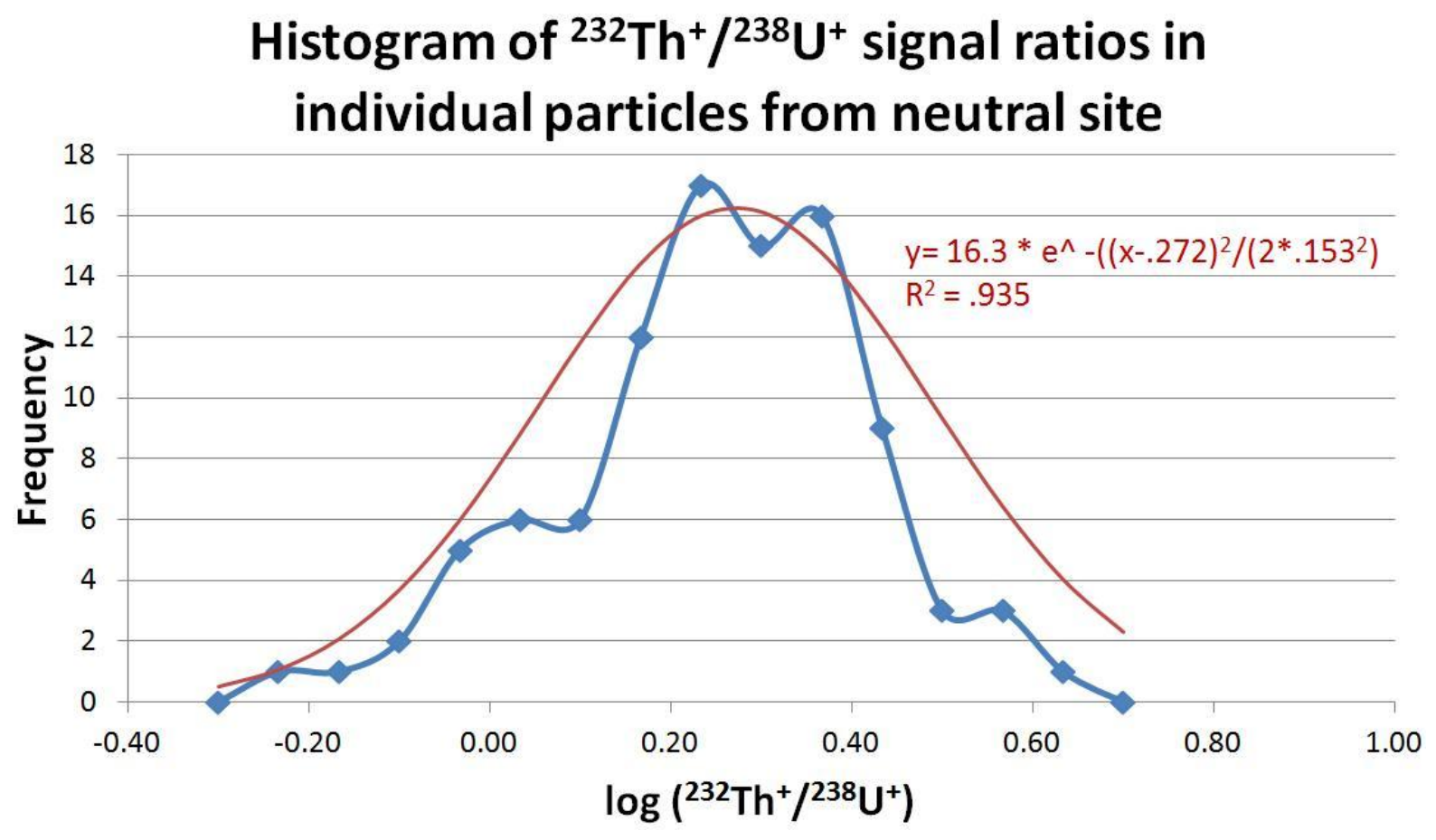

Figure 3. Histogram of ${ }^{232} \mathrm{Th}^{+} / 238 \mathrm{U}^{+}$signal ratios determined in 98 individual dust particles trapped in spider silk gathered from a neutral area. The ratios fall near a normal distribution. 


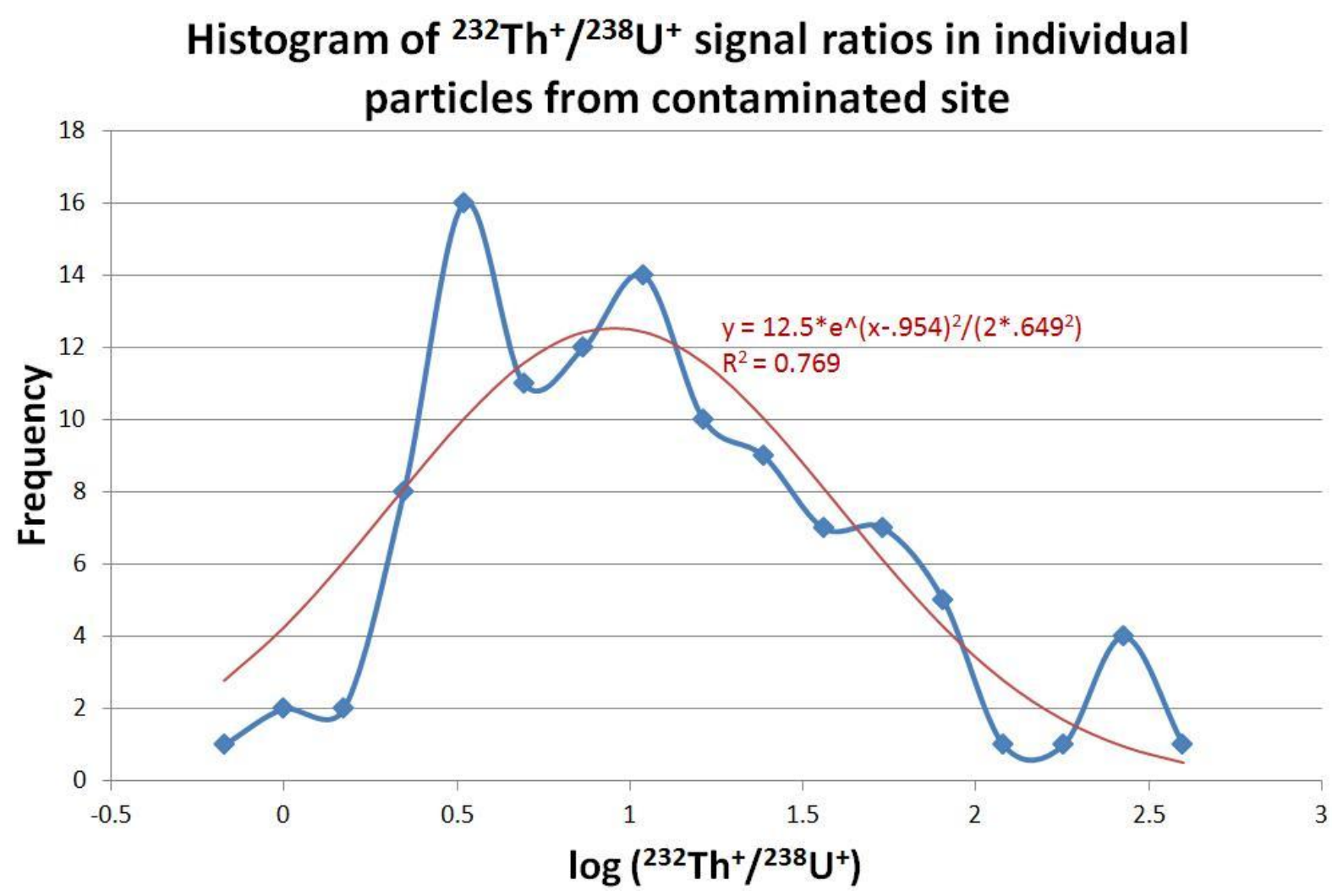

Figure 4. Histogram of ${ }^{232} \mathrm{Th}^{+} /{ }^{238} \mathrm{U}^{+}$signal ratios determined in 111 individual dust particles trapped in spider silk gathered from a known contamination area. The ratios are not fit by a normal distribution. 


\title{
Chapter 7. Improvements to the torch injector and skimmer cone for LA-ICP-MS
}

\author{
Material submitted to the US Department of Energy \\ Chris H. Ebert, Daniel S. Zamzow, Stanley J. Bajic, David P. Baldwin, R. S. Houk
}

\begin{abstract}
Figures of merit are reported for a wide-orifice $(1.0 \mathrm{~mm}$ diam.) skimmer cone in inductively coupled plasma mass spectrometry (ICP-MS). This skimmer cone achieves an improvement in sensitivity during solution ICP-MS and in limit of detection during femtosecond laser ablation (LA) ICP-MS over a standard skimmer cone (0.8 mm diam.). A glassy carbon injector is implemented which extends 15 to $20 \mathrm{~mm}$ further downstream than a standard quartz torch. An increase in sensitivity is observed with this longer injector.

Evidence presented suggests that this glassy carbon injector reduces the effects of elemental fractionation during nanosecond ablation of a silicate glass standard.
\end{abstract}

\section{Introduction}

Since the initial development of laser ablation (LA) as a method for sample introduction in inductively coupled plasma-mass spectrometry (ICP-MS) in 1985 by Gray ${ }^{1}$, there has been extensive research and countless publications toward LA-ICP-MS development. Much of this work has focused on introducing LA-ICP-MS to new fields, including geology, medicine, biology, semiconductors, forensics, and materials science. Other research has focused on improving laser ablation as a sampling technique by studying 
the effects of various laser parameters on ablation efficiency. This research has resulted in many improvements to laser ablation, i.e., optimizing laser fluence and laser power, ablating with femtosecond lasers, using helium as a carrier gas, selecting the proper laser wavelength, and beam homogenization. Still other research has focused on the transportation of laser produced aerosols from the ablation cite to the ICP.

Comparatively little research has gone towards tailoring ICP-MS specifically for the purpose of analyzing laser-generated aerosols. In the ICP, there is a significant difference between the behaviors of a nebulized solution and an assembly of particles produced by LA, even beyond the difference between a wet plasma and a dry plasma ${ }^{2}$. As such, the optimal conditions and physical characteristics of ICP-MS may be different for the two methods of sample introduction. The sensitivity, stability, and accuracy of the signals obtained during LA-ICP-MS analysis could perhaps be improved with modification to the ICP torch, injector, sampler cone, and skimmer cone.

Vaughan and Horlick ${ }^{3}$ studied the effect of the skimmer cone orifice diameter on analyte and analyte-oxide ion signals in solution ICP-MS. They determined that increasing the skimmer diameter increased the sensitivity of monatomic ions. This result is unsurprising; the analyte ions and background gas comprise a supersonic jet as they leave the sampler cone $e^{4}$ and a larger skimmer cone is expected to pass a greater portion of the analyte. They also found that once the skimmer cone orifice diameter is as large as the sampler cone orifice diameter, the signal level of metal-oxide polyatomic ions increases steeply. These $\mathrm{MO}^{+}$ions originate from the boundary between the plasma and the relatively cool sampler cone (Chapter 1, Figure 2). A skimmer cone with an orifice larger than the sampler cone will transmit an undesirable portion of these polyatomic ions. Thus, during solution ICP-MS a 
skimmer cone is chosen with an aperture that is slightly smaller than the sampler cone, even though this will result in poorer sensitivity.

However, this conclusion may be different when performing laser ablation ICP-MS or solution ICP-MS experiments with thorough sample desolvation. Little to no water is introduced to the plasma during these experiments, so the number density of oxygen in the plasma and the abundance of $\mathrm{MO}^{+}$ions are much lower. Using a larger diameter skimmer cone may result in a less substantial increase in $\mathrm{MO}^{+}$ion abundance during ablation experiments, and a small increase in $\mathrm{MO}^{+}$ions may be acceptable if the sensitivity is increased.

During LA-ICP-MS, many particles travel through the ICP off-center in the axial channel $^{5}$. A smaller fraction of the material atomized from these particles is extracted and analyzed than that for a particle that is exactly on axis. Minimizing the number of particles that are off-center has the potential to increase the throughput and sensitivity of LA-ICP-MS. Lengthening the sample injector may have this effect. A typical injector is made of quartz, and sits about $5 \mathrm{~mm}$ downstream of the plasma. The injector cannot sit any closer, because it would erode or warp due to the high plasma temperature. The sample gas flow carries the aerosol the distance between the end of the injector and the downstream end of the plasma. Houk, et al. ${ }^{6}$ demonstrated the use of a graphite injector, which can extend well into the ICP. Graphite vaporizes but does not melt, so it can function as an injector for several hours. They characterized graphite injectors for solution ICP-MS, and found an increase in sensitivity, a reduction in the optimal sample gas flow, and a reduction in metal-oxide polyatomic ions.

Houk et $a l .^{6}$ did not use the graphite injector for analysis in laser ablation ICP-MS. Using a longer injector may particularly improve LA analyses, because it may keep a greater 
fraction of particles on axis. A longer injector also has the potential to reduce the effects of fractionation. During operation the injector reaches temperatures $2000 \mathrm{~K}$ or greater ${ }^{6}$, so it may initiate sample heating earlier and more completely vaporize laser-generated aerosol. Furthermore, if the optimal sample gas flow is lower, the plasma temperature is generally hotter. A hotter plasma can better process the large particles generated in laser ablation ${ }^{7}$.

The present study characterizes glassy carbon as an injector material in LA-ICP-MS. Like graphite, glassy carbon vaporizes rather than melts. Glassy carbon is more rugged than

graphite, and has a higher vaporization temperature ${ }^{8,9}$. This study provides general figures of merit for the injector, and presents preliminary data supporting the hypothesis that using a heated injector reduces fractionation. This work also compares the figures of merit for a skimmer cone with a $0.8 \mathrm{~mm}$ and $1.0 \mathrm{~mm}$ diameter.

The research in this chapter is a compilation of data taken by the author and reported to our funding source in the form of various reports; additional data were included in such reports but were taken by other researchers so they are not reported here.

\section{Methods}

Instrumentation

ICP-MS experiments were performed on a quadrupole instrument (XSeries 2, Thermo Fisher Scientific, Inc., Bremen, Germany). ICP conditions are reported in Table 1. All gas flows are argon during these experiments. This instrument was chosen because the ICP is fairly robust, which is necessary when attempting torch improvements.

During the characterization of the skimmer cones, laser ablation experiments were carried out with a femtosecond laser (LIBRA, Coherent Inc., Santa Clara, CA). General 
information about this laser can be found in chapter 3, Table 1. Femtosecond laser ablation experiments were carried out in 'single spot' mode, in which the laser ablates one location and the sample is not moved. A laser shutter opens and then closes $100 \mathrm{~ms}$ later, allowing 100 laser pulses to ablate the sample for each measurement.

During fractionation studies, laser ablation was performed using a nanosecond laser (LSX-500, CETAC Technologies, Omaha, NE). General information about this laser can be found in Chapter 3, Table 1. A nanosecond laser was chosen for fractionation studies because an improvement in fractionation is more readily observable during ns laser ablation than fs laser ablation. Nanosecond LA experiments were carried out in 'raster' mode, in which the laser fired for 20 seconds and the sample was moved laterally at $150 \mu \mathrm{m} / \mathrm{sec}$ so the laser was constantly ablating fresh surface.

A PFA $400 \mu \mathrm{L}$ self-aspirating nebulizer and a sample desolvator (APEX, Elemental Scientific, Inc., Omaha, NE) was used during all solution experiments.

\section{Skimmer cone}

The XSeries 2 typically operates using a sampler cone with a $1.0 \mathrm{~mm}$ diameter orifice and an Xt skimmer cone with a $0.8 \mathrm{~mm}$ diameter orifice. A second Xt skimmer cone was drilled out to a $1.0 \mathrm{~mm}$ diameter orifice. During operation with this large-orifice skimmer cone, the instrument pressure increased from 5.5e-7 mbar to $8.5 \mathrm{e}-7$ mbar. This increase in pressure is directly related to the increase in skimmer cone orifice area, as described by Douglas and French ${ }^{4}$.

\section{Injector}

Figure 1 depicts the ICP during operation with a) a quartz injector and b) a glassy carbon injector. The standard quartz injector implemented was $4 \mathrm{~mm} \mathrm{OD,} 1.5 \mathrm{~mm}$ ID, and 
$16 \mathrm{~cm}$ in length. This quartz injector can be used for years without damage. Since glassy carbon injector degrade over a period of 8 to 12 hours, a total of four different glassy carbon injectors were used during the course of data collection for this work. A glassy carbon tube (4 mm OD, $1.2 \mathrm{~mm}$ ID, $30 \mathrm{~mm}$ length; SPI Supplies, West Chester, PA) was inserted into a long stainless steel tube. The total length of this injector was 17.5 to $18 \mathrm{~cm}$ at first use. During operation, the glassy carbon tube glowed bright orange, indicating it was $2000 \mathrm{~K}$ or hotter ${ }^{6}$. After 8 to 12 hours of experimentation the glassy carbon tube was 2 to $5 \mathrm{~mm}$ shorter and the ID increases by 1 to $2 \mathrm{~mm}$, at which point it is discarded. The glassy carbon injector protruded into the plasma, just past the first turn of the load coil.

\section{Samples}

A $10 \mathrm{ppb}$ multielement standard containing uranium and thorium in a $2 \%$ nitric acid matrix was used for all solution experiments. The NIST 610 silicate glass series were used for laser ablation experiments. The NIST 610 series are a set of four silicate standards doped with trace metals. NIST 610 has a nominal 500 ppm various metals added, NIST 612 has nominally 50 ppm, NIST 614 has nominally 1 ppm, and NIST 616 has nominally 20 ppb metals added $^{10}$.

Total sample gas flow

For many experiments, the sample gas flow rate was varied for optimization or other purposes. In these instances, a constant $0.6 \mathrm{~L} / \mathrm{min}$ argon flow was used to nebulize a sample solution or to carry an aerosol generated by laser ablation. A makeup argon flow was then added just before the sample was injected into the plasma. This makeup gas flow rate was incrementally increased during an experiment. Such a setup was necessary because directly varying the nebulizer gas or ablation carrier gas can impact the total sample load that reaches 
the plasma. By adding and adjusting a makeup gas, the influence of the total gas flow can be investigated without changing the amount of sample analyzed.

\section{Results and Discussion}

Large orifice skimmer cone - figures of merit

Figure 2 shows the $\mathrm{U}^{+}, \mathrm{UO}^{+}$, and $\mathrm{Th}^{+}$signal during the introduction of a $10 \mathrm{ppb}$ multielement solution as the makeup gas flow is increased with the standard $0.8 \mathrm{~mm}$ orifice diameter skimmer cone. The $\mathrm{U}^{+}$and $\mathrm{Th}^{+}$ion signals are optimized at a total sample gas flow of $0.90 \mathrm{~L} / \mathrm{min}$. Figure 3 shows the $\mathrm{U}^{+}, \mathrm{UO}^{+}$, and $\mathrm{Th}^{+}$signals during the introduction of the same sample as the makeup gas flow is increased while using the new $1.0 \mathrm{~mm}$ orifice skimmer cone. With this large-orifice skimmer cone, the optimum total sample gas flow rate is slightly higher, at $1.04 \mathrm{~L} / \mathrm{min}$. The optimum uranium signal is increased by $\sim 50 \%$ with the large-orifice skimmer cone compared to the normal skimmer cone.

With the $0.8 \mathrm{~mm}$ orifice skimmer cone at the optimum gas flow, the $\mathrm{UO}^{+} / \mathrm{U}^{+}$signal ratio is $0.31 \%$. The $1.0 \mathrm{~mm}$ orifice skimmer cone generates a $\mathrm{UO}^{+} / \mathrm{U}^{+}$signal ratio of $0.37 \%$ at the optimum flow rate, a significant but small increase in uranium oxide abundance compared to the standard skimmer. This increase in uranium oxide abundance can be attributed to the higher total sample gas flow. When a total gas flow of $0.90 \mathrm{~L} / \mathrm{min}$ is used with the large-orifice skimmer cone, the $\mathrm{UO}^{+} / \mathrm{U}^{+}$signal ratio is $0.31 \%$, almost identical to the normal skimmer cone. With the $1.0 \mathrm{~mm}$ orifice skimmer cone at this lower gas flow, the signal is $92 \%$ of the signal level when the small-orifice skimmer cone is used at $0.90 \mathrm{~L} / \mathrm{min}$. With the instrument and sample desolvator used here, a increasing the orifice diameter can 
increase the sensitivity of solution ICP-MS experiments with only a minimal increase in oxides.

Table 2 reports the limits of detection (LOD) for sixteen elements during the fs laser ablation of NIST silicate glasses during operation with each skimmer cone. Generally, the LOD is lower when the large-orifice skimmer cone is used, with a few exceptions. Arsenic and selenium have a much poorer limit of detection with the large-orifice skimmer cone than with the small-orifice skimmer cone. These species each have a high ionization energy, which may explain the abnormality. The plasma temperature is cooler when using the largeorifice skimmer cone because the total sample gas flow is higher, so perhaps a significantly smaller fraction of arsenic and selenium are ionized during analysis with the large-orifice skimmer cone. Lithium also has a poorer LOD with the large-orifice skimmer cone than the small-orifice skimmer cone. This occurs because the background at $\mathrm{m} / \mathrm{z}=7$ is about 3 -fold higher with the large-orifice skimmer cone, due to a higher blank for either ${ }^{7} \mathrm{Li}^{+}$or ${ }^{14} \mathrm{~N}^{+2}$, an interference for ${ }^{7} \mathrm{Li}^{+}$. With these exceptions, the limit of detection is better during the ablation of NIST silicate glass standards. This improvement in the LOD is only partially due to the increase in sensitivity with the large-orifice skimmer cone; the LOD is also driven by the ion background during analysis with the two cones.

During the fs laser ablation of silicate glasses, the $\mathrm{UO}^{+} / \mathrm{U}^{+}$signal ratio is not significantly different for each skimmer cone. The average $\mathrm{UO}^{+} / \mathrm{U}^{+}$ratio during operation with the $1 \mathrm{~mm}$ orifice skimmer cone was $0.025 \%$, while that for the $0.8 \mathrm{~mm}$ orifice skimmer cone was $0.031 \%$. These ratios are low enough to consider $\mathrm{MO}^{+}$polyatomic ions a very small concern, which is typical during laser ablation experiments. 


\section{Glassy carbon injector - figures of merit}

Figure 4 shows the $\mathrm{U}^{+}, \mathrm{UO}^{+}$, and $\mathrm{Th}^{+}$signals during the introduction of a $10 \mathrm{ppb}$ multielement solution as the makeup gas is increased while using the standard $0.8 \mathrm{~mm}$ skimmer cone and an extended glassy carbon injector. The monatomic ion signal is optimized at a total sample gas flow of $0.83 \mathrm{~L} / \mathrm{min}$, significantly lower than with a shorter quartz injector. With a glassy carbon injector, the maximum sensitivity is increased by $\sim 125 \%$ compared to a standard quartz torch despite a lower flow rate.

When operating at a low total sample gas flow rate (say, $0.65 \mathrm{~L} / \mathrm{min}$ ), a large loss in sensitivity is observed with a standard quartz injector. Operating at a low sample gas flow with a glassy carbon injector results in a less extreme loss in sensitivity. This was also observed by Houk et al. ${ }^{6}$ with an extended graphite injector. The comparative increases in sensitivity at optimum and low total sample gas flows are evidence of a reduction in the radial diffusion of ions between the injector and the sampler cone when a glassy carbon injector is employed.

At the optimum gas flow the $\mathrm{UO}^{+} / \mathrm{U}^{+}$signal ratio is $0.55 \%$, moderately higher than that when a quartz injector is used. This result is unexpected; decreasing the sample gas flow generally increases the plasma temperature, which should in turn decrease the abundance of metal-oxide polyatomic ions. A possible explanation is that the presence of the glassy carbon injector in the plasma physically reduces the plasma temperature. The total sample gas flow must be reduced to $0.72 \mathrm{~L} / \mathrm{min}$ in order to decrease the $\mathrm{UO}^{+} / \mathrm{U}^{+}$ratio to the level obtained with the quartz injector. Using the glassy carbon injector at this gas flow, the sensitivity is still $\sim 100 \%$ better than the optimum sensitivity using the quartz injector. 
The durability of a glassy carbon injector is an important concern. The high temperature of the ICP slowly erodes the injector and the lifetime of a single injector is approximately 8 to 12 hours, at which point it does not provide a notable improvement over a normal quartz injector. The lifetime of these glassy carbon injectors is longer than that of graphite injectors studied previously ${ }^{6}$, but not long enough to make general use of glassy carbon injectors practical. Figure 5 shows the loss in signal for the total of the major isotopes of twenty-five elements at the optimum sample gas flow during operation with the quartz injector or the glassy carbon injector. The glassy carbon injector loses signal every hour as it is vaporized by the ICP. After six hours of operation using the glassy carbon injector, the sensitivity decreases $40 \%$ if the sample gas flow is not changed to compensate. After seven hours, full sensitivity could be restored by increasing the makeup gas flow so that the total sample gas flow was $0.89 \mathrm{~L} / \mathrm{min}$.

\section{Glassy carbon injector - impact on fractionation}

Plasma temperature plays an important role in fractionation. Since fractionation, in part, arises from the incomplete vaporization and ionization of particles in the ICP, a cooler plasma is more likely to induce fractionation than a hotter plasma ${ }^{7}$. This effect is observed when changing the total sample gas flow. Figure 6 shows how the $\mathrm{Th}^{+} / \mathrm{U}^{+}$signal ratio is dependent on the total sample gas flow during ns LA of NIST 612 silicate glass and during the introduction of a $10 \mathrm{ppb}$ multielement solution with the quartz injector. During solution ICP-MS, the $\mathrm{Th}^{+} / \mathrm{U}^{+}$signal ratio decreases moderately as the total sample gas flow is increased. This occurs because Th has a higher atomization energy than U, so at high gas flow and cool temperature thorium is atomized slightly less than uranium. 
During LA-ICP-MS, the $\mathrm{Th}^{+} / \mathrm{U}^{+}$ratio decreases much more extensively when the total sample gas flow is increased. This effect is attributed to fractionation. Thorium has a higher vaporization point than uranium (5061 K and $4091 \mathrm{~K}$, respectively). Thus, while large laser-generated particles travel through the ICP, thorium is less fully vaporized than uranium. This effect happens to a greater extent in a cool plasma than in a hot plasma. As a result, $\mathrm{Th}^{+} / \mathrm{U}^{+}$decreases much more quickly as the total sample gas flow is increased during LA experiments than solution experiments.

Figure 7 shows the change in $\mathrm{Th}^{+} / \mathrm{U}^{+}$signal ratio as the total sample gas flow rate is increased during ns LA of NIST 612 glass and during the introduction of the $10 \mathrm{ppb}$ multielement solution using a glassy carbon injector. With a glassy carbon injector, the $\mathrm{Th}^{+} / \mathrm{U}^{+}$ratio decreases with an increasing total sample gas flow at approximately the same rate during LA-ICP-MS and solution ICP-MS. This is evidence that fractionation is reduced when a glassy carbon injector is implemented. A possible explanation for this occurrence is because the glassy carbon injector is much hotter than the quartz injector during operation. Thus, the laser-produced particles enter the plasma at a hotter temperature, and the effects of fractionation are reduced.

\section{Conclusions}

This research demonstrates the possibility of developing ICP-MS components specifically tailored for improving laser ablation experiments. Increasing the skimmer cone diameter to that of the sampler cone improves the LOD for most elements during laser ablation without an observed increase in $\mathrm{UO}^{+}$abundance. Implementing a glassy carbon injector of greater length than a standard quartz injector increases the sensitivity of solution 
ICP-MS. The glassy carbon appears to diminish the effects of fractionation during LA-ICP-MS, possibly by heating the laser-produced aerosol before it reaches the plasma. 


\section{References}

1. Gray, Analyst, 1985, 110, 551-556.

2. D. B. Aeschliman, S. J. Bajic, D. P. Baldwin and R. S. Houk, J. Anal. At. Spectrom., 2003, 18, 1008-1014.

3. M. A. Vaughan and G. Horlick, Spectrochim. Acta Part B, 1990, 12, 1289-1299.

4. D. J. Douglas and J. B. French, J. Anal. At. Spectrom., 1988, 3, 743-747.

5. C. H. Ebert, N. J. Saetveit, D. S. Zamzow, S. J. Bajic and R. S. Houk, J. Anal. At. Spectrom., 2012, Submitted.

6. P. S. Clemons, M. G. Minnich and R. S. Houk, Anal. Chem., 1995, 67, 1929-1934.

7. B. Hattendorf, C. Latkoczy and D. Guenther, Anal. Chem., 2003, 341A-347A.

8. J. Rautavuori and P. Tormala, Journal of Materials Science, 1979, 14, 2020-2022.

9. P. Tormala and M. Romppanen, Journal of Materials Science, 1981, 16, 272-274.

10. K. P. Jochum, U. Weis, B. Stoll, D. Kuzmin, Q. Yang, I. Raczek, D. E. Jacob, A.

Stracke, K. Birbaum, D. A. Frick, D. Guenther and J. Enzweiler, Geostand. Geoanal. Res., 2011, 35, 397-429. 
Table 1. Plasma operating parameters and conditions

\begin{tabular}{|c|c|}
\hline Instrument & Thermo XSeries2 \\
\hline Forward power & $1400 \mathrm{~W}$ \\
\hline Cooling gas flow & $13 \mathrm{~L} / \mathrm{min}$ \\
\hline Auxiliary gas flow & $0.7 \mathrm{~L} / \mathrm{min}$ \\
\hline Nebulizer or ablation gas flow & $0.6 \mathrm{~L} / \mathrm{min}$ \\
\hline Makeup gas flow & Variable, 0.00 to $0.50 \mathrm{~L} / \mathrm{min}$ \\
\hline
\end{tabular}

Table 2. Limit of detection for sixteen metals during the fs ablation of the NIST 610 silicate glass series. All concentrations are in ppb.

\begin{tabular}{|c|c|c|c|c|c|c|c|c|}
\hline $\begin{array}{c}\text { Skimmer } \\
\text { cone diameter }\end{array}$ & $\mathrm{Li}$ & $\mathrm{Mn}$ & $\mathrm{Co}$ & $\mathrm{Zn}$ & $\mathrm{As}$ & $\mathrm{Se}$ & $\mathrm{Rb}$ & $\mathrm{Y}$ \\
\hline $1.0 \mathrm{~mm}$ & 890 & 28 & 12 & 64 & 250 & 410 & 230 & 1.2 \\
\hline $0.8 \mathrm{~mm}$ & 130 & 35 & 20 & 78 & 40 & 150 & 25 & 17 \\
\hline
\end{tabular}

\begin{tabular}{|c|c|c|c|c|c|c|c|c|}
\hline $\begin{array}{c}\text { Skimmer } \\
\text { cone diameter }\end{array}$ & $\mathrm{Ce}$ & $\mathrm{Ho}$ & $\mathrm{Lu}$ & $\mathrm{W}$ & $\mathrm{Tl}$ & $\mathrm{Pb}$ & $\mathrm{Th}$ & $\mathrm{U}$ \\
\hline $1.0 \mathrm{~mm}$ & 1.5 & 0.79 & 0.28 & 1.3 & 3.7 & 25 & 0.29 & 0.28 \\
\hline $0.8 \mathrm{~mm}$ & 23 & 20 & 19 & 8 & 16 & 30 & 17 & 14 \\
\hline
\end{tabular}


a)

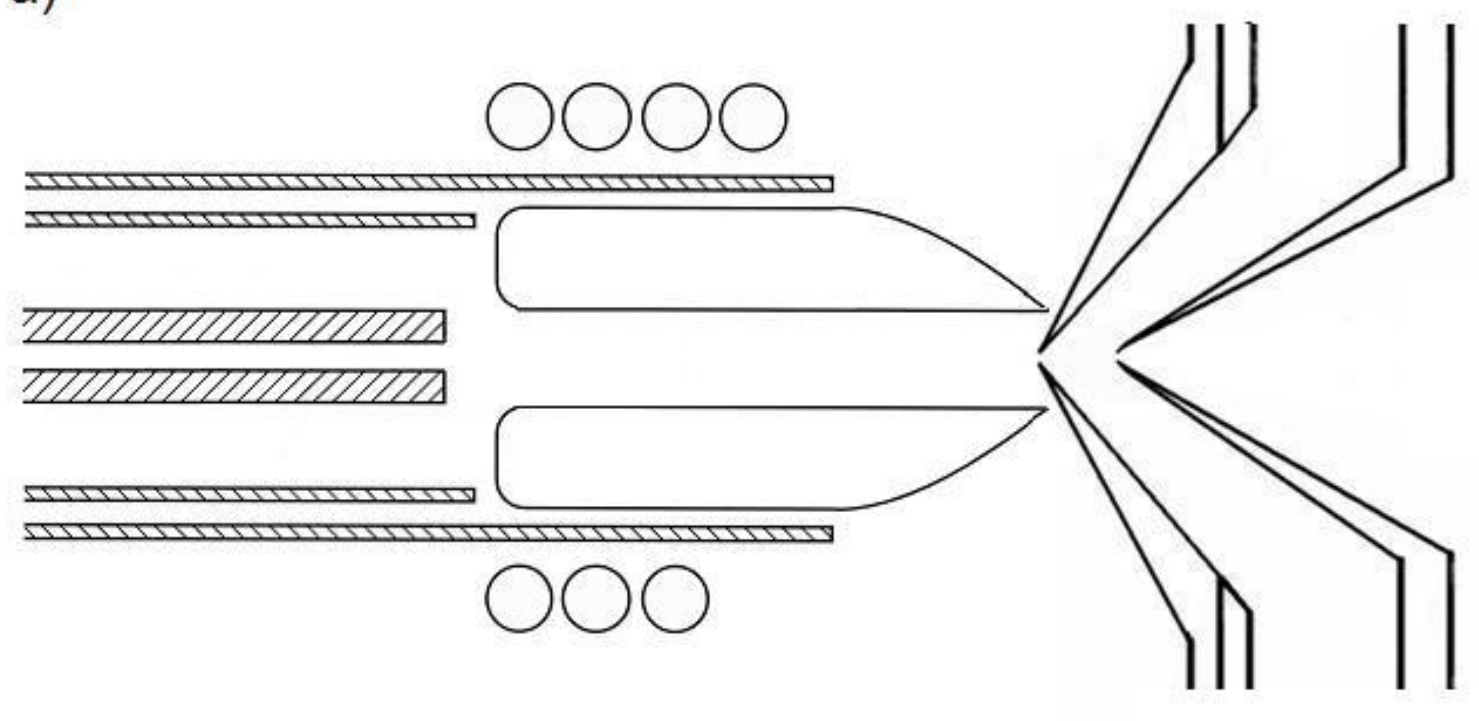

b)

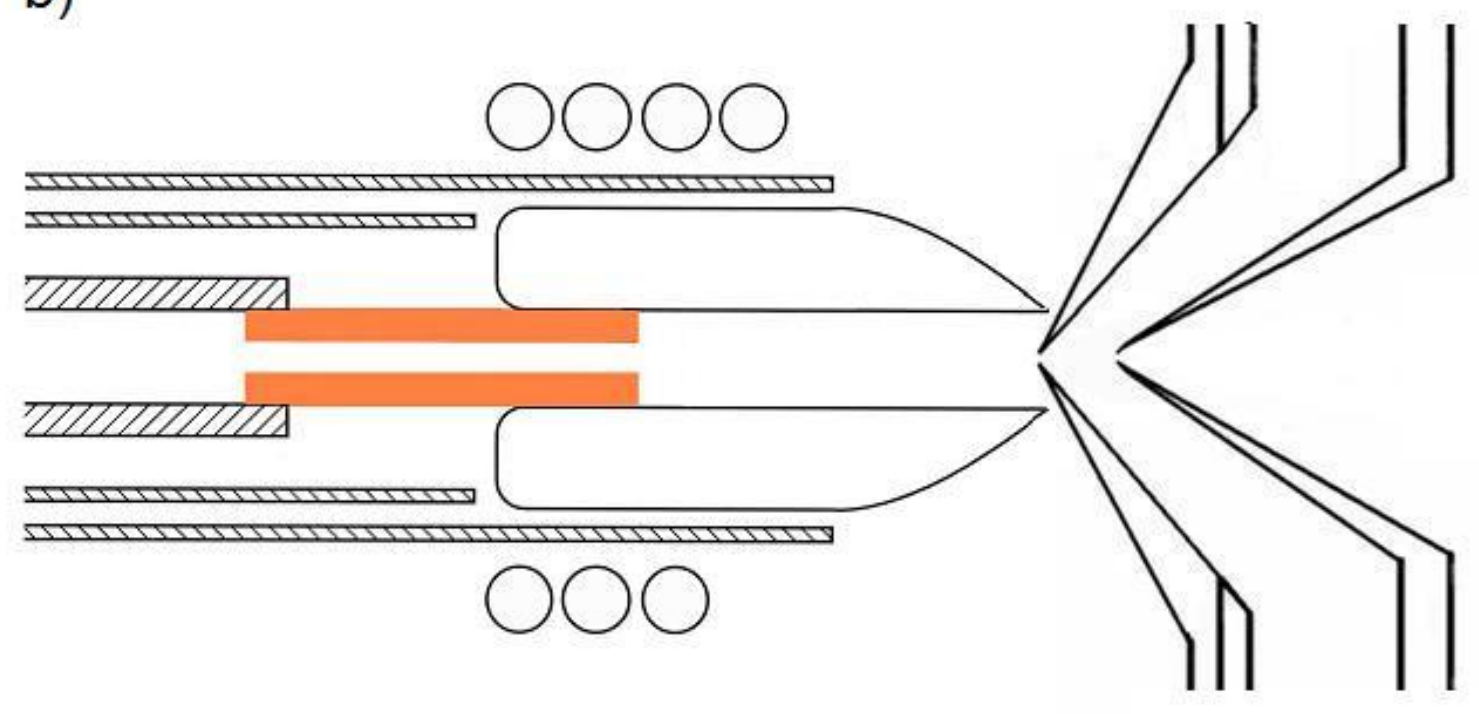

Figure 1. Depiction of the ICP during operation while implementing a) a quartz injector and b) a glassy carbon injector. 


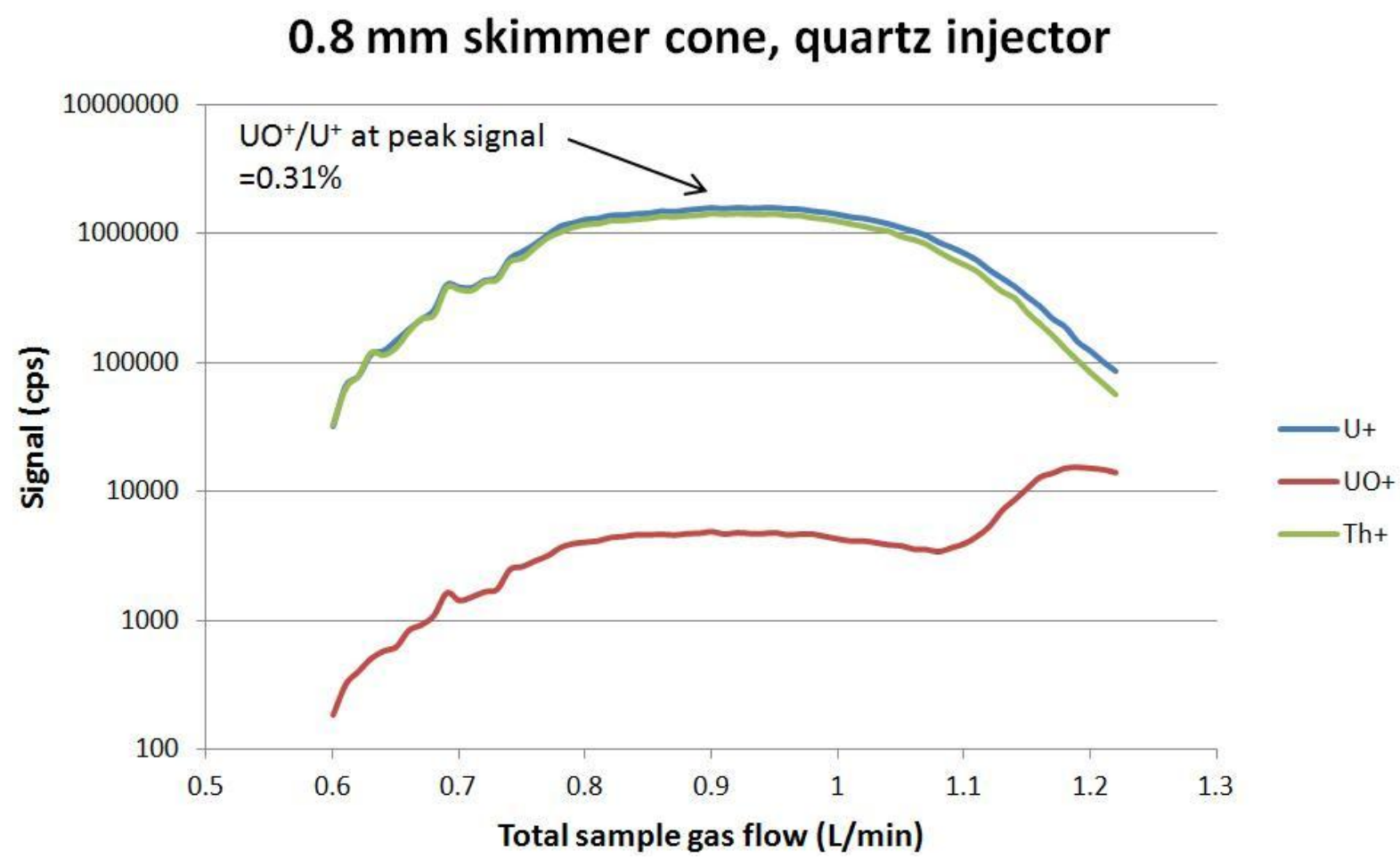

Figure 2. $\mathrm{Th}^{+}, \mathrm{U}^{+}$, and $\mathrm{UO}^{+}$signals during the introduction of a $10 \mathrm{ppb}$ multielement solution. These data are taken with the standard quartz injector and $0.8 \mathrm{~mm}$ orifice skimmer cone. The sample gas is a constant $0.6 \mathrm{~L} / \mathrm{min}$, and makeup gas is ramped at $0.02 \mathrm{~L} / \mathrm{min}$ steps. 


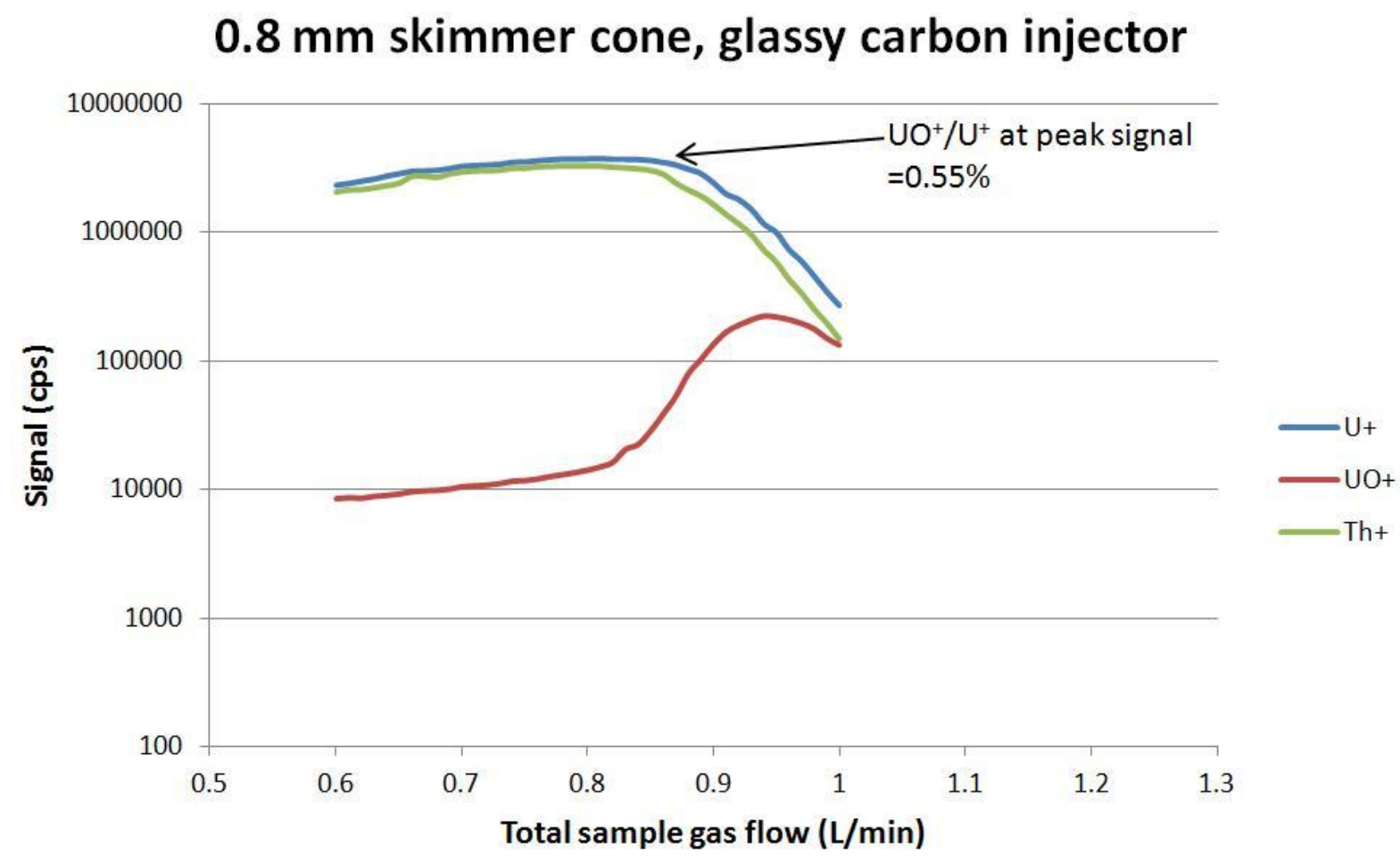

Figure 3. $\mathrm{Th}^{+}, \mathrm{U}^{+}$, and $\mathrm{UO}^{+}$signals during the introduction of a $10 \mathrm{ppb}$ multielement solution. These data are taken with the standard quartz injector and the $1.0 \mathrm{~mm}$ orifice skimmer cone. The sample gas is a constant $0.6 \mathrm{~L} / \mathrm{min}$, and makeup gas is ramped at 0.02 L/min steps. 


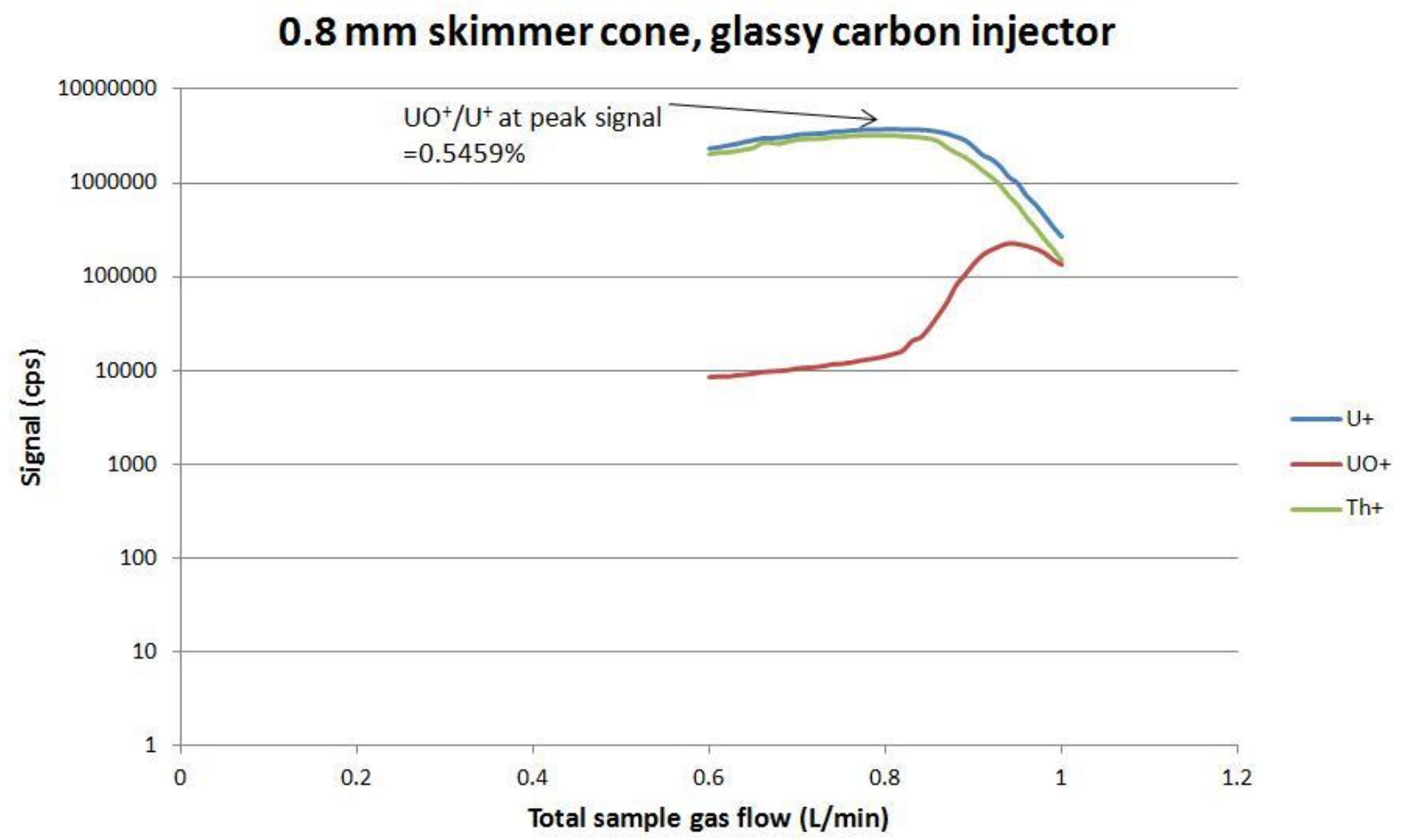

Figure 4. $\mathrm{Th}^{+}, \mathrm{U}^{+}$, and $\mathrm{UO}^{+}$signals during the introduction of a $10 \mathrm{ppb}$ multielement solution. These data are taken with the extended glassy carbon injector and the standard 0.8 $\mathrm{mm}$ orifice skimmer cone. The sample gas is a constant $0.6 \mathrm{~L} / \mathrm{min}$, and a makeup gas is ramped at $0.02 \mathrm{~L} / \mathrm{min}$ steps. 
Signal loss over time

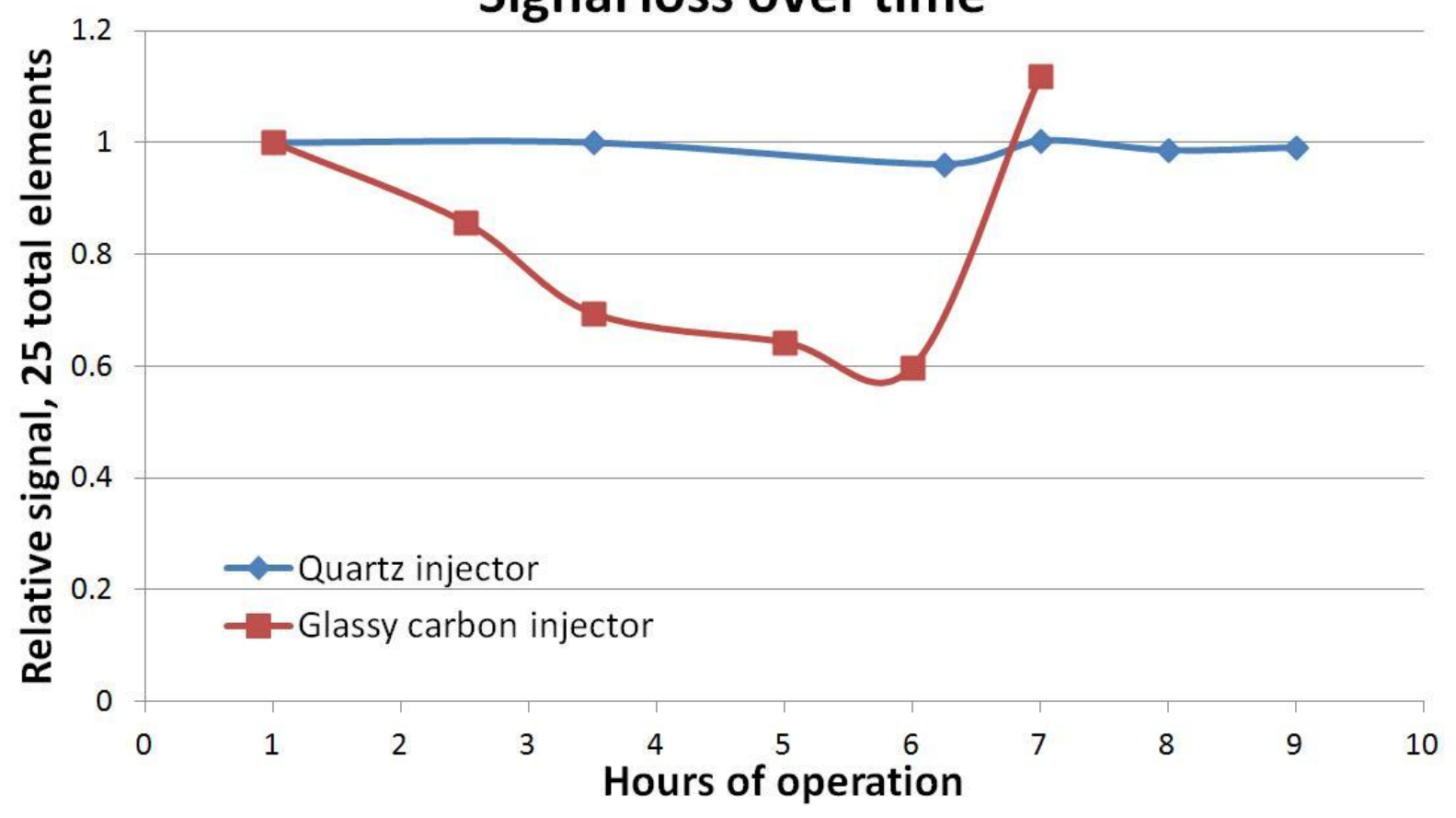

Figure 5. The total signal of the major isotopes of twenty-five different elements during the introduction of a $10 \mathrm{ppb}$ multielement standard, normalized to the signal at $\mathrm{t}=0$. During the course of operation, the glassy carbon injector steadily loses signal as it erodes. This loss in sensitivity can be overcome by increasing the total sample gas flow over time; after 7 hours of operation the optimum sample gas flow increased $0.08 \mathrm{~L} / \mathrm{min}$ and sensitivity was restored. 


\section{Quartz injector}

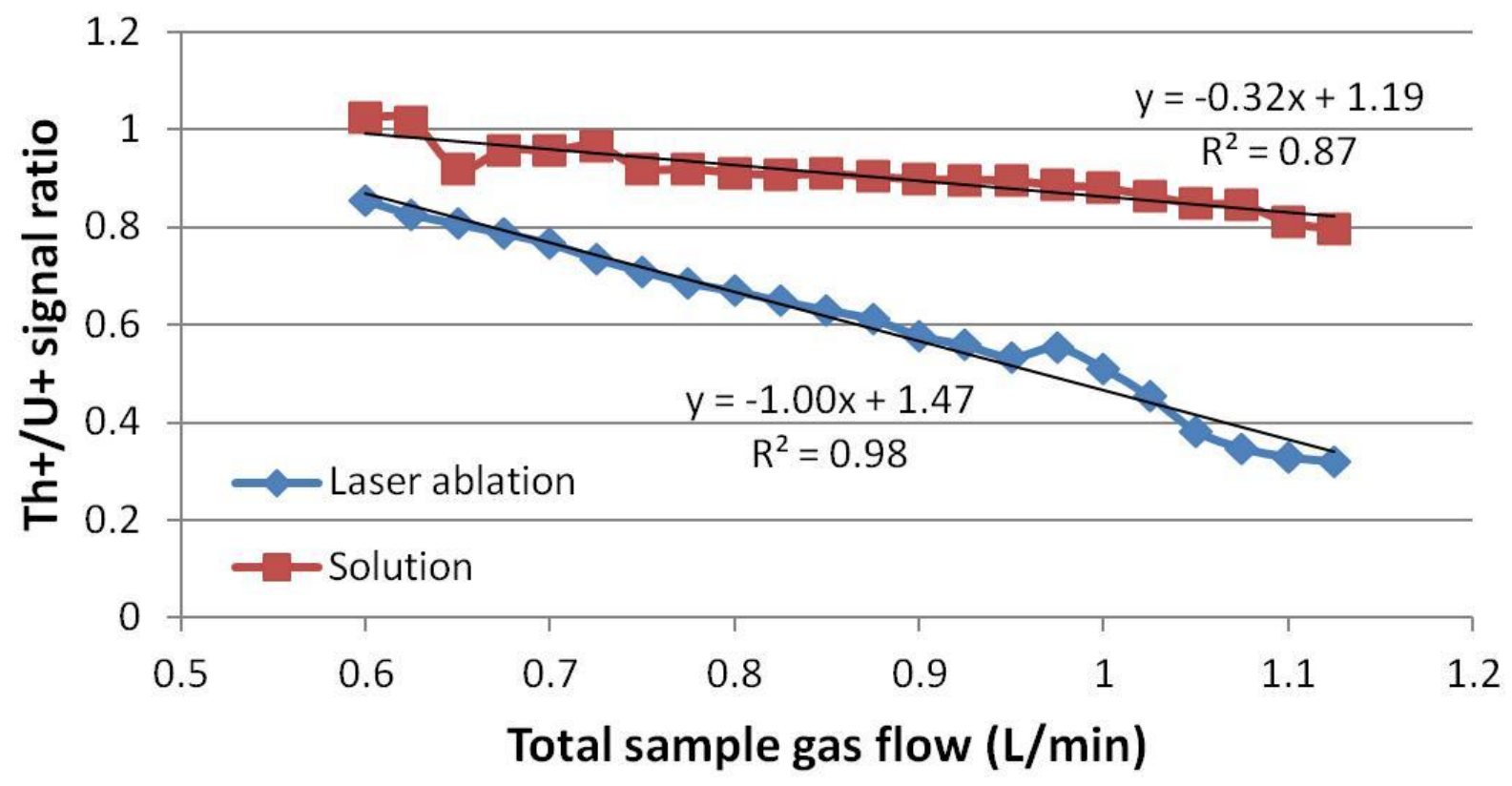

Figure 6. Change in $\mathrm{Th}^{+} / \mathrm{U}^{+}$signal ratio as the makeup gas flow increases, recorded during ns ablation of NIST 612 glass and during the introduction of a $10 \mathrm{ppb}$ multielement solution. These data are obtained during operation with the standard quartz injector. The sample gas is a constant $0.6 \mathrm{~L} / \mathrm{min}$, and a makeup gas is ramped at $0.025 \mathrm{~L} / \mathrm{min}$ steps. Notice the large difference in slope of the two graphs; this effect is attributed to worse fractionation of the LA particles. 


\section{Glassy carbon injector}

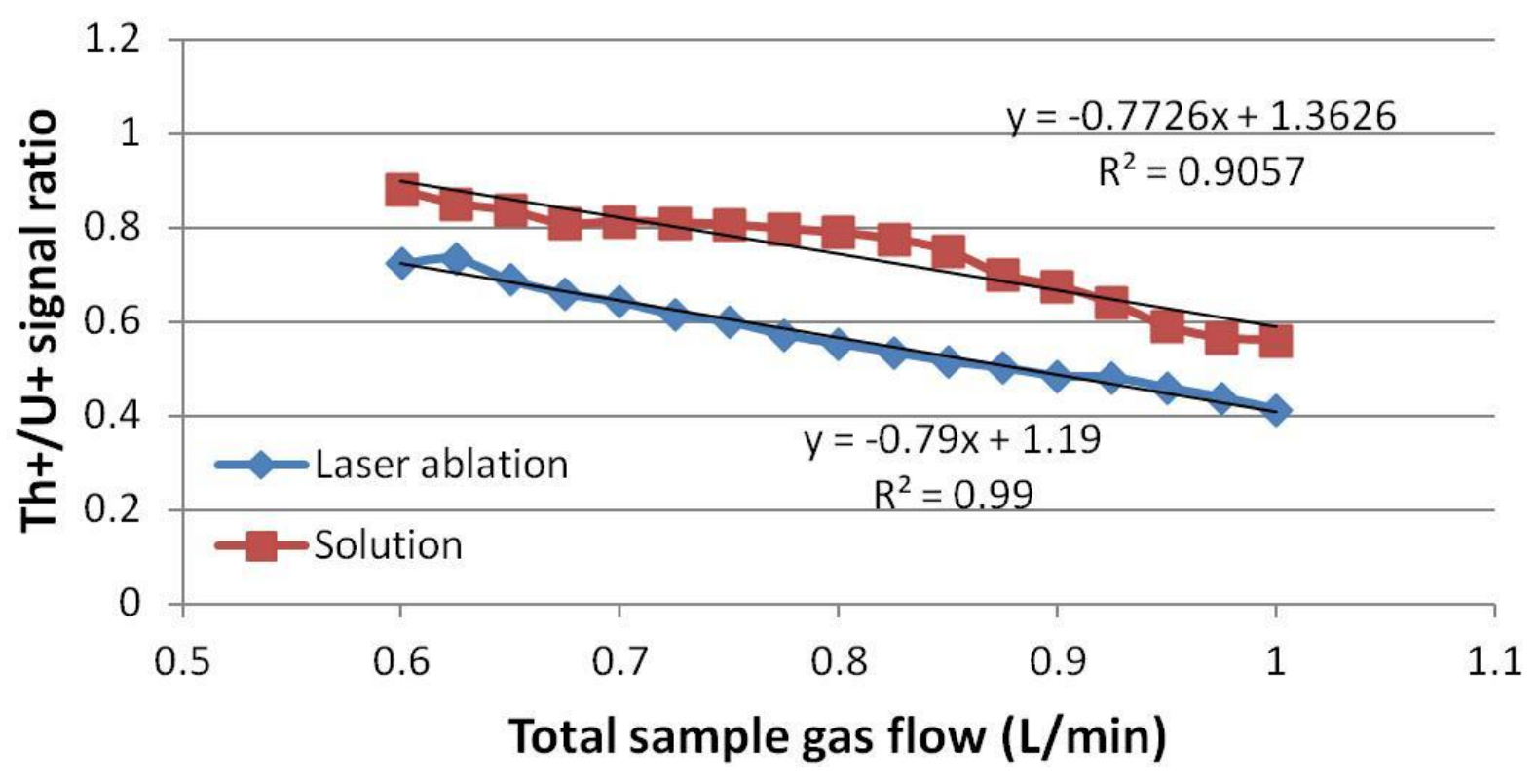

Figure 7. Change in $\mathrm{Th}^{+} / \mathrm{U}^{+}$signal ratio as the makeup gas flow increases, recorded during ns ablation of NIST 612 glass and during the introduction of a $10 \mathrm{ppb}$ multielement solution. These data are obtained during operation with the glassy carbon injector. The sample gas is a constant $0.6 \mathrm{~L} / \mathrm{min}$, and a makeup gas is ramped at $0.025 \mathrm{~L} / \mathrm{min}$ steps. Notice the slopes of the lines are nearly equal; this is attributed to a reduction in fractionation during operation with the glassy carbon injector, caused by pre-heating of the laser-produce aerosol. 


\section{Chapter 8. General Conclusions}

Fundamental studies in ICP-MS have an impact on elemental analysis in many scientific fields. A deeper understanding of fractionation can lead to an improvement in LAICP-MS as a technique for quantification of trace elements in solid samples. The eventual goal of achieving quantification in LA-ICP-MS using non-matrix-matched standards would make the technique a competitive option for countless applications, such biological imaging, semiconductor research, and geological sampling. Optimizing the ICP-MS interface specifically for laser ablation can also further the analytical capabilities of the technique.

The evidence presented that metal-argon ions are lost during ICP-MS analysis due to collision-induced dissociation at the skimmer cone improves the understanding of the behavior of polyatomic ions. It may lead to strategies towards the further removal of polyatomic ions, including metal-oxide ions. This, in turn, will improve the accuracy and limit-of-detection of ICP-MS analyses. Certain specific analyses, e.g. analyzing the purity of rare earth metals, are particularly hindered by polyatomic ions; reducing the abundance of polyatomic ions would make ICP-MS a better technique such applications.

The included methodological development for the elemental analysis of environmental particulates by LA-ICP-MS expands the role of the technique. LA-ICP-MS is capable of processing many different samples and matrices, and continuing work in methods research provides more options for environmental contamination monitoring. 


\section{Acknowledgements}

This work was performed at Ames Laboratory under Contract No. DE-AC0207CH11358 with the U.S. Department of Energy (USDOE). Research was supported by the USDOE, National Nuclear Security Agency. The XSeries2 Libra instruments and were purchased through funding provided by the USDOE, Office of Nuclear Nonproliferation (NA-22).

I would like to thank Dr. R. S. Houk for his leadership and guidance through my graduate studies. I would also like to thank Dan Zamzow and Stan Bajic for their daily help when I was lost for ideas or needed assistance. I would like to acknowledge David Baldwin for his advice during my time here. I would also like to thank Nathan Saetveit for providing me with most of the introductory knowledge of ICP-MS I would need and Travis Witte for quickly familiarizing me with the background and history of polyatomic ions and for

providing all the spectroscopic constants I would ever use. I would furthermore like to thank all present and past Houk Group members; they have been helpful in more ways than I can list and I consider all of them very close friends.

I would like to thank my parents John Ebert and Holly Hysjulien for supporting me through my entire life. I have been very lucky to have these caring and selfless people teaching and proving for me. I would also like to thank my siblings, Jamie and Mitchell, and my entire extended family for equipping me with a still foundation. Finally I would like to thank my wife, Maria Dzul. Her steadfast love helped me maintain my calm and optimism in the difficult years of my graduate studies. 